\title{
Physical Model of Source Region of Subduction Zone Volcanics
}

\author{
J. HuW Davies ${ }^{1}$ \\ Seismological Laboratory, California Institute of Technology, Pasadena
}

D. J. Stevenson

Division of Geological and Planetary Sciences, Californic Institute of Technology, Pasadena

\begin{abstract}
The thermal structure of a generic subduction zone is investigated to elucidate the source region of subduction zone volcanics. The steady state thermal field is evaluated for a model subduction zone where the plates are prescribed by kinematic boundary conditions, such that the subducting slab induces a flow in the mantle wedge. The resulting model suggests that the oceanic crust of the downgoing slab is not melted extensively, if at all, and hence is not the source of subduction zone magmatism (with the possible exception of the special case of very young oceanic crust). The temperature in the mantle wedge is high enough to produce melting at the amphibole-buffered peridotite solidus. It is proposed that the combination of vertical motion of water as a free phase and the transport of hydrous phases (e.g., amphiboles) by the slab-induced mantle wedge flow lead to the net transport of water being horizontal, across the mantle wedge from the slab. Provided the subducting oceanic crust enters the asthenosphere at a velocity $>6( \pm 2) \mathrm{cm} / \mathrm{yr}$, the mantle wedge will be hot enough at the limit of the lateral water transport mechanism to generate melting at the amphibole-buffered solidus. The model was then extended to include the effect of localized sources of buoyancy (melt, residue, etc.) as a stationary body force, to investigate the possibility of reversing the slab-induced flow. Best estimates of the buoyancy sources and appropriate viscosity in the wedge suggest that there is likely to be only a weak modulation of the slab-induced flow unless the slab and wedge are locally decoupled, for instance by shear heating, the presence of water, or dehydration/hydration reactions. If there is decoupling, then it is possible for there to be an appreciable reversal of the slab-induced flow. Such an appreciable reversal of flow, if it persists, leads to cooling of the mantle wedge. Hence flow reversal cannot be a steady state mechanism. Instead it would lead to a cycle in the melting with a period of $O(1$ m.y. $)$. The time dependence of a model with appreciable flow reversal would be reinforced by the need to clear the wedge of infertile material.
\end{abstract}

\section{INTRODUCTION}

The fundamental paradox of subduction zone volcanism is the presence of melt and high heat flow adjacent to an enormous heat sink, the cold subducting slab; see Uyeda [1982]. Petrologists and geochemists have advanced numerous hypotheses regarding the source region of subduction zone magmas. The fundamental question is whether this source region is the eclogitic subducting slab or the peridotitic mantle wedge. The terminology we will use to describe the idealized geometry of the subduction zone is presented in Figure 1.

\subsection{Petrological Models}

Marsh [1979], Maaløe and Petersen [1981], Myers et al. [1985], Brophy and Marsh [1986], and Johnston [1986] have argued that the eclogitic oceanic crust is the source of the subduction zone magmas. This is supported by the fact that high-alumina arc basalts have garnet and clinopyroxene (major eclogite minerals) on the liquidus above $2 \mathrm{GPa}$. They therefore could be in equilibrium with and hence formed from melting eclogite. They suggest that the high-alumina

\footnotetext{
${ }^{1}$ Now at Institute of Theoretical Geophysics, Department of Earth Sciences, University of Cambridge, Cambridge, United Kingdom.
}

Copyright 1992 by the American Geophysical Union.

Paper number 91JB02571.

0148-0227/92/91JB-02571\$05.00 basalts are primary and that high-magnesium basalts are the result of contamination by melting a path through the peridotitic mantle wedge. Marsh [1979] melts the slab by having the flow induced in the mantle wedge heat it in the apex of the mantle wedge (his "magic corner"). This mechanism was investigated numerically by $H$ sui et al. [1983] and was reiterated by Toksöz and Hsui [1987] but, as discussed below, was not definitive.

Many workers suggest that the subduction zone wedge melts by fluxing it with volatiles derived from the slab, which lowers the solidus; see Gill [1981]. They consider that the high-magnesium basalts are primary, arising from a source in the mantle wedge, while the high-alumina basalts arise from extensive mafic fractionation of the primary basalts [Perfit et al., 1980; Kay, 1980; DeBari and Coleman, 1989] or the accumulation of plagioclase phenocrysts [Crawford et al., 1987; Brophy, 1989].

Tatsumi et al. [1983], Nye and Reid [1986], DeBari et al. [1987], and Plank and Langmuir [1988] have proposed that melting is the result of adiabatic decompression of the mantle wedge. The arguments are based on the high temperatures suggested by the equilibration of arc melts with peridotite minerals at mantle pressures and also on the correlation of major element chemistry with crustal thickness. Ida $[1983 a, b, 1987]$ suggested that the proposal of Tatsumi et al. [1983], of diapirs small enough to be heated by conduction but large enough to rise faster than the induced slab flow, was unrealistic; hence he argued that the reverse flow was not individual diapirs but rather a continuous updraft. His source is the subducting slab. 


\section{Geometry of model subduction zone}

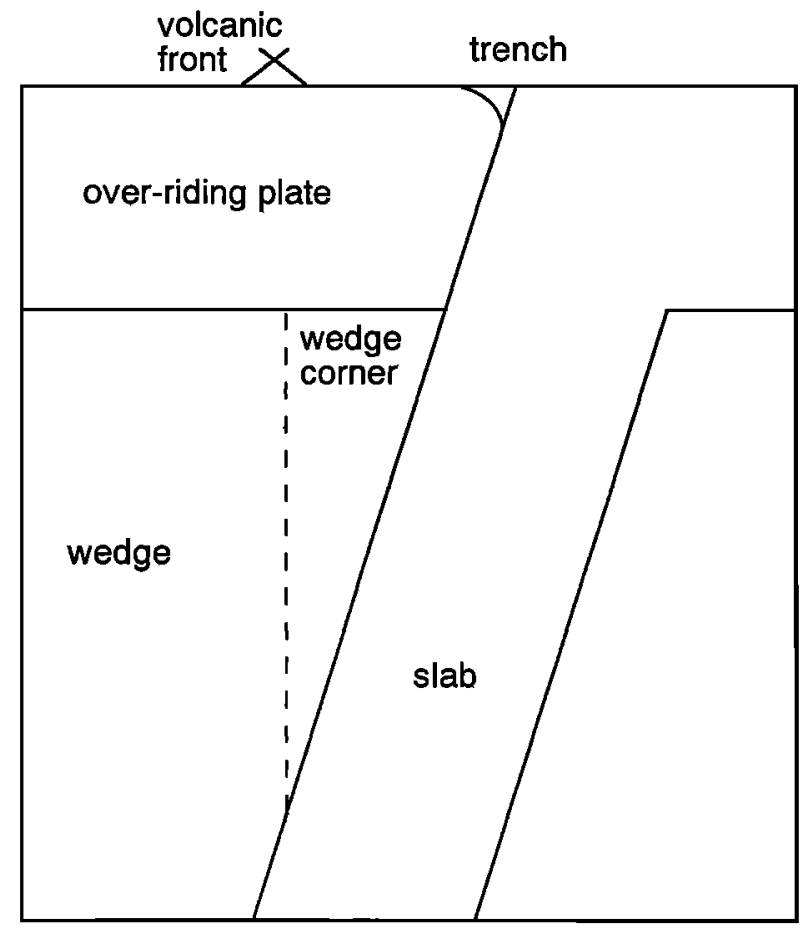

Fig. 1. Cartoon of terms describing geometry of model subduction zone. Note that by overriding plate we mean the rigid lithosphere. By wedge corner we mean either the apex at which the overriding plate and slab meet or, when referring to a volume, roughly the volume of the wedge to the right of the dashed line.

There are also proposals of an intermediate nature such as that of Nicholls and Ringwood [1973] which involve diapirs rising from the slab, hybridizing the wedge and forming a garnet pyroxenite, which subsequently gets extensively melted.

Workers who argue for the wedge to be the primary source also involve the incorporation of components from the slab and sediments to explain the geochemical signature of subduction zone volcanics (SVZ) that differentiate them from mid-ocean ridge basalts (MORB)[Perfit et al., 1980] or ocean island basalts (OIB) [Morris and Hart, 1983]. The relative contribution from the different sources are hard to quantify , and from DeBari et al. [1987] there is a suggestion that for different elements the contribution of different sources varies, suggesting preferential leaching of different elements by a mobile phase. These models frequently allow contamination by the assimilation of sub-volcanic front crust [Hildreth and Moorbath, 1988].

In an attempt to disentangle this web of petrological and geochemical evidence, others have tried to evaluate sufficiently good thermal models such that certain hypotheses can be shown to be unreasonable. We shall now review these attempts and argue that it is worthwhile to improve on them, to address the fundamental question of the whether the mantle wedge or the oceanic crust is the primary source region.

\subsection{Thermal Models}

The earliest thermal models of subduction zones [e.g., Griggs, 1972; McKenzie, 1969] had the explanation of deep seismicity as their focus and solved the zeroth-order problem of the sinking of a cold slab into a hot, constant temperature mantle. These thermal models did not address the thermal interaction of the slab on the wedge or the viscous coupling. Most have attempted to model the heat flow , and one can obtain different thermal regimes depending on the assumptions one makes regarding how the system behaves; witness the wide range of thermal fields derived over the years given different assumptions. This might seem to suggest that thermal models provide no constraints. This is too pessimistic. In fact many of the assumptions of the old thermal models are accepted to be unreasonable or unsuitable, and in this light the differences among models with reasonable assumptions are actually small, sufficiently small to allow reasonable predictions from phase diagrams. For example, Hasebe et al. [1970] had viscous shear heating as a major heat source, while they credited the enhanced heat flow at the volcanic front to advected heat by magma flow; both viscous heating and advection by magma are argued below to be of secondary importance and not relevant in obtaining the first-order model. Another example is the purely viscous model of Bodri and Bodri [1978], which allowed the induced wedge flow to lead to extreme ablation of the wedge corner; their extreme ablation is unreasonable, but otherwise the general principle of ablation is well supported and their thermal model is not too different from other thermal models including induced flow and no major heat sources. We shall now begin by reviewing previous models to illustrate that when one assesses them critically, one arrives at the conclusion that the thermal field of a subduction zone is now more constrained than was assumed in previous syntheses. Having said that, the temperature of the slab mantle interface and the shallow layers are only poorly modeled here, but it is argued that the uncertain regions of the model do not alter the predictions of the source region of subduction zone magmatism. Of course, with special conditions, for example, initiation of subduction or ridge subduction, the details of the derived thermal field will differ somewhat. For the vast majority of cases the same conclusions will apply.

The earliest suggestion was that the subducting plate melted due to the high frictional shear stresses on the fault between the two plates [Oxburgh and Turcotte, 1968; 1970; Turcotte and Schubert, 1973] or the high viscous dissipation due to the shearing of a fluid plate-wedge interface [Turcotte and Schubert, 1968]. Their thermal models assumed that this process was the explanation for the volcanics and hence set the stresses at the level required to melt the plate. This required large stresses of the order of several hundred megapascals. The models of Toksöz et al. [1971] and Minear and Toksöz [1970] have been widely cited primarily due to their inclusion of many heat sources. Frictional heating was also a significant factor in these models, while viscous coupling of the slab and the wedge was ignored. Following the work of Yuen et al. [1978] and Yuen and Schubert [1979] high shear stresses were shown to be unlikely. Beukel and Wortel [1987] have shown that given reasonable rheology and heat flow constraints, shear stresses are likely to be about $25 \mathrm{MPa}$, extend down to about $40 \mathrm{~km}$, and locally lead to temperature increases of no more than $250^{\circ} \mathrm{C}$. Anderson et al. $[1976,1978]$ argued that endothermic dehydration reactions in the plate would absorb most if not all the heat produced in the frictional heating in the shear zone. Therefore frictional heating has been shown not to be a major 
heat source, and thermal models dominated by this premise are dubious.

Following the demise of frictional heating, the next candidate for a major heat source has been advected heat, carried by an induced flow generated in the mantle wedge by viscous coupling to the subducting plate [e.g., McKenzie, 1969; Andrews and Sleep, 1974; Bodri and Bodri, 1978; Anderson et al., 1980; Hsui et al., 1983; Honda, 1985]. The resulting flow under certain circumstances can bring quite high temperatures close to the subducting plate. Hsui et al. [1983] claimed that it is possible for induced flow to raise the temperature in the wedge corner sufficiently to melt the subducting plate extensively. Honda [1985] developed a detailed model for the Tohoku subduction zone, in Japan, incorporating an induced flow in the mantle wedge. The model included other heat sources and sinks and was constrained by heat flow and petrological and seismological observations. He needed to propose relatively high shear stress on the interface to satisfy the surface heat flow. Recent studies have shown that there is substantial continental generation of heat in Japan and with its inclusion one can satisfy the surface heat flow with low shear stresses on the thrust zone [Nagao and Uyeda, 1989; Furukowa and Uyeda, 1989].

The calculation of Hsui et al. [1983] could not be conclusive for three reasons. First, a thermal boundary condition needed to be prescribed at the slab mantle interface. In one case the temperature at this interface was prescribed and hence could not be evaluated, while in the second case a zero heat flux condition was applied at the interface, which is obviously incorrect, and only an approximation, as Hsui et al. [1983] themselves discuss. Second, (as they also discuss) their grid spacing is insufficient to resolve the actual temperature at the interface and in the neighboring mantle wedge. Third, the conclusion that the potential melting is located $100 \mathrm{~km}$ below the volcanic front in their model is directly related to their assumption that the rigid lithosphere of the overriding plate is $100 \mathrm{~km}$ thick. This choice of thickness is open to question; in this study we favor a thickness of $40 \mathrm{~km}$. Honda [1985] addressed many of the above problems but posed the answer in the form of a question, that is, the mantle temperature below the Japan Sea is $1400^{\circ} \mathrm{C}$, and how is the Japan Sea this hot? Honda could not answer this question, since the area he modeled is quite small, less than $200 \mathrm{~km}$ in depth, and belies the fact that the wedge temperature really comes from satisfying the petrologic constraint of Tatsumi et al. [1983].

This study was undertaken so as to avoid the limitations of the previous studies outlined above. Induced flow needs to be considered with a more detailed grid such that the resolution problems of Hsui et al. [1983] and the extent problems of Honda [1985] are avoided. We also avoided assigning boundary conditions to the slab mantle interface by placing the slab in the middle of a grid so that the side boundary conditions did not involve the slab.

We will show, using finite element numerical models and analytic models, that it is difficult to heat up the slab mantle interface and hence that the subducting plate is unlikely to be the major source of the subduction zone magmas. We go further than standard interpretations of comparing thermal models to phase diagrams by taking into account the dynamics of the mantle wedge. This leads us to propose a mechanism for the lateral transport of water out into the mantle wedge and also for the focussing of cracks in towards the mantle wedge corner. We shall show that the combination of all these processes could allows us to explain the height of the volcanic front above the Benioft zone. We also investigate the conditions necessary for local sources of buoyancy , for example, melt, to reverse the slab-induced flow of the mantle wedge and generate an upwelling.

\section{ANALYTIC Models}

Before describing the numerical thermal models, we would like to suggest analytic approximations of various aspects of the problem to give the reader a qualitative feeling for the behavior of the model, and also to reinforce the result that given typical subduction parameters, it is very difficult to heat up and melt extensively the oceanic crust.

The subducting slab is assumed to drag down mantle at its sides. By continuity the mantle below the overriding lithosphere must approach the wedge corner to replace the material descending with the slab. Hence the subducting slab induces a regional flow. As this mantle descends with the slab, it heats the slab and is correspondingly cooled. The extent to which this cooling extends into the mantle increases with depth into the mantle. This is like a boundary layer, and its thickness is about $\sqrt{\kappa \bar{t}}$, or equivalently, $\sqrt{\kappa x / v_{p}}$, where $t$ is time, $x$ is distance down along the slab and $v_{p}$ is the plate velocity.

The boundary layer is thinnest within $10 \mathrm{~km}$ of the wedge corner. This initial thickness of the thermal boundary layer in the mantle occurs at the point where the flow is largely perpendicular to the slab before it begins to descend parallel to the slab. Assuming that this thickness is a balance between horizontal advection into the corner and horizontal conduction into the slab we get that

$$
v_{x} \partial T / \partial x=\kappa \partial^{2} T / \partial y^{2}
$$

If we assumed, unreasonably, that $v_{x}$ is constant and equal to the plate velocity $(\approx 7 \mathrm{~cm} / \mathrm{yr})$, all the way to the slab surface, then the initial thickness is estimated to be around $500 \mathrm{~m}$. It is more reasonable to assume that the normal flow velocity decreases as it approaches the slab. If we assume that it decreases linearly from the plate velocity to zero over $5 \mathrm{~km}$, then we find that an estimate of the thickness of the thermal boundary layer is $\approx 5 \mathrm{~km}$.

It is found that the temperature at the interface of two blocks at different temperatures remains virtually constant as they equilibrate (at the mean temperature of the two blocks [Carslaw and Jaeger, 1959, p. 55]). This is expanded upon in Appendix A to illustrate that the temperature of the slab mantle interface in the "magic corner" [Marsh, 1979], where the flow is impinging on the slab, is very similar to the mean of the temperature of the impinging flow and the coldest temperature in the subducting plate. This is the background to the primary result of the paper: since the flow perpendicular to the slab must decrease to zero at the slab surface, the thermal effect of induced flow at the slab surface is much reduced.

A more complete analytic solution suggested to us by $\mathrm{A}$. Howard and B. Hager (personal communication, 1985), for the part of the problem where the wedge flow is parallel to the slab surface is also presented in Appendix A. This more complete analytic solution shows us that the thickness of the boundary layer is inversely proportional to the 
plate width and demonstrates the $\sqrt{\kappa x / v_{p}}$ behavior. In this model, the interface temperature is also close to the mean of the appropriate mantle and slab temperatures. Of course the interface temperature will vary with depth, since the mantle and slab temperatures increase at different rates as a function of depth.

\section{Numerical MOdEL}

Before introducing the method we will briefly discuss the framework envisaged for the numerical model. Since dynamic modeling of subduction is in its infancy [Gurnis, 1989], we have used the more robust kinematic modeling of the flow of the slab and the surrounding wedge. Since we are restricting our attention to potential source regions for subduction zone magmas, we attempt to model accurately only the thermal field of the subduction zone close to the wedge corner down to a depth of around $150 \mathrm{~km}$. The model outside this region does not require great care. Provided the region of interest is largely insensitive to the exact choices at the model periphery, we do not care which choice is made. In particular we take no account for the details of the fate of the slab, or local sources of thermal buoyancy. The insensitivity of the thermal field to the fate of the slab was demonstrated for a spreading and penetrating slab by running two appropriate $700 \mathrm{~km}$ depth box models.

At a larger distance from the corner and over larger time scales the global convection is significant. Suggestions for this can be seen in the three-dimensional, internally heated, convection calculations of Bercovici et al. [1989] (spherical geometry) and Houseman [1988] (Cartesian geometry). On long time scales, the global flow might be sufficiently chaotic to clear the wedge of infertile material. Also, the global flow is critical in adjusting the local deformation and the global plate velocities to give approximately constant local subduction velocities $\approx 7 \mathrm{~cm} / \mathrm{yr}$ [Otsuki, 1989].
The temperature field was modeled using a finite element convection code. The grid used for the $60^{\circ}$ dipping slab, together with the location of the plates and the thermal boundary conditions is shown in Figure 2. A similar but even finer resolution grid was used for the $30^{\circ}$ dipping slab. Using such a grid had two advantages over a finite difference grid. First, it was easy to implement the variable cell size allowing cells to range from $\approx 3 \mathrm{~km}$ across to $40 \mathrm{~km}$ across (grid of $60^{\circ}$ model), giving us the ability to combine resolution in the region of interest together with distant boundary conditions such that the region of interest was insensitive to the particular boundary conditions. Second, it allowed us to have the slab interface be flat rather than stepped as it would be with a rectangular grid.

The following equations were solved:

The equation for the conservation of mass (i.e., equation of continuity),

$$
\nabla \cdot \mathbf{v}=\mathbf{0}
$$

where $\mathbf{v}$ is velocity.

The equation for the conservation of momentum (i.e., Stokes Equation)

$$
\nabla P=\nabla \cdot(\eta \nabla \mathbf{v})+\Delta \rho g \hat{\mathbf{z}}
$$

where $P=p-\rho g z$, where $p$ is the total pressure and $z$ is the depth below the surface, $\eta$ is viscosity, $\Delta \rho$ is deviation in density, $g$ is the acceleration of gravity, and $\hat{z}$ is the unit vector directed towards the Earth's center. The above two equations were solved by the penalty parameter formulation such that (1) was automatically satisfied to $10^{-6}$, and no boundary conditions are required on the pressure. For details, see Hughes et al. [1979]. The equation for conservation of energy (i.e., the heat conduction-advection equation) is

$$
\partial T / \partial t+\mathbf{v} \cdot \nabla T=\kappa \nabla^{2} T
$$

\section{Grid and Temperature Boundary Conditions}

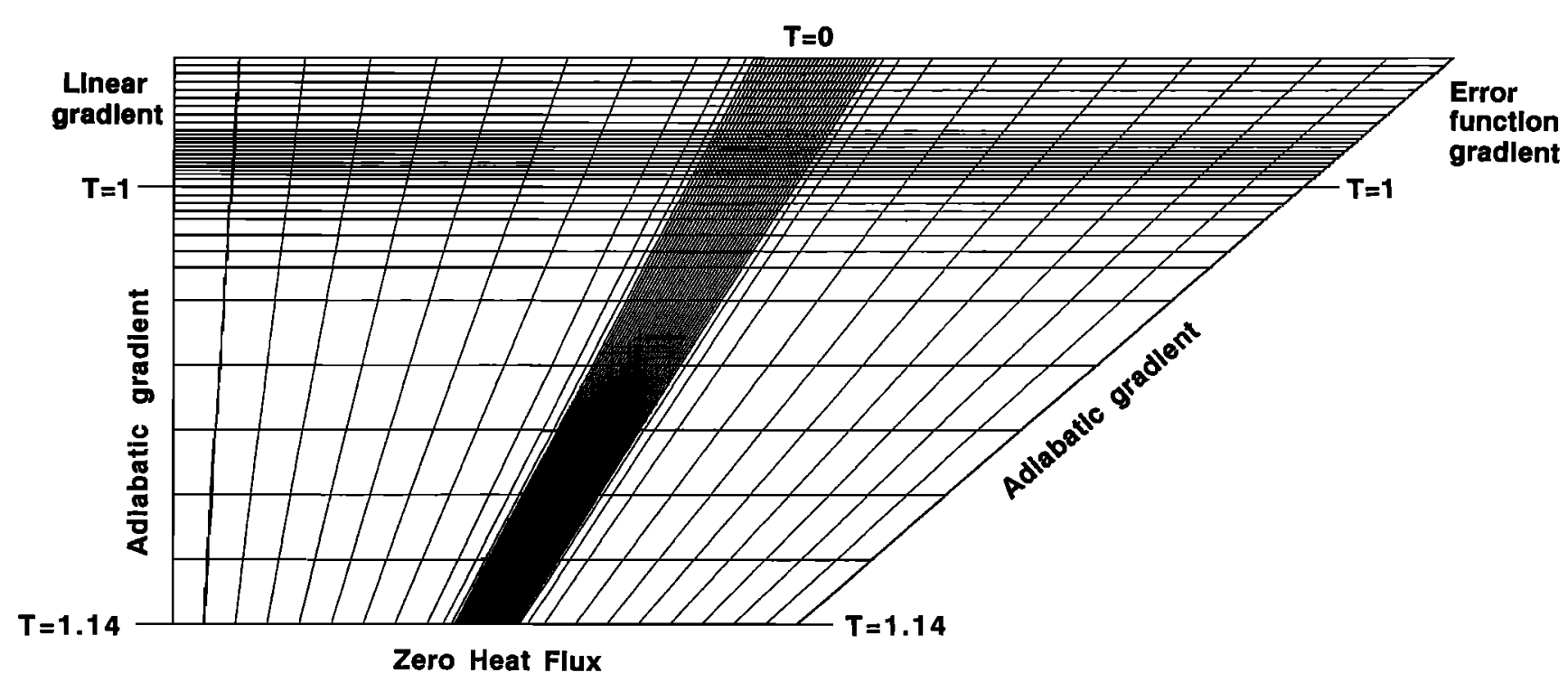

Fig. 2. Finite element grid and the temperature boundary conditions for the $60^{\circ}$ slab. Note the fine grid near the region of interest to achieve better resolution. The horizontal marks on the two sides correspond to the thickness of the thermal lithosphere, that is, $100 \mathrm{~km}$. The base of the model is at a depth of $400 \mathrm{~km}$. 
where $T$ is temperature, $t$ is time, and $\kappa$ is thermal diffusivity.

We have used the Boussinesq approximation [Tritton, 1977], which ignores all variations in density other than as a body force in the Stokes Equation. One of the conditions for the applicability of the Boussinesq approximation is that the depth of the model is less than the pressure scale height; this is not a problem for a model $400 \mathrm{~km}$ deep. This leads to the continuity equation reducing to a requirement for incompressibility. We assume that $C_{p}, \kappa$, and $\alpha$ are constant. We used real rather than potential temperatures; this allowed us to compare the results directly with phase diagrams. This is a rather poor excuse since converting from potential to real temperatures is easy. The resulting errors (due to ignoring adiabatic decompression) from using real temperatures are small in comparison to the uncertainty and disagreement in locating the phase boundaries; this is also true of the other approximations mentioned.

Using the robust kinematic boundary conditions, it was discovered that variable (note that we would be limited numerically to no more than 5 orders of magnitude in viscosity contrast) or constant viscosity made little difference to the flow produced near the wedge corner, our region of interest. This can perhaps be understood because using kinematic boundary conditions requires the slab to behave as if it has infinite viscosity. In comparison, any other viscosity contrast is insignificant. Or restated, the primary influence of variable viscosity is expected at the cold boundaries, but these regions are also velocity boundary layers, and the velocities in these regions are dominated by the boundary conditions and are less sensitive to the viscosity. As a result, constant viscosity was used. Temperature dependent viscosity is potentially important in the Earth, but this will be effectively implemented only when kinematic boundary conditions are replaced by a dynamic system. Similarly, Newtonian viscosity was used as opposed to power law rheology, even though the high stresses expected suggest that the rheology is most probably nonlinear, at least near the corner. For a discussion of power law rheology corner flow, see Tovish et al. [1978]. Note if the plate is mechanically decoupled from the mantle wedge the kinematic boundary conditions no longer control the flow far away from the slab; hence in this case the rheology of the wedge will be important if there are local sources of buoyancy.

Since in our formulation the density and viscosity are independent of temperature, the solution of the flow and temperature field are decoupled. The flow need only be solved once, and only the energy equation needs to be advanced through time, leading to computational savings. Hence we have forced convection rather than free convection. Using kinematic boundary conditions makes it difficult to evaluate the proportion of the global thermal buoyancy that has been accounted for with the kinematic velocity boundary conditions. It is expected that the flow resulting from the smooth large-scale temperature variations are well accounted for by the boundary conditions, while the temperature variations whose flow generation are unaccounted for, will lead to only minor, local changes to the flow. To accurately include the effects of thermal buoyancy, one will need a dynamic model with temperature dependent viscosity. By contrast, it is felt that large local compositional differences (e.g., due to the presence of melt and residue) can lead to substantial local flow variations, especially away from the forced flow of the slab boundary conditions. These are investigated in section 5 using locally prescribed body forces.

These equations are nondimensionalized as follows: $x^{\prime}=$ $x / d, t^{\prime}=\kappa t / d^{2}, P=\eta \kappa p^{\prime} / d^{2}$. The primes correspond to nondimensionalized quantities. Dropping the primes, we get the following nondimensionalized equations

$$
\begin{gathered}
\nabla P=\nabla^{2} \mathrm{v}+B_{m} \hat{z} \\
\partial T / \partial t+\mathrm{v} \cdot \nabla T=\nabla^{2} T
\end{gathered}
$$

where $B_{m}=d^{3} \Delta \rho g / \kappa \eta$ is the buoyancy number, $\Delta \rho$ is the body force acting per unit volume, and a buoyancy number can be defined for each element in the grid.

The temperature boundary conditions are also illustrated in Figure 2. We shall distinguish two lithospheres, first, a thermal lithosphere, which is the Earth's thermal boundary layer, and second, a mechanical lithosphere which will be considered to be the rigid part of the plate on the time scale of the process (of the order of $10 \mathrm{~m} . y$. to achieve steady state). The thermal lithosphere of the overriding plate was made $100 \mathrm{~km}$ thick and was characterized by a linear temperature distribution. The thermal lithosphere of the subducting plate was made of variable thickness varying from 20 to $120 \mathrm{~km}$ thick and was characterized by an error function temperature distribution. All the figures are from models with subducting oceanic lithospheres that are $\approx 90 \mathrm{~km}$ thick. The sides of the box below the thermal lithosphere were given a linear temperature profile corresponding to an adiabatic gradient increasing from $T=1$ at the base of the thermal lithosphere to $T=1.14$ at the bottom of the box (modeled to be $400 \mathrm{~km}$ ). The thermal boundary condition at the bottom was one of zero heat flux.

The velocity boundary conditions are illustrated in Figure 3. Note that the boundary conditions on the edges of the wedge are zero normal stress, implying that the derivative of the velocity in the direction normal to the boundary is zero. This gives a velocity field in the wedge corner very similar to the corner flow solution found by Batchelor [1967] for an infinite wedge. Note the descending slab is prescribed by the kinematic boundary conditions as a nonmigrating slab dipping uniformly at $60^{\circ}$ or $30^{\circ}$. We modeled different local subduction velocities. For the moment we shall assume that only relative velocities are important. We combine global flow, trench migration, and internal plate deformation (e.g., arc compression or back arc spreading) and consider only the resulting local normal (that is, we ignore components of the subduction velocity along strike) subduction velocity. Wdowinski et al. [1989] have modeled the deformation in the overriding plate as the response of a viscous mechanical lithosphere to an applied horizontal force and shear tractions from the underlying corner flow. The resulting modification of the corner flow is weak.

It was demonstrated that the boundaries of the model were far enough away by running experiments with altered boundary conditions. In one experiment the velocity boundary conditions along the side were made vertical and horizontal rather than the stress free boundary conditions. In another the zero heat flux boundary condition at the base of the box was replaced by a constant temperature boundary condition. It was found that neither made a difference to the temperature of the slab or wedge corner down to $200 \mathrm{~km}$ depth. As a corollary one should not interpret the thermal field close to the base or sides of the box. 


\section{Velocity Boundary Conditions}

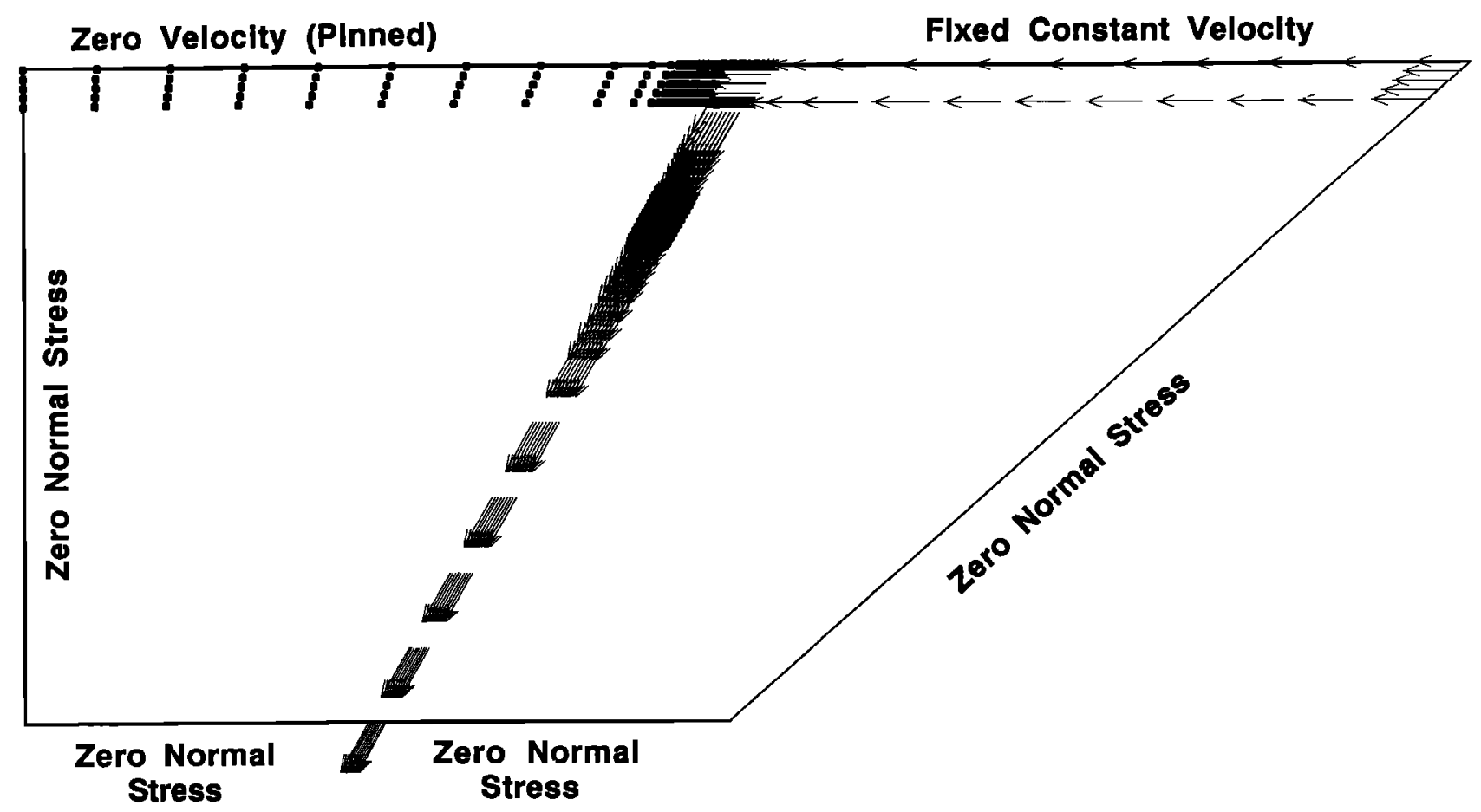

Fig. 3. Velocity boundary conditions. The circles correspond to fixed zero velocity boundary conditions. The side and bottom boundaries have zero normal stress boundary conditions.

The issue of slab shape is not fully addressed here, but because the flow is laminar and most of the heat flow is by advection, the exact shape is not critical to the global temperature field but would be important for temperature locally in regions where the slab shape is curved. Spence [1989] shows that the slab dip below $\approx 30 \mathrm{~km}$ is approximately uniform through $100 \mathrm{~km}$ depth to at least $\approx 200$ km depth. Isacks and Barazangi [1977] find that dips vary downdip but are largely constant at $100 \mathrm{~km}$. Down to $\approx$ $30 \mathrm{~km}$ depths the dip is shallow, $\approx 10^{\circ}$; this leads to more heating of the downgoing lithosphere compared to our model and equally a stronger cooling of the overriding lithosphere. Since the overriding lithosphere is cold at these depths and is made colder by the underthrusting slab, this effect is minimal. This is illustrated in the work of Sydora et al. [1978]. The effect of geometry of subduction path was also considered by Furlong et al. [1982], but only the thermal field of the slab was evaluated; the wedge was effectively a stationary hot bath like the zeroth-order model of McKenzie [1969].

The continental plate in our model was stationary, while the downgoing plate had a constant velocity, varying from 1.8 to $9 \mathrm{~cm} / \mathrm{yr}$. In estimating what real velocity corresponds to the nondimensional model velocity, one needs to know the applicable diffusivity of the model, since $v=v^{\prime} \kappa / d$. It has been found that thermal conductivity decreases appreciably with temperature but increases with pressure; as pressure increases, radiative transfer makes an increasing contribution. Fujisawa et al. [1968] found that the diffusivity of forsterite at $3 \mathrm{GPa}$ and $825^{\circ} \mathrm{C}$ was $9.4 \times 10^{-7} \mathrm{~m}^{2} \mathrm{~s}^{-1}$, and $10.3 \times 10^{-7} \mathrm{~m}^{2} \mathrm{~s}^{-1}$ for $725^{\circ} \mathrm{C}$. Density increases slowly with depth, while above the Debye temperature, the specific heat capacity is largely constant. The relevant diffusivity is that of the slab and mantle wedge in the thermal boundary layer where conduction is important. Since it is cold here, we estimate that the net result is a thermal diffusivity largely unchanged compared to the value at the surface. We use $\kappa=10^{-6} \mathrm{~m}^{2} \mathrm{~s}^{-1}$. The uncertainty in the estimate of $\kappa$ translates into a corresponding uncertainty in the estimate of the real plate velocity. We conservatively estimate that the applicable $\kappa$ could range from $0.8 \times 10^{-6}$ to $1.2 \times 10^{-6} \mathrm{~m}^{2}$ $\mathrm{s}^{-1}$. This translates to percentage uncertainties in modeled velocities of up to $20 \%$.

The rigid lithosphere is taken to be $\mathbf{4 0} \mathrm{km}$ thick. It is arbitrary, but we believe that it is the most representative choice that we could make. Since some workers have selected rigid lithospheres to be equivalent to thermal lithospheres at $\approx 100 \mathrm{~km}$, we outline five lines of reasoning that motivate our choice. Provided the thickness is less than $\approx 80 \mathrm{~km}$, this choice changes only the details rather than the qualitative behavior of the model. Hence the following paragraph can be ignored provided you are willing to accept that the rigid lithosphere beneath the volcanic front is less than $\approx 80 \mathrm{~km}$ and $\geq 10 \mathrm{~km}$.

Given that the time scale for the wedge to reach steady state is of the order of $5 \mathrm{~m} . \mathrm{y}$. the relevant transition viscosity from elastic to viscous behavior (for a Maxwell body) is $\approx 10^{24} \mathrm{~Pa}$ s. Given our high-stress regime, this suggests a critical isotherm of $600^{\circ}-700^{\circ} \mathrm{C}$. Before cooling by subduction, it is not unreasonable for this geotherm to be at a depth of 40-50 km, for old overriding lithospheres. Note that for midplate oceanic lithosphere at low strain rates, 
Bengman and Solomon [1984] suggest from seismicity that the critical isotherm is at $\approx 800^{\circ} \mathrm{C}$, while Wiens and Stein [1983] suggest $700^{\circ} \mathrm{C}$ for old oceanic lithosphere. Second, given the expected high temperatures from the high heat flow and the relatively high stresses due to the corner flow, one expects this region to undergo some degree of ablation [Andrews and Sleep, 1974; Bodri and Bodri, 1978]. In the case of oceanic lithosphere crossing a hotspot, it is found that the lithosphere thins rapidly to the thickness of 24 m.y. old oceanic lithosphere, that is, $\approx 45 \mathrm{~km}$ [Crough, 1978; Detrick and Crough, 1978; Crough and Thompson, 1976]. This resulting thickness seems to be independent of the original plate age, the velocity of the moving plate, or the strength of the hotspot involved. The rate of thinning requires advection (delamination or ablation), while the constant resulting thickness suggests that it is controlled by material rheological properties that are independent of temperature. Third, the flexural thickness of oceanic lithosphere below island arcs ranges from 10 to $35 \mathrm{~km}$, for loads of the order of 1 m.y. [Bodine et al., 1981]. It is unlikely that the thickness of the rigid lithosphere is less than the flexural thickness, but it could be similar. Fourth, island arc crust ranges from 5 to $35 \mathrm{~km}$; this suggests that crust is stable down to at least this depth and hence is probably a lower bound on the thickness of the rigid lithosphere. Our $40 \mathrm{~km}$ model will not be suitable for attempting to model those regions of the Andes where the crust is estimated to be up to $70 \mathrm{~km}$ thick [James, 1971]. A model with a thicker mechanical lithosphere would lead to a cooler wedge and less melting, as is observed in the regions of thick crust [Plank and Langmuir, 1988]. Fifth, the transition from elastic to ductile behavior ends at a depth of $60 \mathrm{~km}$ in the thrust zone (as defined by the extent of the rupture zone of thrust earthquakes) [Astiz et al., 1988]; this can be considered an upper bound. More direct estimates of the extent of rupture in the Andes by Tichelaar and Ruff [1989] give depth ranges of $40-50 \mathrm{~km}$. From the combination of the above arguments we believe that a thickness of $40 \mathrm{~km}$ is most probably a reasonable choice. All workers interested in proposing a reversal in flow direction have required the mechanical lithosphere to be, at most, $50 \mathrm{~km}$ thick [Plank and Langmuir, 1988; Ida, 1983a,b, 1987; Nye and Reid, 1986]. We note that Honda [1985] argued from heat flow constraints and the lack of seismicity observed in the mantle that the mechanical lithosphere in Japan was the same thickness as the crust, that is, $30 \mathrm{~km}$ thick. Similaxly, Thatcher et al. [1980] modeled the relaxation following the Riku-u earthquake of 1896 using a $30 \mathrm{~km}$ thick elastic plate on a viscoelastic asthenosphere of viscosity of $10^{19} \mathrm{~Pa}$ s. The thickness of the rigid lithosphere in our model was kept constant away from the corner, since the material prop- erties controlling ablation and delamination are poorly understood. Most probably this mechanical boundary layer is thinnest beneath the volcanic arc and is the explanation for the general high heat flow there. The occasionally exceptionally high heat flow in the volcanic arc is probably the result of heat advection by magma and water. Experiments were made with thickening rigid lithospheres away from the wedge and also appreciable but local ablation in the wedge corner. It was discovered that the resulting changes in the thermal field were minimal in potential source regions. Since no thermal buoyancy is evaluated other than that inherent in the kinematic boundary condition, the possible effect of sidewall cooling in a narrow rift below the volcanic arc is not allowed to develop; hence the effects of Mutter et al. [1988] were not observed. These might be important locally.

In the thermal model there are no explicit heat sources or heat sinks. Rough estimates of the magnitude of potential heat sources and sinks are made in Table 1 . The estimates applicable to the wedge have been evaluated for a radius of $150 \mathrm{~km}$ from the apex of the wedge corner, for a slab subducting at $45^{\circ}$. The most dramatic observation is that the advection of cold by the subducting slab is the biggest effect. This leads to large gradients across the slab mantle boundary, and hence conduction of heat into the lithospheres is the major heat sink from the wedge. Therefore the first-order thermal field of the wedge will be dominated by its contribution. It is balanced by the advection of heat by the induced flow. Given our limited understanding of other components of the model, such as melting, the subduction zone rheology, and phase diagrams, it is appropriate to ignore these other sources and sinks presently. Note that the frictional heating is outside the wedge and most of it heats up the underlying cold slab. We have not estimated viscous dissipation, but we note that it is unlikely to be the dominant mechanism since dissipation increases the temperature, which leads to a lowering of the viscosity and hence reduced dissipation. Melting also has a negative feedback; more melting cools the system until the rate of melting stops increasing. Note that the estimate of energy consumed by dehydration is similar to the heat of hydration. Hence some of the sources and sinks that we are ignoring will partially counteract each other.

An effect that is not directly addressed in this model is the advection of heat by fluid components, for example, $\mathrm{H}_{2} \mathrm{O}$ and melt. Water or melt from the slab is cooler than the wedge, while melt from either slab or mantle is hotter than the overlying lithosphere; hence fluid advection could heat or cool. Estimates of heat advection by $\mathrm{H}_{2} \mathrm{O}$ have been made by Peacock [1987], and he shows that one would need very large volumes of water for this to be a major effect. Similarly, Honda [1985] made an estimate of the melt flux

TABLE 1. Heat Sources

\begin{tabular}{|c|c|c|}
\hline Heat Source/Sink & $\begin{array}{l}\text { Power per Meter } \\
\text { Along Strike } \\
\mathrm{Wm}^{-1}\end{array}$ & Comments \\
\hline $\begin{array}{l}\text { Advection by the slab } \\
\text { Conduction into slab } \\
\text { Frictional heating } \\
\text { Melting } \\
\text { Dehydration and } \\
\text { hydration } \\
\text { Radioactivity in mantle wedge }\end{array}$ & $\begin{array}{l}-5 \times 10^{3} \\
-3 \times 10^{4} \\
+10^{3} \\
-10^{3} \\
-10^{3} \\
+10^{3} \\
+2 \times 10^{2}\end{array}$ & $\begin{array}{l}100 \mathrm{~km} \text { thick slab, } 800^{\circ} \mathrm{C} \text { deficit } \\
900^{\circ} \mathrm{C} \text { drop in } 25 \mathrm{~km} \\
\text { Average } \sigma=10 \mathrm{MPa} \\
\text { Subduction Zone Volcanics addition } 1 \mathrm{~km}^{3} \mathrm{yr}^{-1} \\
40 \text { wt } \% \text { hydrous minerals over } 2 \mathrm{~km} \\
\Delta H=10^{5} \mathrm{~J} /(\mathrm{kg} \mathrm{of} \mathrm{hydrated} \mathrm{crust}) \\
Q=8 \times 10^{-12} \mathrm{Wm}^{-3}\end{array}$ \\
\hline
\end{tabular}

Source of $\Delta H$ for dehydration is from Anderson et al. [1976]. We have assumed the same value for hydration; it is probably good to within $50 \%$. 
required to explain the heat flux deficiency that his model had at the arc. He required a melt flux of $0.05 \mathrm{~cm} / \mathrm{yr}$ and hence a ratio of intrusives to extrusives of $20: 1$; this is on the high side of all current estimates. If instead we assume a thermal pipe model such as that of Turcotte [1989], then we find that a melt flux of $0.05 \mathrm{~cm} / \mathrm{yr}$ gives an excess heat flux estimate of $60 \mathrm{~mW} \mathrm{~m}^{-2}$, but the heating of the intervening material would be negligible. We suggest that advection of heat plays a minor role in changing the thermal field globally, though it is accepted that channelled flows could have a large effect locally.

Since we have few constraints on the initial conditions of subduction, it was decided to concentrate on the steady state thermal regime of the subduction zone. Hence an implicit convection code was used, allowing faster convergence to steady state. The model practically achieves steady state in $<10 \mathrm{~m} . y$. If the wedge was purely rigid, and all the heat flow was by conduction, it would take hundreds of millions of years to reach steady state. Later it was discovered that some mechanisms do not work at steady state but could work in a periodic cycle. An explicit time dependent code was then used to model these situations, taking the results of steady state calculations as the initial temperature conditions.

Before comparing the model with phase diagrams, we need to dimensionalize the temperature. An estimate of the temperature below the lithosphere can be made assuming that the potential temperature below the lithosphere is largely constant and that it explains the relatively constant thickness of oceanic crust. McKenzie and Bickle [1988], applying this assumption, used experimental melting data and inferred a temperature of $1325^{\circ} \mathrm{C}$ below a $100 \mathrm{~km}$ thick lithosphere. Using an estimate of $0.6^{\circ} \mathrm{C} \mathrm{km}^{-1}$ for the adiabatic gradient, one gets an estimate of $1500^{\circ} \mathrm{C}$ at $400 \mathrm{~km}$. The dry solidus of peridotite at $100 \mathrm{~km}$ depth is $1400^{\circ} \mathrm{C}$, and there is little evidence away from mid-ocean ridge for extensive melting; see Sato et al. [1988b,c]. Another reasonable constraint is the conditions for the phase change of the $400 \mathrm{~km}$ seismic discontinuity assuming it has been correctly equated with the olivine-spinel phase change. The depth of this discontinuity can be resolved seismically only to $\pm 10 \mathrm{~km}$, and its Clausius-Clapeyron slope is $0.4 \mathrm{MPa} / \mathrm{km}$; hence Jeanloz and Thompson [1983] could only estimate a temperature of $1425^{\circ} \pm 300^{\circ} \mathrm{C}$ for this phase change. Of course the variability in the depth of this discontinuity could equally be of this order, and hence the upper bounds on lateral temperature variations at this depth are of the order of $\pm 300^{\circ} \mathrm{C}$. Other workers have preferred to place the discontinuity at $1500^{\circ} \mathrm{C}$ or $1600^{\circ} \mathrm{C}$ when modeling its seismic jump from mineral physics [Anderson and Bass, 1986; Weidner and Ito, 1987]. We assume that the temperature in the mantle, away from the slab, is $1325^{\circ} \mathrm{C}$ at a depth of $100 \mathrm{~km}$, and $1500^{\circ} \mathrm{C}$ at a depth of $400 \mathrm{~km}$.

\section{Model Results and INTERPRetation}

We shall consider the effects of two sources of buoyancy on the dynamics. They are the long-wavelength component of the temperature variation, which gives the descent of the slab seen in the seismicity, and the buoyancy due to the differentiation (melt and residue), to form subduction zone magmas. We shall first include only the slab-induced regional flow. This is discussed in section 4.1. Then we shall also include the potential effects of buoyancy as a result of melting, leading to local changes in the flow. This buoyancy can potentially give a local reversal in the mantle wedge flow; this is discussed in section 5 .

\subsection{Slab-Induced Corner Flow}

Results of thermal models. Using the above methodology, we ran a series of numerical experiments using models in which the mantle flow was prescribed by the kinematic plate flow and there were no intrinsic sources of buoyancy, that is $B_{m}=0$ everywhere. Two grids were considered, one with the subducting slab dipping at $30^{\circ}$ and the other with the slab dipping at $60^{\circ}$. These models were set up to address the

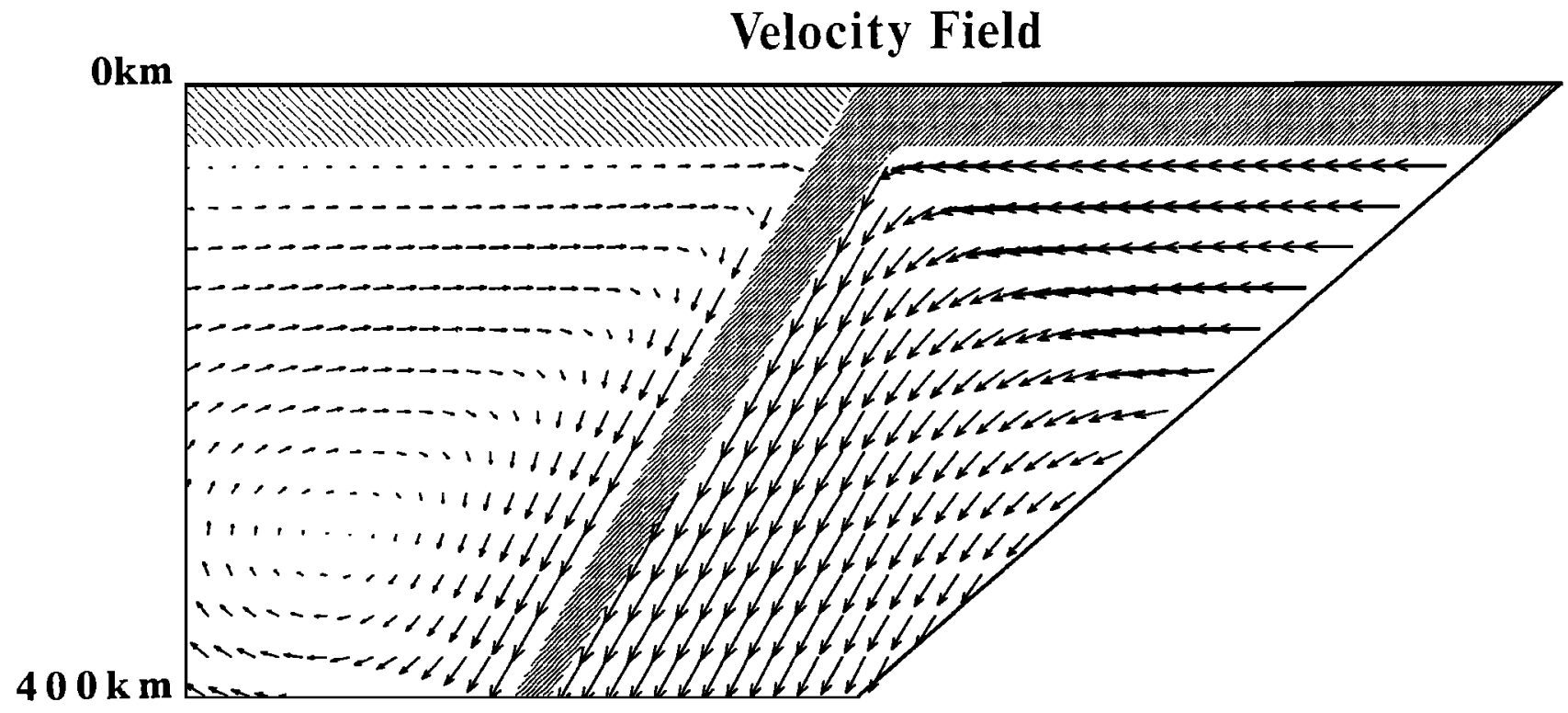

Fig. 4. Plot of velocity field. The descending slab (fine shading, down to right) and overriding mechanical lithosphere (coarse shading, down to left) are shaded with diagonal lines. The velocity has been interpolated from the uneven spaced grid of the calculation to an even grid for clearer presentation. 
question of whether an extreme induced corner flow could melt the slab and if any other regions could be made to melt. For these models the geometry of the streamlines is independent of the magnitude of the slab velocity provided we have the same dip, no thermal or intrinsic buoyancy forces, and a linear constant viscosity. Hence the velocity plot in Figure 4 illustrates the flow field for all the $60^{\circ}$ models in this section, that is the velocity field only varies by a scaling from one model to another.

The results of the $60^{\circ}$ dipping slab at three subduction velocities, $1.8,4.5$, and $9 \mathrm{~cm} / \mathrm{yr}$, are presented in Figure 5. The thermal models are sensitive to subduction velocities. It is found that lower subduction velocities imply much cooler mantle wedges with much thicker slab/wedge thermal boundary layers. Similarly, the slab interiors are hotter. It is found that for a plate velocity of $1.8 \mathrm{~cm} / \mathrm{yr}$ the wedge corner (see Figure 1) is not hotter than $800^{\circ} \mathrm{C}$ !

Varying the other input parameters had the following effects: shallower dips lead to similar thickness slab/wedge thermal boundary layers, bringing these boundary layers
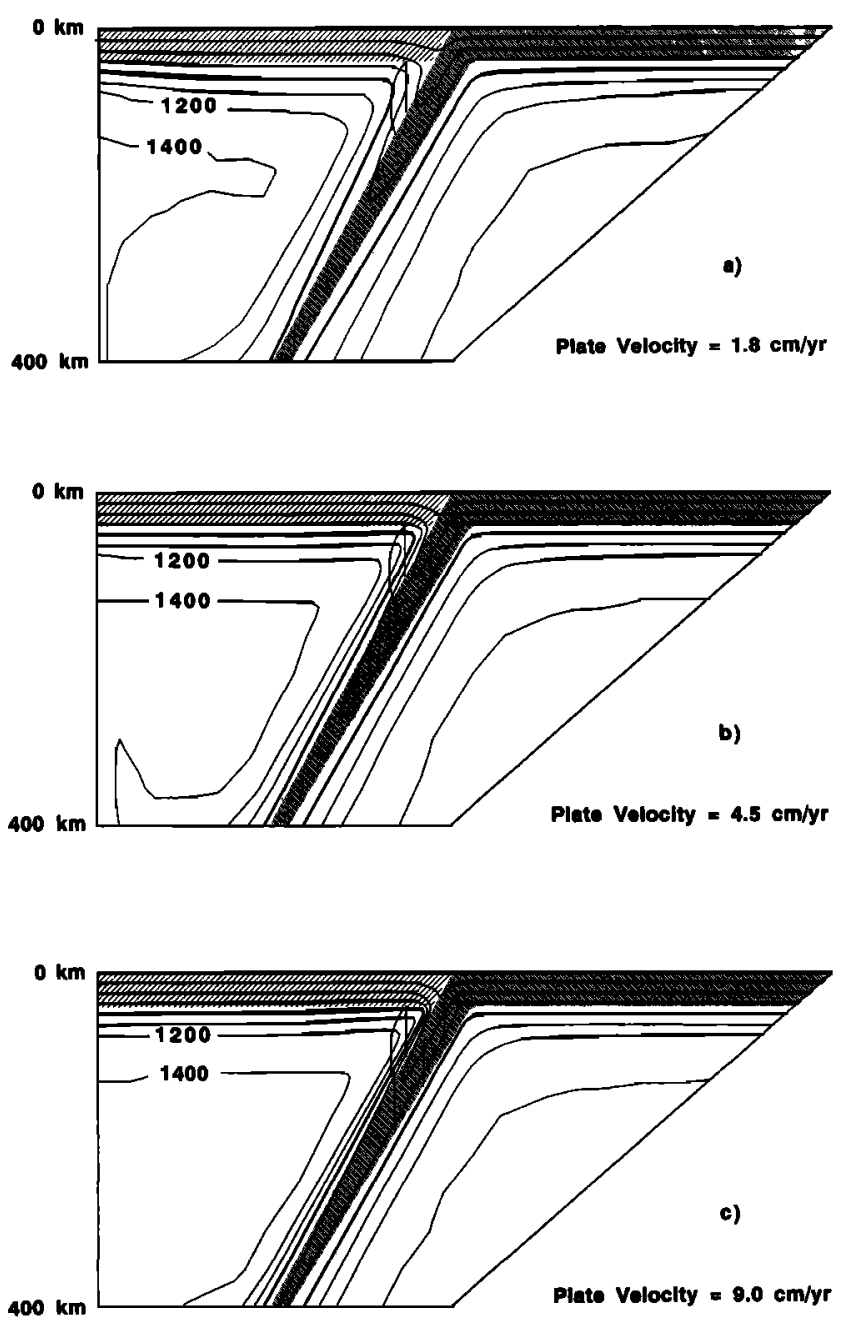

Fig. 5. Contours of thermal field at different relative normal subduction velocities: (a) $1.8 \mathrm{~cm} / \mathrm{yr}$, (b) $4.5 \mathrm{~cm} / \mathrm{yr}$, and (c) 9.0 $\mathrm{cm} / \mathrm{yr}$. The coarser shading is the mechanical overriding lithosphere, while the finely shaded area is the descending oceanic lithosphere. The heavy contour corresponds to $800^{\circ} \mathrm{C}$, and the contours are spaced $200^{\circ} \mathrm{C}$ apart. Note that the higher subduction velocity leads to hotter wedges.

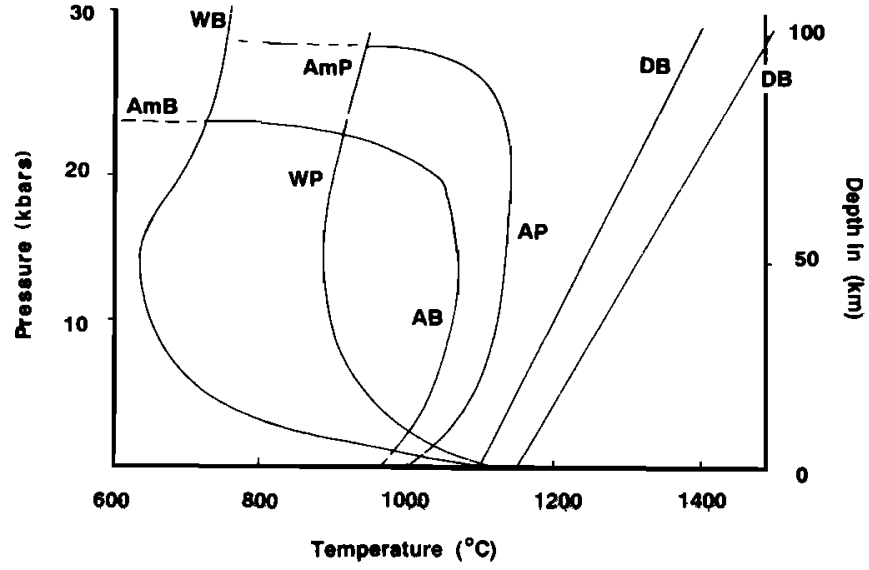

Fig. 6. Phase diagram of solidi in the peridotite $(P)$ and basalt (B) systems. Included are excess water, wet (W), amphibolebuffered (A), and dry (D) solidi from 0 to $30 \mathrm{kbar}$. Also we have AmP and AmB, which are the subsolidus breakdown (dehydration) curves for amphiboles in the peridotite and basalt system, respectively. The figure is a compromise between data based on $B V T P$ [1981], the work of Wyllie and coworkers compiled by Wyllie[1979] and that of Green and coworkers compiled by Green [1973].

closer to the cold upper lithosphere. This tends to squeeze out the hot tongue of mantle wedge that heads towards the apex of the wedge corner, and therefore we get marginally cooler mantle wedges. In the limit of very low dips there is no hot tongue of mantle wedge; this possibly explains why there is no magmatism above slabs with dips $\leq 20^{\circ}$ (e.g., certain regions of Andes). Also, it is found that the surface of the oceanic crust has higher temperatures at shallower dips. A thicker mechanical lithosphere leads to the isotherms being pushed deeper, but relative to the mechanical lithosphere they are shallower and the wedge is hotter. Similarly, the interior and surface of the slab are also slightly hotter. Varying the thickness (or, equivalently, the age) of the subducting oceanic plate had virtually no effect on the temperature in the mantle wedge, while thinner, younger, hotter slabs heated up more and as a consequence had higher temperatures at their interface with the mantle wedge.

Phase diagrams. In Figure 6 we illustrate the dry (D), wet (W), and amphibole-buffered (A) solidi in both the basalt (B) and peridotite (P) systems, for example AP is the amphibole-buffered solidus in the peridotite system. We also present the dehydration curves of amphiboles in both the peridotite (AmP) and the basalt system (AmB); these are just subsolidus continuations of the amphibole-buffered solidi. The amphibole-buffered solidus is at a higher temperature than the wet solidus (free water) when amphibole is stable above the wet solidus. Note that the amphibolebuffered solidus is for a rock that is perfectly dry. The curves are a synthesis of the work of Wyllie and his coworkers, compiled by Wyllie [1979], Green and his coworkers, compiled by Green [1973], and other work collected by the Basaltic Volcanism Study Project BVTP [1981]. An indication of the uncertainty can be obtained by noting that the AP solidus at $2.5 \mathrm{GPa}$ is placed at $1050^{\circ} \mathrm{C}$ by Wyllie and at $1150^{\circ} \mathrm{C}$ by Green. The largest discrepancy away from the curves presented was the work of Mysen and Boettcher [1975] that suggested that the WP solidus was closer to $800^{\circ} \mathrm{C}$ than $1000^{\circ} \mathrm{C}$ at $3 \mathrm{GPa}$. Green [1976] suggests that Mysen and Boettcher 
[1975] had misinterpreted glassy deposits from the vapor phase as glass quenched from liquid. Delaney and Helgeson [1978] theoretically calculated the stability of hydrous phases in a subduction zone. Their calculations are of limited use though, since they did not consider the amphibole pargasite hornblende, which is the hydrous phase expected from experimental work [e.g., Green, 1973]. Olafsson and Eggler [1983] found that amphibole became unstable at 2.3 $\mathrm{GPa}$ in peridotite, as opposed to $3 \mathrm{GPa}$ of Green [1973] which we assume for our discussion. The system of Olafsson and Eggler [1983] had $\mathrm{CO}_{2}$ as well as $\mathrm{H}_{2} \mathrm{O}$. Wallace and Green [1988] also looked at a peridotite system with $\mathrm{CO}_{2}$ and found that amphibole was stable to $\approx 3.2 \mathrm{GPa}$ but that a carbonate-rich melt was formed between 2 and 3 $\mathrm{GPa}$ while the amphibole remained stable. If the result of Olafsson and Eggler [1983] is applicable, then the initiation of melting would be shallower and quantitative predictions of our model would be changed. Their results could be important if $\mathrm{CO}_{2}$ makes up more than $10 \%$ of the volatiles and if $\mathrm{Na}_{2} \mathrm{O}$ is available for the clinopyroxene. There is some variability in the stability estimates of amphiboles in peridotite, and hence the behavior assumed for the present model might need to be adjusted in light of improved understanding. Qualitatively though, the proposed behavior of the system should be unchanged.

The phase diagrams should be considered with a litlle caution, since the early experiments were frequently done at uncertain oxygen fugacities and all suffered problems of iron interaction with containers (loss to noble metals, gain from iron, reduction by graphite). Oxygen fugacity is now regularly controlled, while the container problem is circumvented by the "sandwich technique" [Stolper, 1980; Falloon et al., 1988]. We shall have to wait and see if these were significant problems. Since our dimensionalization of temperature (discussed above) is also based on similar experiments via McKenzie and Bickle [1988], this effect might be minimized. The presence of $\mathrm{CO}_{2}$ generally moves the solidi to higher temperatures at pressures below $2.2 \mathrm{GPa}$ [Falloon and Green, 1990; Wyllie, 1979]. Above $2.2 \mathrm{GPa}$ its influence is different since it is buffered by stable carbonates, but generally the solidus is not too different from the WP solidus. We suggest though that $\mathrm{CO}_{2}$ is not a significant volatile in this tectonic environment for the following reasons. First, Gill [1981] suggests that the amount of $\mathrm{CO}_{2}$ in fumaroles is low, although this direct observation is questioned by some petrologists, notably Barnes et al. [1988]. Second, it is uncertain how much calcite is subducted, but it seems probable that calcite will remain stable and survive until deep into the mantle [Huang et al., 1980]; the influence of other minerals and water should be investigated in confirming the relative stability of calcite. There is no equivalent to hydrothermal circulation, though there is hydrothermal carbonation largely as a result of the precipitation of calcite. Little of the seafloor sediments containing limestone etc. are expected to proceed down the thrust zone past the accretionary prism.

Very little melting is expected at the wet solidus since we have little free water, but at the temperature corresponding to the amphibole-buffered solidus we can expect of the order of $10 \%$ melting [Green, 1972]. The degree of melting is a function of both the amount of free water and the temperature. At temperatures just below the amphibole-buffered solidus even small amounts of water will produce appreciable melting, but when the amount of free water is as small as $\approx 10^{-4}$, this is practically irrelevant. Therefore we expect the relevant solidus (where appreciable melt is produced) to be the amphibole-buffered solidus. Notice that at high pressures and very low pressures the amphibole-buffered solidus intersects with the wet solidus (i.e., in regions where amphibole is unstable). Since we ignore the latent heat of fusion in our thermal models, an allowance can be made by considering the effective temperature for melting to be higher (e.g., around $40^{\circ} \mathrm{C}$ higher for $10 \%$ degree of melting).

Interpretation of results of thermal models. The lines for stability of amphibole, amphibole-buffered melting, and wet

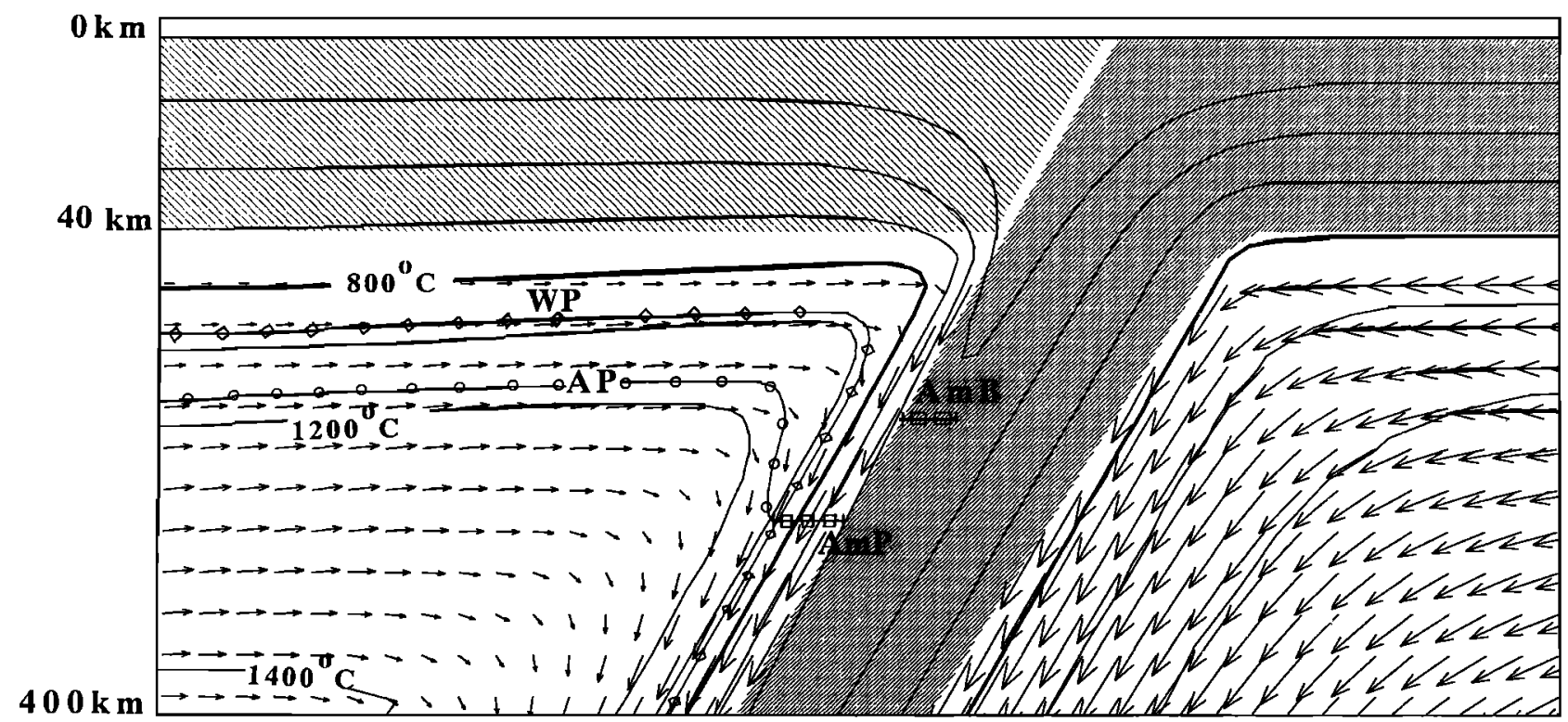

Fig. 7 a Thermal field of $60^{\circ}$ dipping slab with relative subduction velocity of $7.2 \mathrm{~cm} / \mathrm{yr}$. The heavy contour corresponds to $800^{\circ} \mathrm{C}$, and the contours are spaced $200^{\circ} \mathrm{C}$ apart. The lines of squares mark the breakdown limit of amphibole in basalt (AmB) and in the wedge (AmP). The line of diamonds represents melting with the excess water (WP), while the line of circles marks where amphibole is consumed by the melting (AP). 


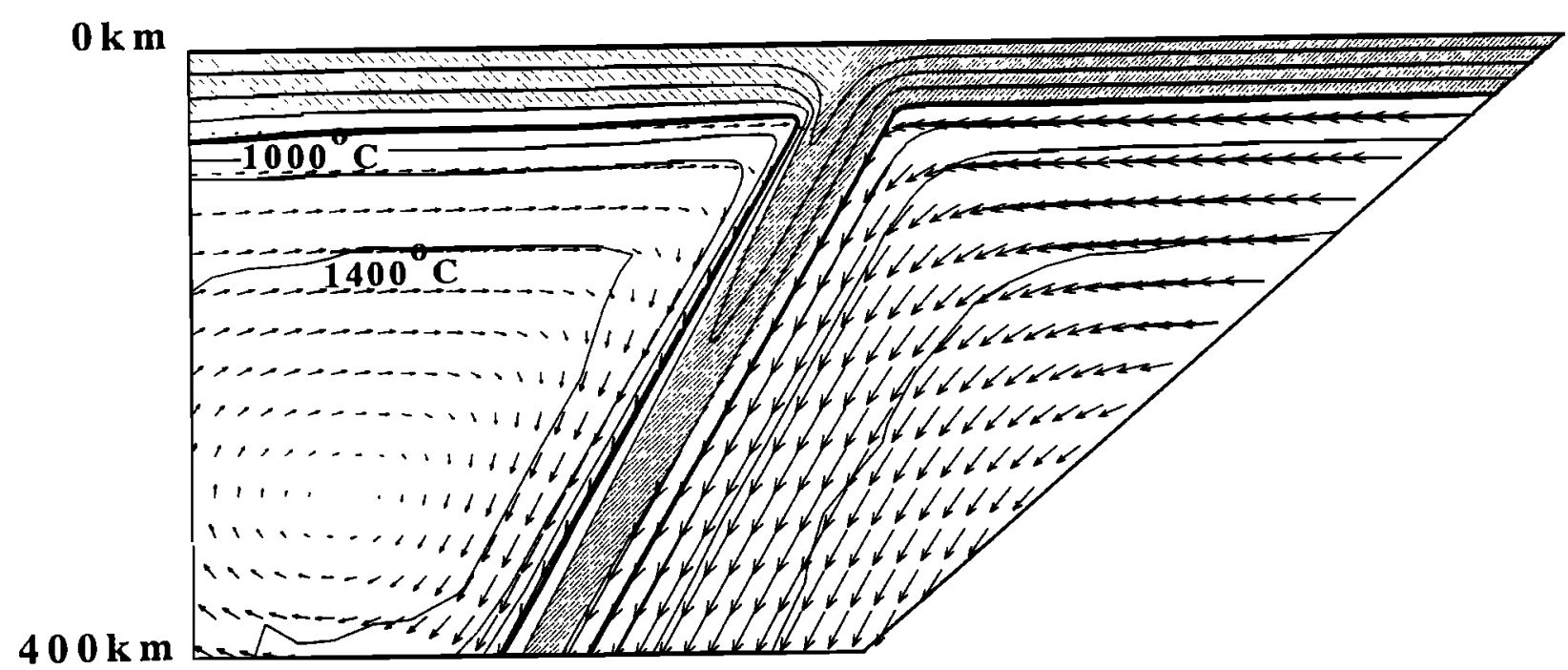

Fig. $7 b$ Identical to Figure $7 a$ without the phase diagram lines and showing the whole model.

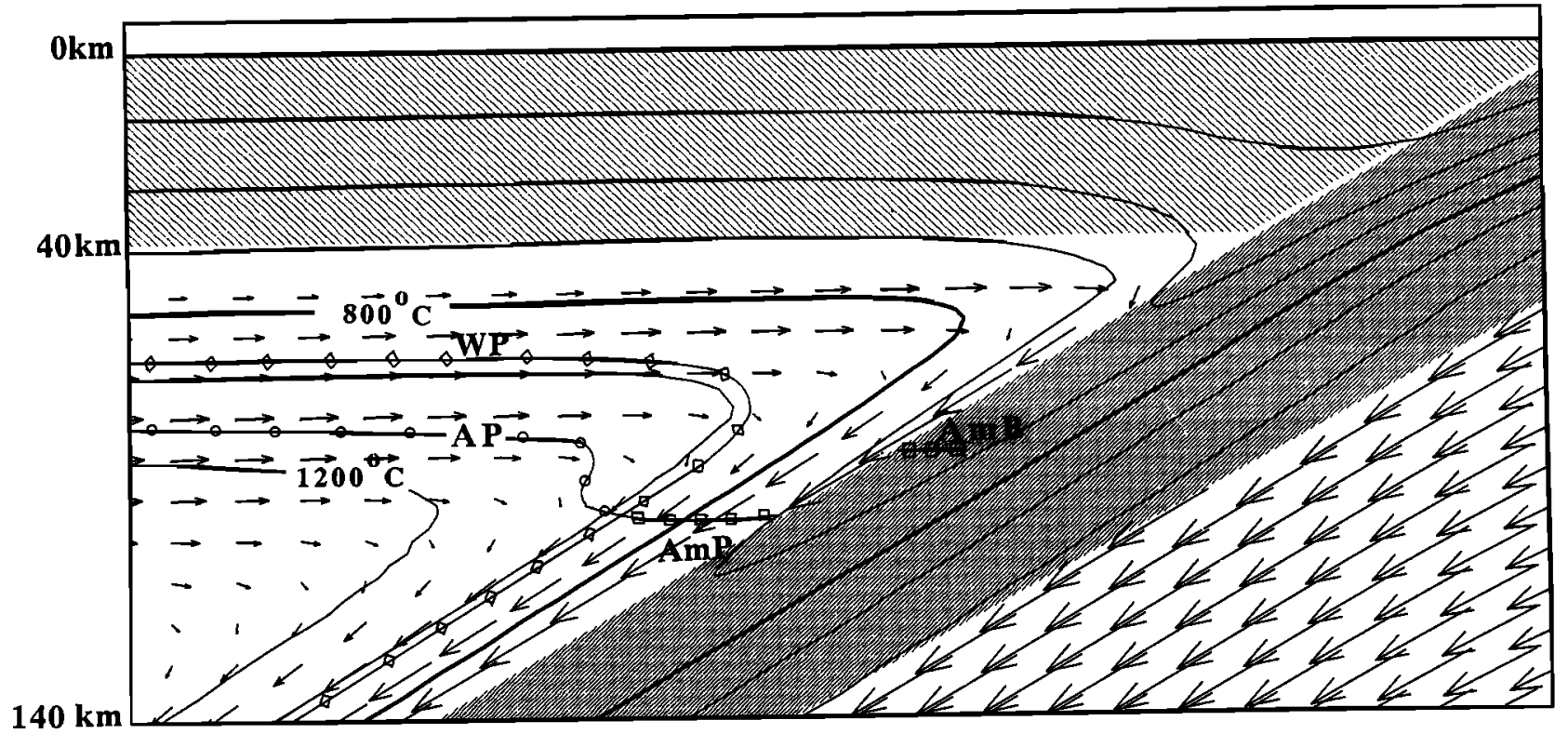

Fig. 7 c As Figure 7 a but for a $30^{\circ}$ dipping slab.

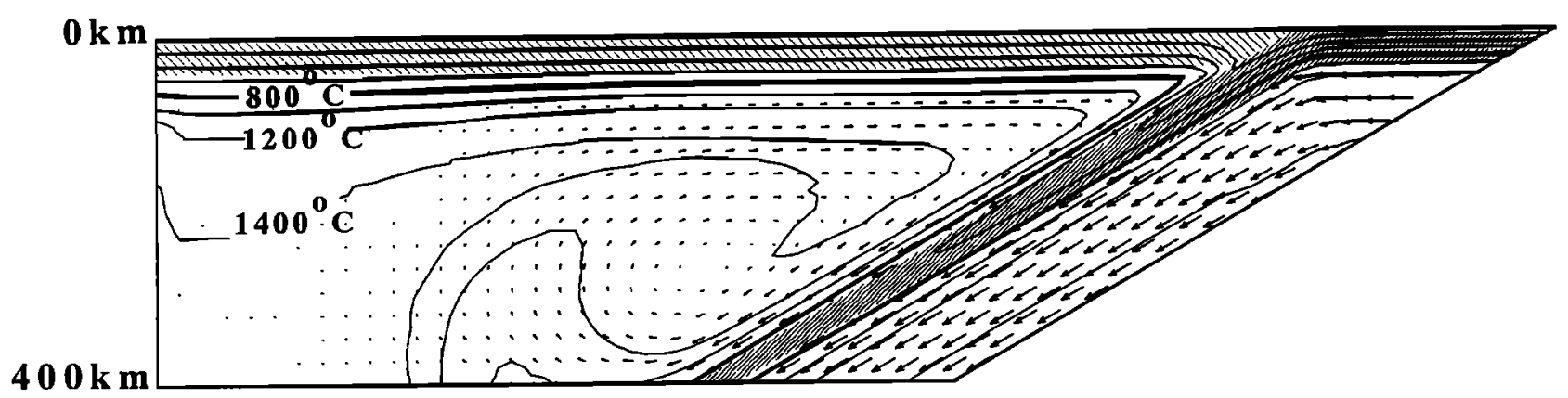

Fig. $7 d$ As Figure $7 b$ but for a $30^{\circ}$ dipping slab.

melting from Figure 6 are interpreted in Figures $7 a$ and $7 c$. Figures $7 b$ and $7 d$ illustrate the whole thermal models from which the above figures are taken. These are very complicated looking figures since they are not only attempting to convey the thermal field by contours and the interpreted phase boundaries but also are showing the velocity field. These figures should be understood in stages. First, we shall only consider the phase boundaries interpreted on the cross section. Notice that at low temperatures the stability curves of amphibole in both peridotite (AmP $\approx 2.9 \mathrm{GPa}$ ) 
and basalt $(A m B \approx 2.4 \mathrm{GPa})$ are horizontal, and these reactions occur at nearly constant depth. Hence the line at a depth of $\approx 100 \mathrm{~km}$ in the wedge and a depth of $\approx 80$ km in the oceanic crust of the slab mark the maximum depth of amphibole stability in these different bulk compositions. The vertical curve in the wedge, which turns horizontal at a depth of around $70-80 \mathrm{~km}$, corresponds to the amphibole-buffered solidus of peridotite (AP). We have not drawn its continuation beyond the depth where amphiboles are unstable in the mantle, since by definition amphibolitized peridotite no longer exists. The other vertical curve in the wedge which turns horizontal at an even shallower depth $(50-60 \mathrm{~km})$ is the wet peridotite solidus, that is, the water-saturated solidus (WP). The point where the curves meet marks the point where the amphibole-buffered peridotite solidus and the amphibole stability curve intersect with the water-saturated solidus. Provided sufficient water is present to amphibolitize the mantle, peridotite will melt everywhere below the AP line, that is, it is the distribution of water that localizes the melting. The temperatures are dimensionalized assuming that $T=1.0$ equals $1325^{\circ} \mathrm{C}$ at a depth of $100 \mathrm{~km}$ on the side of the overriding plate. Figures $7 a$ and $b$ are for a $60^{\circ}$ dipping slab while Figures $7 c$ and $d$ are for a $30^{\circ}$ dipping slab. From the Figures $7 a$ and $c$ one can see that we achieve sufficient temperatures at the appropriate pressures to (1) dehydrate amphiboles in the subducted oceanic crust, (2) melt the mantle if it is amphibolitized and definitely if it is wet, (3) dehydrate amphibole in the mantle at $100 \mathrm{~km}$, but (4) not to melt an amphibolitized slab. Extensive melting of the slab will be even harder in the Earth since we have ignored the endothermic behavior of slab dehydration.

Since the dehydration of amphibole in the mantle occurs at $\approx 100 \mathrm{~km}$ and the slab's thermal boundary layer is thin at this depth, Tatsumi [1989] argues melting initiates very close to the slab surface due to released water lowering the solidus, and that the resulting melts rise vertically. This is his explanation for the nearly constant depth of the Wadati-Benioff zone below the volcanic front $(124 \pm 38 \mathrm{~km}$ [Gill, 1981]; 112 $119 \mathrm{~km}$ [Tatsumi, 1986]). Below we discuss a distinct variation involving two novel ideas, the first involves lateral transport of water into the wedge and the second involves the focusing of melt towards the wedge corner due to the propagation direction of cracks. They lead to similar depths of the underlying plate below the volcanic front but suggest a slightly wider range and a slight increase at large dips as observed.

The actual temperature at the slab surface, as expected, is largely independent of velocity and dip. The slab heats up slightly more if it is younger so that if mechanisms depended on temperature to dehydrate the hydrated minerals in the slab it would lead to different depths of release of water depending on the age of the plate. There is no correlation of either the volume of magma production or the depth of the Wadati-Benioff zone below the volcanic front with the age of the subducting plate. This is consistent with the critical dehydration reactions being controlled by pressure rather than temperature, as the phase diagrams suggest for amphibole in a cold slab or wedge.

Brophy and Marsh [1986] suggest that high-alumina basalts are primary melts derived from melting oceanic crust. They suggest that these basalts are ultimately the result of $50 \%$ degree of melting and as a result they do not exhibit the rare Earth element signature of the presence of residual garnet in the source since nearly all (or all) the garnet is consumed in the extensive melting. They propose that the melts cannot segregate, and thus due to the presence of melt the quartz eclogite becomes diapirically unstable at $20 \%$ degree of melting. The resulting diapir then continues to heat up during its rise through the mantle wedge until the degree of melting reaches $50 \%$, at which point the melts can segregate by repacking of the solid. Following Brophy and Marsh [1986], a reasonable phase diagram for such high degrees of melting (20-50\%) is that of anhydrous high-alumina quartz tholeiite (given that the water content of high-alumina basalt is $<1 \%$ ). This phase diagram suggests temperatures $>1300^{\circ} \mathrm{C}$ at $2 \mathrm{GPa}$ and $>1350^{\circ} \mathrm{C}$ at $3 \mathrm{GPa}$ for $20 \%$ melting. Our thermal model does not allow such temperatures; therefore in general the diapiric instability that they propose cannot be initiated. Hence it is only by ridge subduction that the required temperatures could be achieved.

\subsection{Water Transport Mechanism}

From Figures $7 a-7 d$ it can be seen that andesites cannot be generated by extensive ( $50 \mathrm{wt} \%$ ) melting of the slab, which requires temperatures in excess of $1250^{\circ} \mathrm{C}$. Further if we entertain the mechanism of Brophy and Marsh [1986] for melting the oceanic crust, it can also be ruled out on thermal grounds as discussed in the previous paragraph. Melting of the continental or the arc crust might be feasible if they extend down to where the isotherms are $\approx 1000^{\circ} \mathrm{C}$. However, there is no petrological evidence that the bulk of the extruded basalts and andesites are recycled crust. Also it would be impossible to start an island arc by melting arc crust! It is argued that the crust melts in the Andes [Hildreth and Moorbath, 1988], but it is considered a secondary response to melts rising from a deeper primary source. It is seen from the thermal field that if there were no volatiles present, the only other way melt could be produced in this model is for the mantle to be very hot and for there to be some melt everywhere. There is no evidence for extensive melting, and it is most unlikely to lead to the sharp volcanic front found in subduction zones. By elimination, the only other possibility is that volatiles from the slab migrate into hot regions of the mantle wedge, lowering the solidus and causing melting.

Evidence of water in subduction zones. We have argued from our thermal models that the presence of lavas at island arcs can be explained only if water lowers the wedge solidus. A wide range of observations hints at the influence of sediments and water in subduction zones. These include ${ }^{10} \mathrm{Be}$ [Tera et al., 1986; Tatsumi and Isoyama, 1988], rare gas systematics [Staudacher and Allegre, 1988], and $\mathrm{Pb}$ isotope arguments [Davidson, 1987]. Less sophisticated but more general observations of subduction zone lavas indicate that they are generally more hydrous, frequently have amphibole phenocrysts, and are more likely to be explosive than most other types of volcanics. The continuous suites stretching from basalts across andesites to rhyolite at subduction zones suggest that along this fractionating path we are avoiding the low-pressure olivine-plagioclase-clinopyroxene and the high-pressure olivine-clinopyroxene-orthopyroxene thermal divides. Avoiding the thermal divide could be achieved by anhydrous fractionation at pressures $<1 \mathrm{GPa}$ and $>\approx 100$ 
MPa or with the presence of water [Wyllie, 1979]. Water lowers the thermal stability of plagioclase more than pyroxene, and of pyroxene more than olivine. Mineral stability in andesites suggest water contents of 2 wt \% [Gill, p.194, 1981], as does comparing eruption temperatures to the liqvidi of andesites [Gill, 1981, p. 64].

Oxygen fugacity and volatile speciation. The oxygen fugacity $\left(\mathrm{fO}_{2}\right)$ of the wedge is important in deciding the speciation of the volatile component. If the conditions were more reducing than the magnetite-wustite buffer, then $\mathrm{CH}_{4}$ would be the principal component of any fluid present, and there would be very little, if any, water present. Subduction zone volcanics commonly show high $\mathrm{fO}_{2}$, but there is a wide range. The increased $\mathrm{fO}_{2}$ could again reflect a hydrous component from the slab. Bonatti and Michael [1989] have shown subduction zone peridotites to be the most depleted, while Haggerty and Tompkins [1983] suggested that more depleted rocks have a lower $f \mathrm{O}_{2}$. This suggests that the mantle wedge with no volatiles has a low $\mathrm{fO}_{2}$. Similarly, one would expect the harzburgite of the descending slab to have a low $f_{2}$. From above we can see many lines of evidence suggesting a water source from the oceanic basalt and/or downgoing sediments. Water migrating from the slab would lead to high $\mathrm{fO}_{2}$ in its neighborhood. Mattioli et al. [1989] from a study of published analyses of coexisting minerals in spinel peridotites suggest that there is a large variation in the $\mathrm{fO}_{2}$ of subduction zone volcanics but that it is generally higher than or close to the fayalite-quartz-magnetite buffer. We can understand not only the high $\mathrm{fO}_{2}$ but also the wide range discovered due to the various sources and their varying $\mathrm{fO}_{2}$. Given a sufficient flux of volatiles, it is probable that this flux controls the $\mathrm{fO}_{2}$ (also suggested by Blundy et al. [1991] and Ballhaus et al. [1990]). Given the above estimates of $\mathrm{fO}_{2}$, it is very likely that most $\mathrm{H}$ will be in $\mathrm{H}_{2} \mathrm{O}$ while most $\mathrm{C}$ will be in $\mathrm{CO}_{2}$. By water we mean $\mathrm{H}_{2} \mathrm{O}$ as a vapor rather than liquid water; in fact under mantle conditions water is above its critical point and is a fluid.

How does the water leave the slab? We shall arrange this section following the path of a volume of water from the slab to the wedge, into melt, and through the melt to the base of the lithosphere.

The miniscule volumes of water produced by dehydration of individual amphiboles will be unable to set up a sufficiently long crack to propagate large distances, unless these small volumes of water can interconnect. Hence the most probable means of propagation, at least initially, is by porous flow. The exact phase in which water leaves the slab to enter the mantle is unknown. The thermal models above suggest a fluid, but unfortunately the validity of the thermal models are most questionable at the slab-mantle interface, as discussed below. Therefore we present two possibilities. The first involves a silica-rich hydrous phase, while the second involves a water-rich melt.

We shall show that they are expected to lead to similar conditions. This is because silicic melts that are produced will be very hydrous ( $\approx 25$ wt $\% \mathrm{H}_{2} \mathrm{O}$ ), while the hydrous fluids that are produced can be expected to be silica-rich $(\approx 20$ wt \%)[Eggler, 1987]. Since their volumes are small in comparison to the total magma they produce, it will be difficult to differentiate between them. Geochemically, identifying the mobile phase is important, but in identifying the spatial extent of the source region of subduction zone magmas we suggest that it is irrelevant.
Let us consider the water leaving the slab in a silicic melt. At water-saturated conditions it is found that the solidus of basalt/eclogite at 2-3 GPa is in the range $600^{\circ}-750^{\circ} \mathrm{C}$. The thermal model of an old oceanic plate subducting gives subsolidus temperatures at the slab-wedge interface. This interface is the focus of many heat sources and sinks that have been ignored. These include frictional heating on the thrust zone, advection of water up along the decollement, dehydration, and melting. The first two could locally lead to temperature increases of up to $200^{\circ} \mathrm{C}$. Dehydration is an endothermic process, while if there is melting it would be limited by the latent heat of fusion. Therefore in a subduction zone where the oceanic crust is young or frictional heating is high, it is conceivable that small volumes of very silicic, hydrous melts $\left(20-30\right.$ wt $\left.\% \mathrm{H}_{2} \mathrm{O}\right)$ are produced. Basaltic melts have been shown to form an interconnected network with olivine [Waff and Bulau, 1979, 1982; Cooper and Kohlestedt, 1982, 1986]. The dihedral angle of melts in an eclogitic assemblage has not been directly measured. From the observation that there are frequently large garnet crystals, and that garnet seems to be immersed in pools of melt in highly molten systems, a suggestion has been made that basaltic melts will have a dihedral angle much less than $60^{\circ}$ in eclogitic assemblages (B. E. Watson, personal communication, 1989; M. Wolf, personal communication, 1990). We therefore suggest that the melt can interconnect through a garnet-rich eclogite slab. The melts would migrate the short distance from their source to the slab-wedge interface where they must interact with peridotite if they are to migrate through by porous flow. To establish a porous network, the melt and matrix must reach textural equilibrium. This will of necessity involve an approach towards chemical equilibrium. The work of Wyllie et al. [1989] demonstrates that assimilation of peridotite by the silicic melt will canse crystallization. As its viscosity increases and the melt fraction decreases, it will stop migrating. It will assimilate more peridotite until it is solid. The water in the melt will be incorporated into amphiboles in the mantle wedge. This is not too dissimilar to the hybridization mechanism of Nicholls and Ringwood [1973], though they conceived of more appreciable melting of the slab.

Now let us consider the migration of water from the slab to the wedge in a silica-rich hydrous phase. There are also no experiments for the textural equilibrium of water in an eclogitic assemblage. The only experiments on the textural equilibrium of water have involved olivine and quartz, and were done by Watson and Brenan [1987] and Watson et al. [1990]. Their work suggests that water stays at four grain corners in olivine at low temperature and low pressure $(<$ $1 \mathrm{GPa}$ and $1000^{\circ} \mathrm{C}$ ). We argue that the primary factor in deciding the dihedral angle between a melt or fluid and its matrix is the composition of the fluid or melt and the solid phases. We suggest that the behavior of a solute-rich hydrous phase will be intermediate between pure water and dry melt. At higher temperatures and pressures (1 and 2 $\mathrm{GPa}$, at $1200^{\circ} \mathrm{C}$ ) Watson et al. [1990] have found that water will interconnect in olivine, that is, conditions of higher solute solubility. Following the speculation regarding the wetting of garnets when discussing basaltic melts, it is suggested that a water-rich fluid phase would interconnect in the slab. This would lead to rapid transport of water to the face of the slab. Since the slab interface is cold at $\mathbf{5 0}$ $\mathrm{km}$ depth, there might be insufficient dissolved solids in the 
fluid to allow the fluid interconnection to extend into the predominantly olivine mantle, but we do note that the permeability of an amphibolitized mantle is unknown. If there is sufficient height of water in the slab, it could migrate into the mantle by hydraulic fracture, when the difference between the lithostatic and hydrostatic gradient exceeds the strength of the rock. If $\Delta \rho \approx 2 \times 10^{3} \mathrm{~kg} \mathrm{~m}^{-3}$ and $h \approx$ $5 \mathrm{~km}$, then $\Delta \rho g h \approx 100 \mathrm{MPa}$; estimates of strength range widely, but Spera [1987] quotes $50 \mathrm{MPa}$. The direction of fracture will be normal to the least compressive stress in the upward direction; this direction is into the mantle wedge. Such a crack, having a very limited source of fluid, will not propagate very far. The water so released would react with the peridotite to produce hydrous phases including amphiboles. In the region of the slab/overriding plate interface where the thrust earthquakes occur (down to $\approx 60 \mathrm{~km}$ maximum), the interface may be permeable and a conduit for water. Hence much of the water released down to this depth might be expected to migrate back up the thrust zone to the surface. Water though is also released deeper where there are no longer large earthquakes at the surface of the oceanic crust. It is likely that the deformation at the surface of the slab at this depth occurs by ductile flow, and hence there is no reason to expect this to be a zone of high permeability.

Lateral transport mechanism for water across mantle wedge. The water has now entered the mantle either as a hydrous silicic melt or a silica-rich hydrous fluid, the result of which has been the formation of amphiboles in the mantle wedge. Present experimental evidence suggests that amphiboles will be the primary hydrous phases; but the mechanism for lateral transport requires only that there be a region in the mantle wedge near the subducting slab where not all the water can be incorporated into hydrous phases (in this presentation, deeper than the breakdown of amphibole). Hence amphibole has been taken as the representative hydrous mineral for what might actually be a more diverse collection of hydrous minerals. The amphiboles are then carried by the induced mantle flow until they reach a depth at which they become unstable and release their water. Unfortunately, there are no appropriate experiments to estimate the dihedral angle of a hydrous fluid with peridotite at pressures of $3 \mathrm{GPa}$ and greater. From the systematics of Watson et al. [1990] it is seen that interconnection is favored by high pressure and high temperature. Hence if the water does not interconnect on release, it will be ever more likely to interconnect as it is dragged to higher pressures and slightly hotter temperatures. Provided it does interconnect before it is absorbed to form a stable hydrous phase (e.g. dense hydrous magnesium silicates, DHMS) then it will rise vertically up until it reaches mantle in the stability region of amphibole. It will pass through mantle that is saturated with amphibole but will stop on reaching mantle which is not saturated. Here it will react to form amphibole, which will get dragged down as part of the induced matrix flow, such that the cycle repeats. When it is between the wet solidus (WP) and the amphibole-buffered solidus (AmP), amphibole is still stable, but the free phase rising vertically is no longer water but is a hydrous melt. These melts percolate by porous flow and hence are close to chemical equilibrium with the mantle. Hence when they rise into amphibole-free mantle they will crystallize forming amphibole which is carried back down, continuing the cycle until amphibole is no longer stable. This is illustrated in cartoon fashion in Figure
8 , assuming that the water does interconnect immediately on dehydration. It can be seen from Figure 8 that the net effect of this process is to transport all the water released laterally across the mantle wedge at the dehydration depth to the amphibole-saturated solidus. It is seen that this is a robust transport mechanism provided that (1) water leaves the slab to enter the wedge, (2) it rises vertically as a free phase at a velocity greater than the vertical component of the induced flow carrying it down, and (3) the direction of mantle flow is down and the horizontal component of the mantle flow is away and not towards the slab. The last condition can hold for large horizontal distances away from the slab (e.g., $30 \mathrm{~km}$ for $60^{\circ} \mathrm{dip}$, as can be seen from looking at the velocity field in Figure $7 a$, similarly up to $60 \mathrm{~km}$ at $30^{\circ}$ dip, as seen in Figure $7 \mathrm{c}$ ), the exact range depends on the flow. In Appendix B we present a simple analysis of the water transport mechanism in the mantle assuming that the upward transport of the water is by porous flow. This leads to an estimate of $<0.02 \mathrm{wt} \%$ free water as well as $0.4 \mathrm{wt}$ $\%$ water in amphibole being transported laterally at a horizontal velocity of the order of centimeters per year. If the upward transport mechanism is very rapid, for example, hydraulic fracturing, then there is no change in the amount of water transported laterally by the amphibole, but the amount of free water would be much smaller. It is seen that this mechanism will also process any other water generally present in the upper mantle and brought into the wedge corner by the slab-induced flow.

Liu [1989] suggests that there is a region of the mantle in which water can exist as a free phase, but he suggests that this might not be the case at subduction zones, since water might be stabilized in other hydrated phases, including $\mathrm{Mg}$-chloritoid, $\mathrm{Mg}$-pumpellyite, and $\mathrm{Mg}$-staurolite, if these

\section{Cartoon of Water Transport Mechanism}

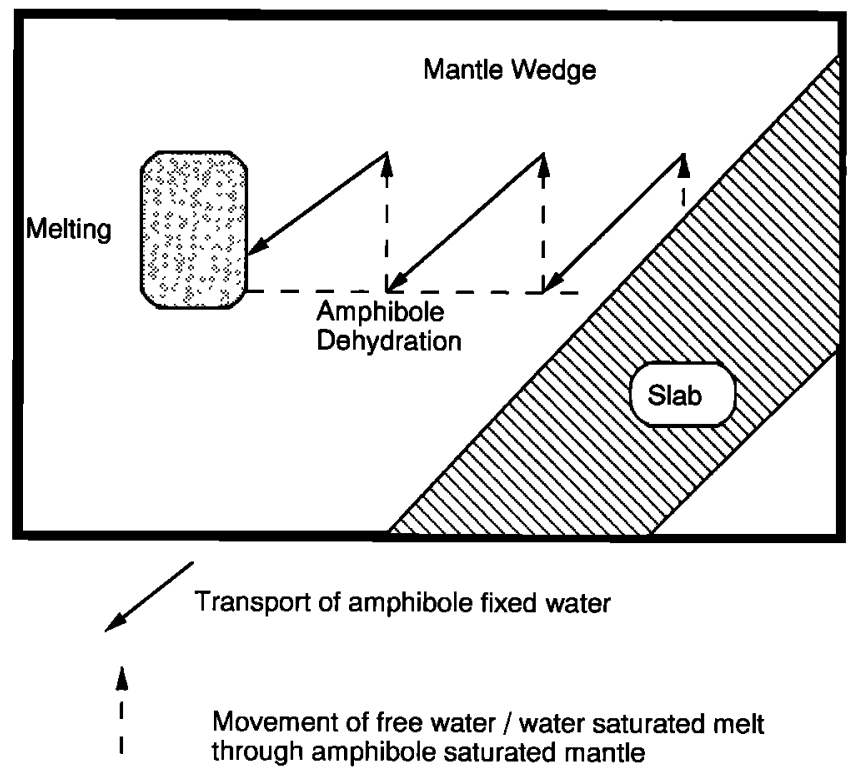

Fig. 8. Cartoon of lateral water transport mechanism. We are schematically following the path of one molecule of water. To reinforce the two primary components of the lateral water transport mechanism, we have simplified the cartoon by assuming that water interconnects immediately on dehydration. This is probably unlikely at the cold temperatures near the slab-wedge interface at pressures of $1.5 \mathrm{GPa}$. 
phases are stable in the peridotite composition. Liu [1989] bases his discussion on the thermal model of Hasebe et al. [1970]. As was discussed earlier, the model of Hasebe et al. [1970] involves excessive heating along the leading edge and no induced flow in the mantle wedge. If Liu had based his conclusion on our model, he would have reached a different conclusion. Unlike Liu [1989] though, we are suggesting that water can exist as a free phase even in regions where hydrous phases are stable since the peridotite composition has only a finite water holding capacity and this can be saturated. We conclude that most water exists as a free phase in the suboceanic mantle adjacent to the slab $\left(\approx 1000^{\circ} \mathrm{C}\right)$ from around $100 \mathrm{~km}$ (the breakdown of amphibole) down to a depth of at least $250 \mathrm{~km}$ (below which the hydrated mineral phase $A$ is stable). Some water could be held in phlogopite and K-amphibole [Sudo and Tatsumi, 1990], which are stable below $100 \mathrm{~km}$. A lack of $K$ in the mantle wedge suggests that very little if any of these phases will be formed, but they do suggest that some water can be returned to the deep mantle. Assuming that the water entering the deep mantle at subduction zones is returning to the surface at MOR, we suggest that estimates of $<\approx 0.1$ wt $\% \mathrm{H}_{2} \mathrm{O}$ in MOR source region limits the amount of water entering the deep mantle at subduction zones.

The presence of $\mathrm{CO}_{2}$ reduces the solubility of solutes in hydrous fluids and increases the temperature of the volatilesaturated solidus. Watson et al. [1990] find that the dihedral angles of $\mathrm{CO}_{2}$-rich fluids with olivine are $>60^{\circ}$. Hence the presence of large volumes of $\mathrm{CO}_{2}$ would limit the mobility of water and reduce its impact in reducing the solidus. As discussed in the subsection on phase diagrams in section 4.1 we argue that much less $\mathrm{CO}_{2}$ enters the mantle wedge compared to $\mathrm{H}_{2} \mathrm{O}$.

Water-induced melting. As was mentioned previously, the largest variation in the thermal models is produced by varying the subduction velocity. Slow subduction velocities (the velocities at which slabs enter the asthenosphere) lead to very cold wedges, suggesting that this induced-flow mechanism would not be successful in explaining the existence of arc volcanism over the wide range of convergence velocities (the relative velocities of the converging plates as defined for points on the plates far away from the subduction zone, and ignoring motion of the subduction zone relative to the asthenosphere, e.g., trench migration). Otsuki [1989] suggests that the normal component of the rate at which the subducting plate is consumed in the asthenosphere is constant at $7.2 \mathrm{~cm} / \mathrm{yr}$ for all plates with Wadati-Benioff zones extending below $400 \mathrm{~km}$. If this is true, then there is no reason why the mantle wedge cannot melt. We do note though that the effect of reducing the normal velocity is potentially observed in the Aleutians; where as we go further west, the velocity becomes more parallel to the strike of the subduction zone, and there is also an associated decrease in magmatism [Marsh, 1982]. So we suggest that heat is brought in by the induced flow and that the melting is allowed and localized by the presence of hydrous phases arising from the migration of water from the slab. Note that for slabs with no extensions below $200 \mathrm{~km}$, Otsuki[1989] suggests velocities of $3.4 \mathrm{~cm} / \mathrm{yr}$. Our numerical model cannot apply to this case, since our slabs penetrate $400 \mathrm{~km}$, but even a velocity of 3.4 $\mathrm{cm} / \mathrm{yr}$ is sufficient to obtain reasonably high temperatures in our numerical model, though these occur further away from the slab. (It is unclear what the flow regime would be in this case, and hence it is difficult to judge whether the lateral transport mechanism for water can transport the water the additional distance.) Otsuki's observation is related to trench migration, "roll-back" of the subduction hinge, back arc spreading and arc compression/extension. It is these velocities that change the widely varying global convergence velocities to this high constant normal subduction velocity. Trench migration relative to the underlying deep mantle has the additional effect of necessitating large-scale global mantle flows that will be supplemented on the local induced corner flow.

In the above section we discussed the transport mechanism for water and showed that water could allow melting to initiate at a depth of $100 \mathrm{~km}$. Water is highly incompatible and enters the melt. If we consider that the system is in steady state, then a constant water flux implies a specific relationship between the water content of the melt and melt velocity (permeability, porosity) at each depth. This is outlined in Appendix C. Davies and Bickle [1991] have extended this greatly and show that the mechanism leads to reasonable estimates of melt temperature, melt flux, melt water contents, major element composition, and average degree of melting. It also suggests that increasing lithosphere thickness can play a significant role by reducing the height of the melting column and lowering the temperature, leading to lower melt fluxes with higher water contents.

More simplistically, this whole region can be considered as one box at one temperature, pressure, and water content, and the degree of melting can be evaluated. This of course is a gross simplification, but gives us a zeroth-order estimation of the amount of melt produced. Consider $T \approx 1175^{\circ} \mathrm{C}$, $P=2 \mathrm{GPa}$, and water content of peridotite $=0.4 \mathrm{wt} \%$; then from Green [1973] we estimate a degree of melting of the order of $10-15 \%$. This would suggest an average water content in the magmas of 3-5 wt \%. The liquidus of basalt with $2-5$ wt $\% \mathrm{H}_{2} \mathrm{O}$ at $2 \mathrm{GPa}$ is in the range $1200^{\circ}-1250^{\circ} \mathrm{C}$ [Wyllie, 1979]; hence given all the uncertainties, including the fact that the basalts at the source in the mantle have a different composition from those used in the experiments, it is possible that the $50^{\circ} \mathrm{C}$ difference is not significant. This water content is higher than that estimated for the magmas that reach the surface ( 2 wt \%). If these figures are valid, one possible explanation is that all the melt at the source does not make it to the upper crust but is stranded in the mantle and lower crust. Water solubility in melts remains quite high until very shallow depths, for example, $10 \mathrm{wt} \%$ at $500 \mathrm{MPa}$ [Green, 1973]; hence it is difficult for the magmas to become water saturated unless they crystallize anhydrous minerals.

Comparison of water and magma production rates. Since we are proposing that arc basalts and andesites derive from a water-fluxed mantle, it is important that there is sufficient water. In Appendix B, estimates of water and lava production are assessed to consider the extent of mantle hydration. Estimates of oceanic crust hydration in the literature range from 2 to $6 \mathrm{wt} \%$. We conservatively estimate that only $10 \%$ of this water is released into the asthenosphere if the water released along the thrust zone can proceed back along the fault zone to the surface and contribute to the large flow of water observed along the decollement [Vrolijk et al., 1988]. This depends critically on the thrust zone not being "tight," and also that there is sufficient permeability in the oceanic crust for the water to reach the fault zone. It is more likely 
that the oceanic crust will undergo metamorphism from the greenschist facies to the amphibolite facies without losing much of its volatiles. Hence, by using $10 \%$ of the estimate of bound water subducted, we are deriving a conservative lower bound estimate on the volume of water subducted. For a $7 \mathrm{~km}$ thick slab descending at $7 \mathrm{~cm} / \mathrm{yr}$, of density $3 \times 10^{3} \mathrm{~kg} \mathrm{~m}^{-3}$, with 2 wt $\% \mathrm{H}_{2} \mathrm{O}$, we estimate that $3 \times 10^{3}$ $\mathrm{kg}$ of water enters the wedge per year per meter along strike of the trench. Results of Ocean Drilling Program (ODP) drilling [Becker et al., 1989] suggest that the literature estimates of 2 wt \% $\mathrm{H}_{2} \mathrm{O}$ might be too large (see Appendix B for discussion of this point). In light of these results, Davies and Bickle [1991] favor the presence of the equivalent of only $1 \mathrm{wt} \%$ water restricted to the upper $2 \mathrm{~km}$ of the oceanic crust, when beyond a depth of $50 \mathrm{~km}$; that is, $5 \times 10^{2} \mathrm{~kg}$ of water entering the wedge. Given the uncertainty, they did consider a broad range about this favored value.

Reymer and Schubert [1984] suggest that igneous additions at island arcs during the Phanerozoic have averaged $1.1 \mathrm{~km}^{3} \mathrm{yr}^{-1}$, while Brown and Musset [1981] have estimated $0.5 \mathrm{~km}^{3} \mathrm{yr}^{-1}$. Given a total arc length of $3.6 \times 10^{4} \mathrm{~km}$ and $\mathrm{a}$ density of $2.8 \times 10^{3} \mathrm{~kg} \mathrm{~m}^{-3}$, we get from $2.5 \times 10^{4}$ to $5 \times 10^{4}$ kg of crust added per year per meter along strike. These lavas are estimated to have from 0.5 to $2 \mathrm{wt} \% \mathrm{H}_{2} \mathrm{O}$ in the mantle; this suggests that the lavas return from $1.25 \times 10^{2}$ to $10^{3} \mathrm{~kg}$ of $\mathrm{H}_{2} \mathrm{O}$ to the crust per year per meter along strike. Hence we can achieve balance, but only if we take the lowest estimates of water input into the wedge and the highest estimates of water return to the surface in lavas. Therefore there is clearly sufficient water to generate the magmas, but there is probably a need to explain the fate of excess water. Ito et al. [1983] similarly estimated that much more water is subducted than is returned by the subduction zone magmas to the crust.

Where does the water go? We speculate that very hydrous lavas are also produced in the subduction zone environment and that they do not reach the crust. This conclusion was also reached earlier in this section, section 4.2. These lavas in large part do not reach the crust because their hydrous nature implies lower initial temperatures and hence higher viscosity [Sykes and Holloway, 1987]. If they crystallize anhydrous minerals, then they will become water saturated and begin to exsolve water. This causes them to become more viscous, and they rapidly come to a standstill. Many of these magmas will be entrapped in the lithospheric part of the mantle. Some of these magmas will pond at the base of the crust and after a sufficient volume has collected could become diapirically unstable and become the parents of tonalitic plutons, and ultimately granites, [ $P_{\text {res- }}$ nall and Bateman, 1973; Bohlen and Mezger, 1989]. These water-rich magmas will be reworked by inputs of more melt and by lithospheric deformation. Hence these might be the mantle precursors to the activity observed in the field by Saleeby [1989]. Some of these water-rich magmas as they solidify in the lower crust will exsolve water that cannot be incorporated in hydrous phases and remains as a free phase. This might be a contributing factor in the explanation for the lower crust seismic reflectivity and for electrical conductivity [Hyndman and Shearer, 1989]; however, the melts and shear zones can give similar signatures, and hence separating the contribution of the different components will be difficult. Magmas with very large water contents probably do not even reach the mechanical lithosphere but are frozen and swept back into the wedge to be melted again [Arculus and Powell, 1986].

As was previously discussed, some water might be returned to the deep mantle by $\mathrm{K}$-amphibole, phlogopite, and DHMS. Some water is also held in nominally anhydrous phases, for example, garnet [Aines and Rossman, 1984], olivine [Miller et al., 1987], and pyroxene. Since MORB and OIB melt under essentially anhydrous conditions (<0.1 wt \% $\mathrm{H}_{2} \mathrm{O}$ ), it is improbable that large amounts of water are held in a deep reservoir that does not allow sampling by ridges and plumes in a vigorously convecting mantle. We suggest that since it is difficult to develop a model that allows water to enter the deep mantle but not return to the near surface, the water estimated in the source regions of MORB is in approximately steady state equilibrium with the water that gets carried deep into the mantle at subduction zones. Ahrens [1989] suggests that the Earth after accretion and the large Moon-forming impact had only a few present-day oceans' worth of water in the mantle. The above scenario of at most 0.1 wt $\% \mathrm{H}_{2} \mathrm{O}$ throughout the mantle would suggest an upper limit of around four present-day oceans worth of water in the mantle, not too dissimilar to the estimate of Ahrens [1989].

As we commented earlier, we discovered that younger, thinner plates are heated up more and have higher temperatures at their interfaces with the wedge. This fact combined with the importance of the dehydration and release of water from the slab might be partly responsible for the explanation of two different observations. Nur and Ben-Auraham [1983] observed that there was no volcanism corresponding to the path of oblique ridge subduction. Abbott and Lyle [1984] suggested that younger plates are hotter and dehydrate faster, with the water leaving vertically immediately. Similarly, we find that younger plates dehydrate at shallower depths, but we are not so confident in predicting the vertical escape of water. If the thrust zone is not "tight", then water may escape up the thrust zone. This would explain the observations of Nur and Ben-Avraham [1983], since little or no water would remain to enter the asthenosphere and lower the solidus. In another observation that might be influenced by the dehydration reactions, Ruff and Kanamori [1987] find that the maximum magnitude of subduction zone thrust earthquakes increases for younger, more rapidly subducting slabs. In addition to the explanation of Ruff and Kanamori [1987] that this could be a function of the slab buoyancy, it could be related to the fact that the magnitude of such earthquakes has been shown to correlate with the "width" $W$ (distance downdip) of the thrust zone. The earthquake magnitude $\left(M_{w}\right)$ is proportional to $W^{3}$ [Byrne et al., 1988]. The release of water could increase the width, since the transition from brittle to ductile behavior moves deeper as the water pressure increases [Dahlen and Suppe, 1987].

Direction of fracture propagation. The transport of magmas from the source region to magma chambers high in the crust must involve crack propagation if for no other reason than to avoid freezing [Turcotte, 1987]. To avoid freezing on their way through the crust, the cracks need to be wide. The aspect ratio of cracks $W / L$ is $\approx \sigma / G$ where $W$ is the width, $L$ the length, $G$ the shear modulus of the melt, and $\sigma$ is the available stress, and since the available stress is much lower than $G$, the cracks must also be long. In the wedge, the temperature difference between melt and country rock is 
not as high as in the cold lithosphere; hence the cracks need not be quite as wide or as long. For long cracks, it is argued that elastic forces are insignificant compared to buoyancy forces in defining their width and propagation speed [Spence and Turcotte, 1985; Turcotte, 1987; Lister, 1990]. These are argued to be controlled by the fluid dynamics of the melt away from the crack tip. By contrast, it has been suggested that elastic forces rather than buoyancy would control the direction of propagation, since propagation is sensitive to the local structure and stresses near the advancing crack tip [Emerman and Marrett, 1990]. This has yet to be rigorously demonstrated, and little work has been done on finite, melt-filled cracks propagating into prestressed material with principal stress axes nonparallel to the direction of gravity. If elastic forces do control the direction of propagation of small cracks, then it will be perpendicular to the direction of the least compressive stress, as shown by Tsunakawa [1983], provided the magma pressure is greater than a critical pressure. For a corner flow regime, this results in the favored direction of crack propagation being part of a logarithmic spiral (though we get only a very short nearly linear segment) towards the corner in the upper part of the wedge but away in the lower part of the wedge. For details, see Appendix D.

We assume three different regimes. The first is inside the overriding mechanical lithosphere, where we assume that the least compressive stress is in the horizontal plane. In this regime the cracks propagate vertically. The second is in the shallower asthenosphere, where we have argued above that the least compressive stress will be aligned so that cracks are focussed towards the corner. The third is in the lower part of the asthenosphere where we will assume that buoyancy will overcome the deviatoric stress field and decide the propagation direction, since this region is hotter with lower viscosity and hence lower deviatoric stress. Hence from the source region to the point where cracks are focussed towards the wedge corner the cracks will be assumed to rise vertically rather than be focussed away from the wedge corner. In the real Earth of course, there will be a more gradual transition between these regimes, but given the high temperature gradients and the exponential temperature dependence of viscosity, the transitions might be narrow.

Height of volcanic front above Wadati-Benioff zone. Does this mechanism of lateral transport of water, followed by stress-controlled fracture propagation, lead to the volcanic front being located $\approx 124 \pm 34 \mathrm{~km}$ [Gill, 1981] above the Wadati-Benioff zone? If the mechanical lithosphere (in which the stress regime is uniform laterally and controlled by the plate forces at a distance) is $\approx 100 \mathrm{~km}$ thick, then, as argued by Marsh [1979] (if one can melt the slab in the "magic corner") and Spiegelman and McKenzie [1987] (if the mantle wedge viscosity is $\geq 10^{21} \mathrm{~Pa}$ s), the melts can be generated or focussed into the corner and rise vertically from this point, automatically satisfying the depth constraint. As was argued in section 3 above, it seems unlikely that the rigid lithosphere is generally this thick beneath the volcanic front; we suggest $\mathbf{4 0} \mathbf{~ k m}$.

We suggest that the top of the source region is at the depth of maximum temperature. This will also be the region of maximum melt production. This would mean that the water does not, as a rule, continue up to the shallow amphibole-buffered solidus but is rapidly removed (in the melt) by cracks to the base of the rigid lithosphere. With

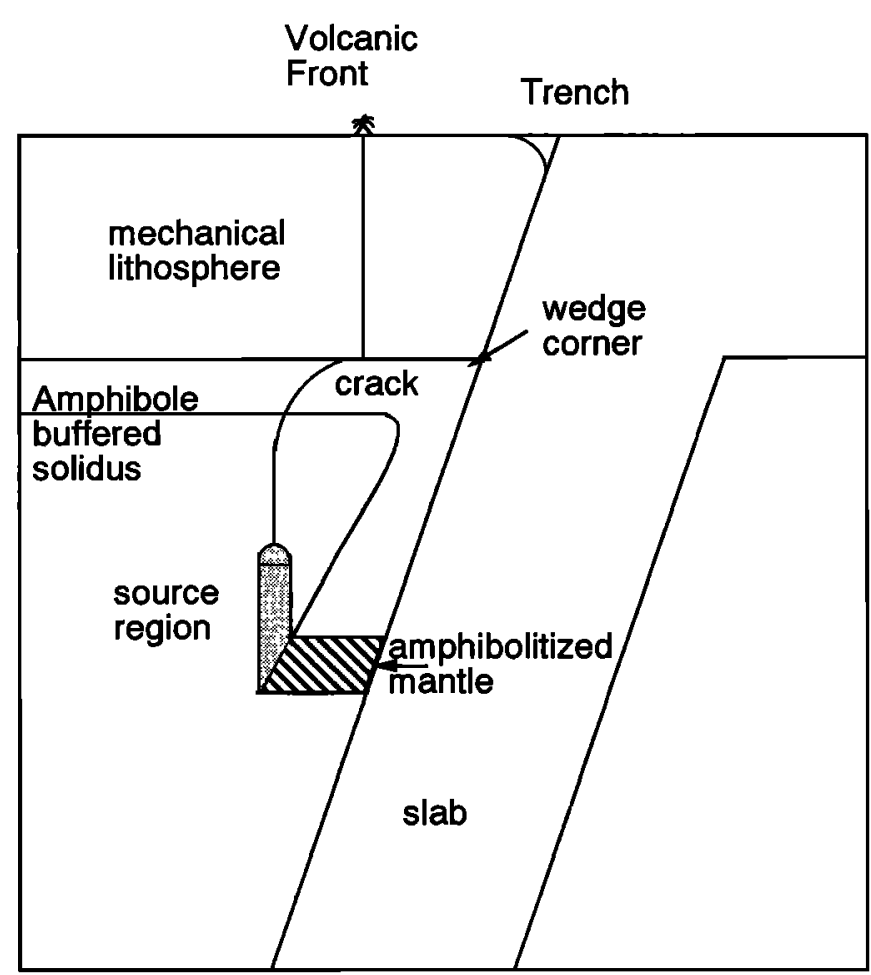

Fig. 9. Cartoon of geometry of subduction zone source region.

no water, the solidus of the wedge shallower than the region of maximum melt production will be at or close to the anhydrous solidus. Water will be present locally where water-rich magmas that cannot make it to the rigid lithosphere freeze.

For the $60^{\circ}$ dipping slab, we suggest that water initiates melting at a depth of around $100 \mathrm{~km}$ depth and $20 \mathrm{~km}$ away from the slab (Figure 9). This water is then carried by melts to higher, hotter regions in the wedge where it induces ever greater degrees of melting. However when the hottest isotherm is reached we suggest that the melting cannot advance vertically, since there is insufficient water in the melt. At the colder temperature the buffered solidus is attained only at a higher water content; equally, the basalt is at its liquidus only at higher water contents. The melts are not able to migrate further and start to stagnate and crystallize. Crystallization allows some of the melt to progress slightly further since it achieves higher water contents, and at very high water contents the melt exsolves a vapor phase that could help in initiating cracks. Hence this freezing region provides a lid to the source region against which the melts accumulate and from which cracks propagate to the base of the mechanical lithosphere. The exact mechanism for initiating cracks in hot rock is unclear, but there is evidence for cracking of hot material [see Nicolas,1986; Sleep 1988].

With a few assumptions we can extend the estimate of the height of the volcanic front above the Wadati-Benioff zone (H) (A to B in figure 10a) from the two slab dips explicitly modelled above to all slab dips. At different dips we find that the thickness of the thermal boundary layer on the surface of the subducting slab is unchanged (provided that the subduction velocity is similar) but the horizontal distance to be traversed to reach the solidus will be proportional to $\operatorname{cosec} \theta_{d}$, where $\theta_{d}$ is the dip angle of the plate. From Figure $10 a$, we estimate the thickness of the thermal boundary layer (E-F) (i.e., perpendicular to the slab; we have shown 


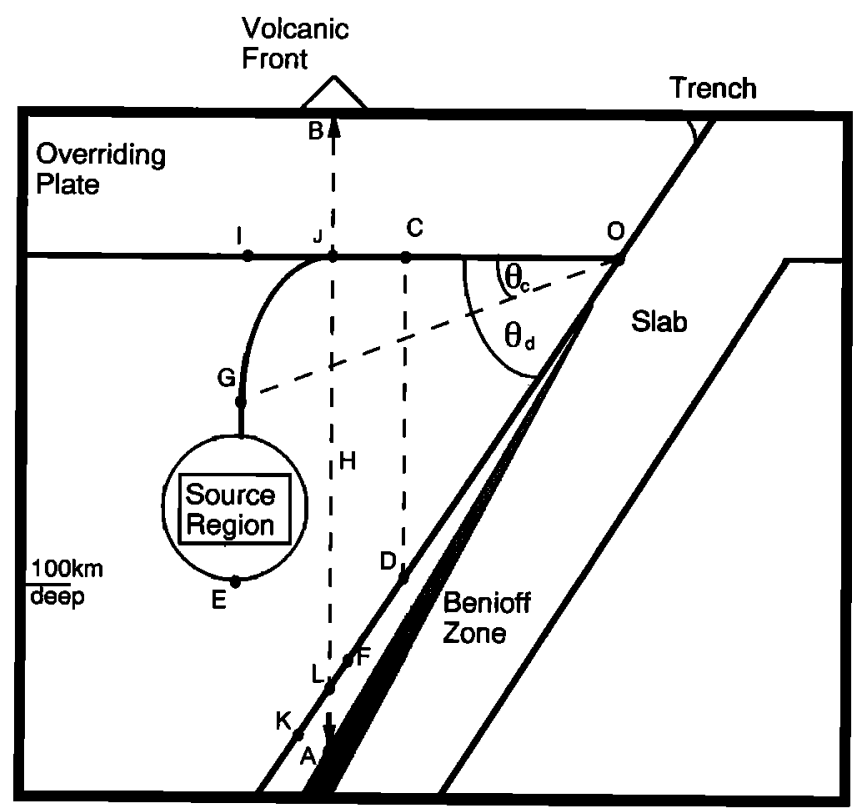

Fig. 10a Diagram to illustrate the derivation of the theoretical prediction of $H$ (the height of the volcanic front above the Benioff zone). See text for explanation.

it to be a strong function of the normal relative subduction velocity) at the depth of $100 \mathrm{~km}(\mathrm{D}-\mathrm{E})$ to be $20 \mathrm{~km}$. Hence the horizontal distance that the source region is away from the wedge corner $R=\mathrm{OC}+\mathrm{DE}=60 \times \cot \theta_{d}+20 \times \operatorname{cosec} \theta_{d}$ $\mathrm{km}$. We assume that the melts rise vertically through the source region and that the cracks propagate out vertically until they reach the point at which small cracks would be focussed towards the wedge corner. The crack intersects the mechanical lithosphere at a distance $R /\left[\exp \left(\theta_{c}\right) \cos \left(\theta_{c}\right)\right]$ $=r_{0}(\mathrm{O}-\mathrm{J})$ from the trench, where $\theta_{c}$ (which is equal to $\left.\left.\tan ^{-1}\left[\left(\sin \theta_{d}-\theta_{d} \cos \theta_{d}\right) / \theta_{d} \sin \theta_{d}\right)\right]\right)$ is the angle at which we change from the regime focussing small cracks away from the wedge corner to focussing them towards the wedge corner (see Appendix D). Therefore $H$, the height of the volcanic front above the Wadati-Benioff Zone, is $\mathrm{BJ}+\mathrm{JL}+\mathrm{LA}=$ $40+\left[5 / \cos \left(\theta_{d}\right)\right)+\left(\tan \left(\theta_{d}\right) r_{0}\right]$; where the first term is the thickness of the mechanical lithosphere, the second term is the distance that the surface of the slab is above the WadatiBenioff Zone assuming that it is $5 \mathrm{~km}$ below the surface of the slab (i.e., perpendicularly to the slab surface $(A-K)$ ), and the third term is the extent in the wedge between the mechanical lithosphere of the upper plate and the subducting plate. The predictions of this model are compared to the data of Gill [1981, table 2.1, p. 15, excluding the Iranian and Eolian points], in Figure 10b. We note that the points exhibit a fair degree of scatter and that the predicted curve is fairly flat and passes through their middle. We suggest that $H$ increases at large dips. This is actually seen in the data (Figure 10b), but it is frequently suggested to be a bias resulting from the larger errors involved in estimating the vertical position due to the steep dips [Tatsumi, 1986].

We suspect that a more detailed understanding of the rheology of the mantle wedge and of crack propagation will alter the details of the above calculation. The calculation should be viewed only as a consistency check for the present model. It is probable that in a dynamic model with nonlinear temperature dependent rheology that the flow will be focussed into a thinner region parallel to the slab. This will not change the interface temperature greatly, since it is parallel, but it might bring the region of extensive melting closer to the slab. In such a scenario it might be possible for the cracks to propagate more or less vertically and satisfy the geometric constraint. Equally, there is uncertainty as to the breakdown conditions of amphibole, with recent work suggesting a more temperature sensitive breakdown [Holloway et al., 1991]. Here we have considered that the melts rise much faster than mantle wedge flow, so that they can be assumed to rise vertically; but if they rose slower, then they

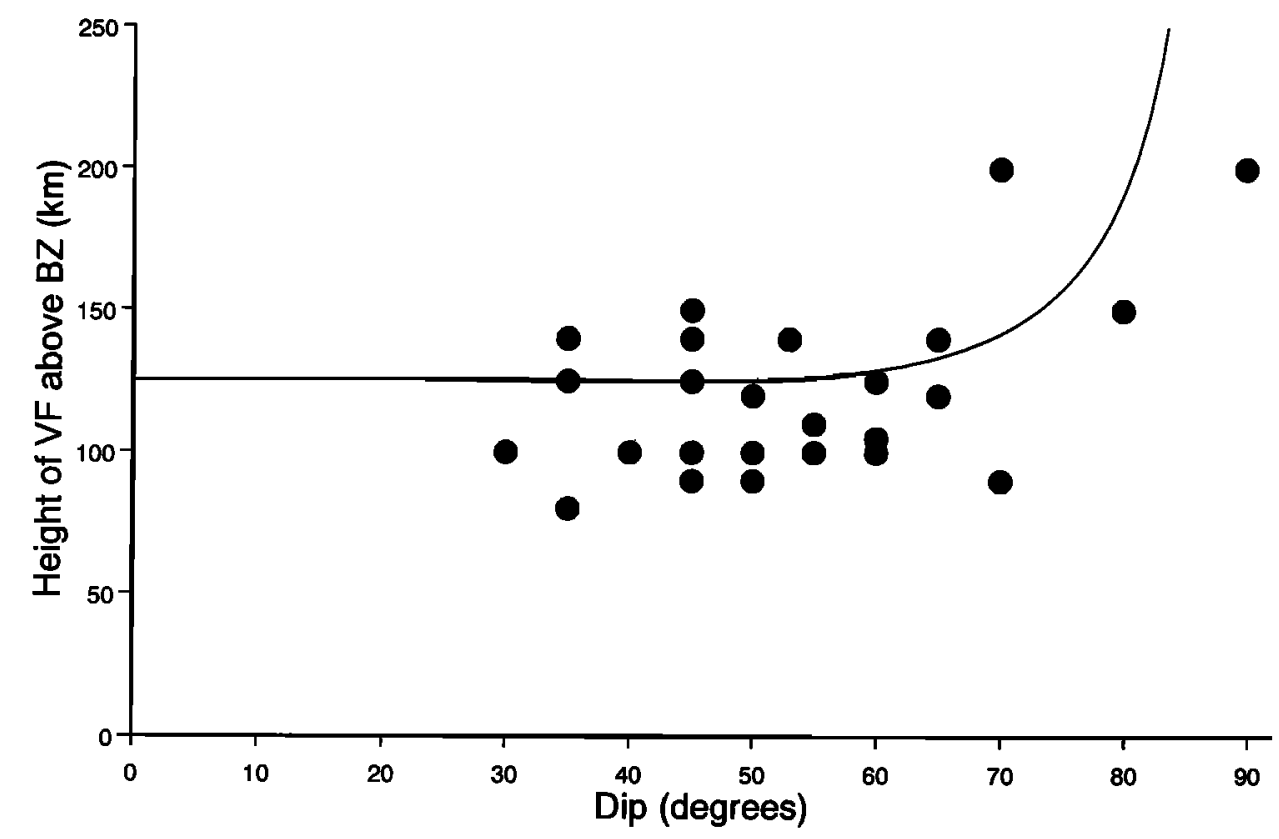

Fig. $10 b$ Comparison of model prediction of the height of the volcanic front above the Benioff zone (solid line) as a function of the slab dip to the data from Gill [1981] (solid circles). 
would be advected by the induced flow, which would focus them towards the wedge corner. Finally, as was mentioned, the initiation of crack propagation and the controls on the direction of crack propagation are poorly understood; hence improvements in understanding here might force us to alter the above assumptions. Though the proposal for the stress control of the direction of fracture propagation is slightly speculative, we believe that the mechanism for the lateral transport of water across the mantle wedge is robust.

The above models predict the generation of melt and residue but have not considered their potential contribution to the dynamics, due to their buoyancy. In section 5 , we shall illustrate how this effect can generate a local flow reversal (i.e., reversing the flow induced in the mantle wedge by the subducting slab) and extend the above discussion.

\section{Flow Reversal in Wedge}

Higher temperatures can be generated in the wedge by invoking a mechanism involving a reversal of the flow in the wedge leading to melting by adiabatic decompression [Ida, 1983a,b, 1987; Nye and Reid, 1986; DeBari et al., 1987; Plank and Langmuir, 1988; Davies and Stevenson, 1988; D. Turcotte, personal communication,1988; Tatsumi et al., 1983]. This mechanism has been investigated for the case of a spatially fixed buoyant body force in two dimensions. We have considered a case where the flow reversal is an internal feature of the system, superposed on a conventional external flow. This may be generated by the buoyancy arising from the extensive hydration of the mantle wedge and the small degrees of melting at the wet and amphibole buffered solidi; melting introduces buoyant residue and melt [Scott and Stevenson, 1989]. This large cylindrical diapir rises vertically until the degree of melting increases beyond the point of interconnection. Then we get segregation of the melt from its source and extraction by small cracks through the mantle wedge [Nicolas, 1986] as described above. A stationary body force might not be an unreasonable description of such a system, since the cracks transport the melt rapidly, and hence their contribution to the buoyancy force is minimal. Therefore the source of buoyancy is solely the source region, which is reasonably fixed since it is related to the water flux and the advection controlled temperature field.

We investigated a suite of numerical examples where the magnitude of the buoyancy force is characterized by the buoyancy number mentioned in section 3 above. Some resulting velocity fields are illustrated in Figures 11-13. We observe that for these models we can reverse the wedge flow some distance above the location of the source of buoyancy but the flow is nearly all downwards immediately below the source of buoyancy. In this model we do not see the "updraft" that Ida [1983a,b, 1987] sees in his buoyancy-driven reversal. In Figure $11 a$ we present the whole model (note that the depth is $700 \mathrm{~km}$ ) and the box represents the magnified regions shown in Figures 11-13. In Figure $11 b$ we present the corner flow with no source of buoyancy. In Figures $11 c$ and $d$ we illustrate the different flow patterns resulting from doubling the buoyancy. In the upper two plots of Figure 12, the total integrated buoyancy is equal. We see that the resultant flow pattern away from the buoyant region is approximately equivalent. This emphasizes that it is the total integrated buoyancy that is important. Total integrated buoyancy is the product of the volume and buoyancy of the buoyant region. Comparing the upper right plot with the one on the lower left, we see that the location of the buoyancy force relative to the plate is important. The buoyancy force is practically the same, but the reversal is more intense for the source of buoyancy placed further away from the slab. It was shown numerically that the critical value of the buoyancy to produce a reversal is such that

Plate Veloclty $=7 \mathrm{~cm} / \mathrm{yr}$

a) Buoyancy Number $=210^{6}$

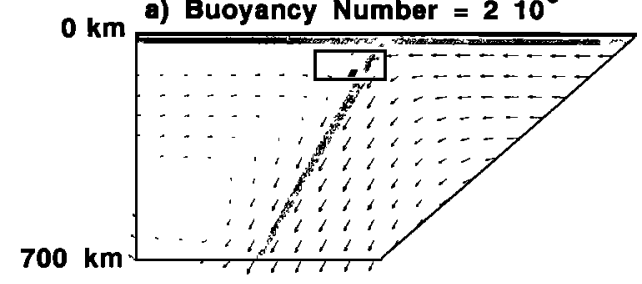

b) Buoyancy Number $=0.0$

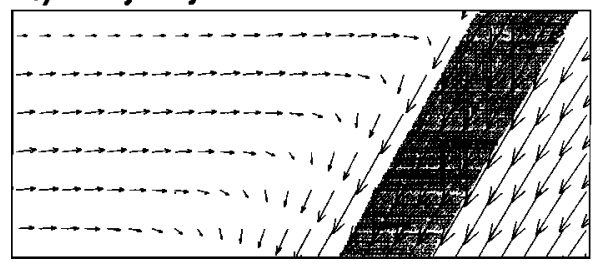

c) Buoyancy Number $=10^{6}$

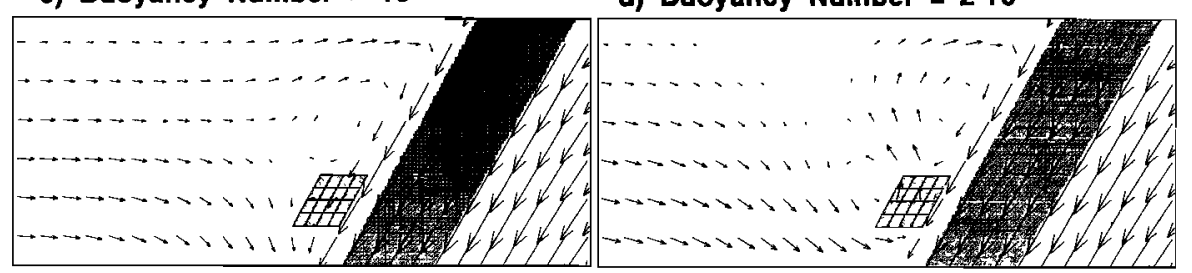

Fig. 11. Four velocity plots. (a) Box $700 \mathrm{~km}$ deep in which the following models were run. The small box represents the position of the magnified views presented in Figures $11 b-d, 12 a-d$, and $13 a$ and $13 c$. The shaded areas represent the mechanical lithospheres, that is, $40 \mathrm{~km}$ thick. $(b)$ Velocity field with no buoyancy force present. The bottom of the box is at a depth of $140 \mathrm{~km}$, while the top of the box is at $60 \mathrm{~km}$. (c) Buoyancy with buoyancy number of $10^{6}$ in the shaded parallelogram. Note that there is only a very weak localized return flow. (d) Same as Figure $11 \mathrm{c}$ but the buoyancy has been doubled. Notice that the flow reversal is more vigorous. 

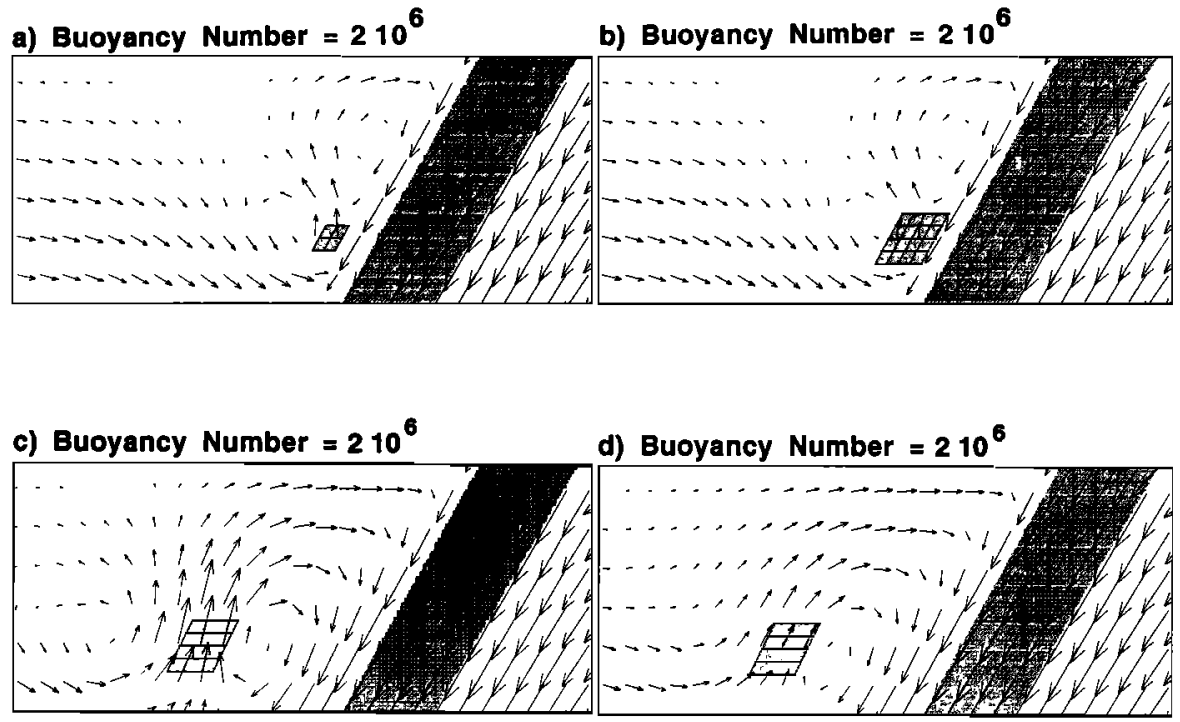

Fig. 12. Same convention as Figure 11. ( $a$ and $b$ ) Same total buoyancy but more concentrated and restricted in Figure 12( $a$ ). The similarity in the resulting flow fields illustrates that the total buoyancy is more important than concentration. (c) Position of the buoyancy force relative to the slab has a large effect. (d) With half the buoyancy a much weaker flow reversal occurs.

the upward velocity of the buoyant region as predicted for a Stokes cylinder is greater than the induced plate flow at that point. The velocity of a buoyant rigid cylinder in an infinite medium is given by Landau and Lifshitz $[1959$, p.68] as

$$
v=\frac{R^{2} \Delta \rho g(0.5-\gamma-\log (v R \rho / 4 \eta))}{4 \eta}
$$

where $\gamma$ is Euler's constant $(\approx 0.577), \eta$ is the viscosity of the matrix through which the cylinder flows, and $R$ is the radius of the cylinder. Note that the velocity is also on the right-hand side, but being in a logarithmic term it leads to a very weak non-linearity only.

In comparing the two lower diagrams in Figure 12 it is seen that the critical buoyancy number for this distribution of buoyancy is slightly $<10^{6}$. If the diapir is a cylinder of radius $10 \mathrm{~km}$ and the buoyancy is $\approx 8 \mathrm{~kg} \mathrm{~m}^{-3}$, then a critical buoyancy number of the order of $10^{6}$ is achieved with a local wedge viscosity of $\leq 7 \times 10^{18} \mathrm{~Pa} \mathrm{~s}$. A buoyancy of $8 \mathrm{~kg}$ $\mathrm{m}^{-3}$ is equivalent to $2 \mathrm{wt} \%$ melt, if $\Delta \rho$ between the matrix $\left(\approx 3.34 \times 10^{3} \mathrm{~kg} \mathrm{~m}^{-3}\right.$ [Klein and Langmuir, 1987]) and melt $\left(\approx 2.95 \times 10^{3} \mathrm{~kg} \mathrm{~m}^{-3}\right.$ [Rigden et al., 1984]) is $\approx 410^{2} \mathrm{~kg} \mathrm{~m}^{-3}$.

Plate Veloclty $=7 \mathrm{~cm} / \mathrm{yr}$ Locally Decoupled Above $200 \mathrm{~km}$

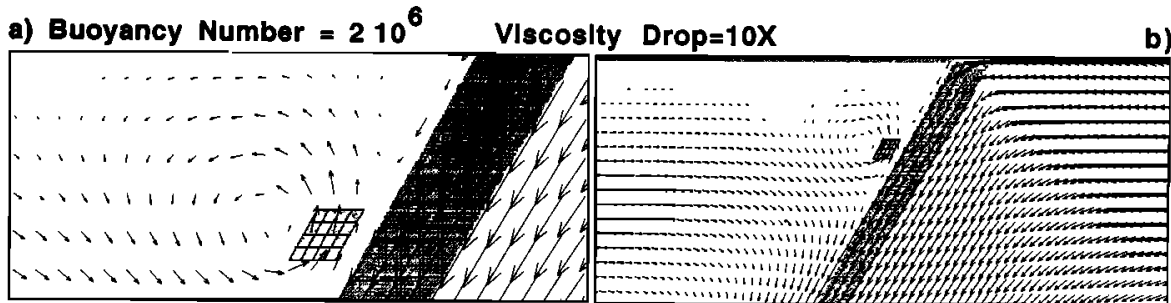

c) Buoyancy Number $=210^{6}$

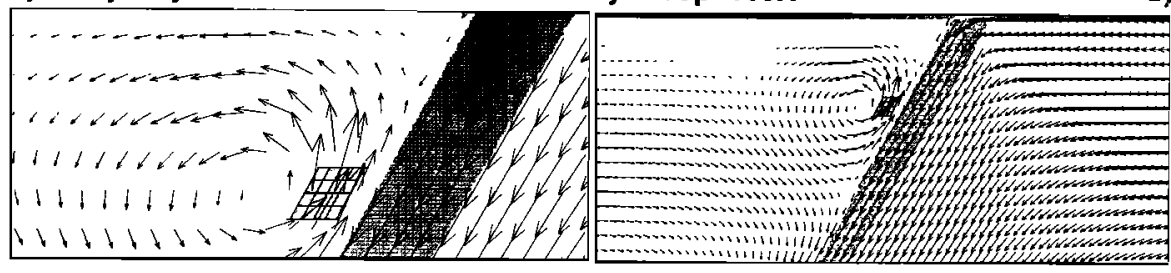

Fig. 13. Same convention as Figure 11. All plots show the flow of the wedge if the plate and wedge are decoupled by a weak zone down to $200 \mathrm{~km}$. In ( $a$ and $b$ ) The weak layer has a viscosity a factor of 10 lower; $(c$ and $d$ ) the weak layer is a factor of 100 less viscous. Figures $13 b$ and $13 d$ are the same as Figures $13 a$ and $13 c$ but show more of the flow field. 
Sato et al. [1988a] obtained a large increase in electrical conductivity when 2 wt $\%$ melt was present. They believe that the large increase in conductivity occurs as a result of interconnection. Estimates of the largest seismic compressional velocity variations between the wedge and the center of the plate suggest anomalies of $\approx 10 \%$ at a depth of 100 km [Anderson, 1988]. If the temperature contrast between the molten region and the center of the plate is $800^{\circ} \mathrm{C}$, and $\partial V_{p} / \partial T=-4.0 \times 10^{-4} \mathrm{~km} \mathrm{~s}^{-1}{ }^{\circ} \mathrm{C}^{-1}$ [Anderson et al., 1968], then it appears that $5-7 \%$ of the contrast has to be explained by the presence of melt. Mavko [1980] suggests that 3 wt $\%$ melt organized in a tube geometry (which is closer than films or spheres to the geometry expected from melt texture experiments) can explain anomalies of this size. Similarly, the laboratory results of Sato et al. [1989] suggest that this size anomaly would correspond to 2 wt \% melt. Sato et al. [1989] reinterpret the study of Suyehiro and Sacks [1979] of seismic velocity below Japan and suggest that very little melt is present, since they found anomalies of only $\approx 6 \%$. This could locally be the case; that is, the degree of melting along strike could vary, but we believe that there might be other explanations. It is possible that the seismic energy from the Benioff zone earthquakes (that are the sources for their work) did not sample the center of the slab, and hence they might not see the full anomaly. Remember, the slab is an anti wave-guide. Further, we argue that the source mantle in a subduction zone is hydrated and infertile rather than consisting of dry fertile peridotites on which the laboratory experiments were conducted. Similarly, estimates of melt content can be made from the attenuation structure of subduction zones. The low $Q$ s are consistent with $2 \mathrm{wt} \%$ melt; however the $Q$ structures of mantle wedges are poorly resolved, and the laboratory extrapolation of ultrasonic results [Sato and Sacks, 1989] depends on the same mechanism of attenuation operating at both of these widely differing frequencies. The choice of $10 \mathrm{~km}$ radius for the source is given by the lateral extent of the intersection of the extent of hydration with the wet solidus isotherm, and the height of the source is given by the height that the maximum temperature occurs above the amphibole dehydration depth. The width, as defined above, implies that all the water is released at the base of the source region and is carried upwards in melt. Alternatively, if the relationship of the flow field to the line AmP (at which amphibolitized mantle melts) in the mantle is slightly changed, the the water could be equally carried across the source region in amphiboles of varying stability, whose breakdown defined the width. Obviously, it is naive to believe that all amphiboles dehydrate under exactly the same conditions; amphiboles are a large family with a lot of compositional variation. We argue that our simplistic view works because the majority of amphiboles formed in the mantle wedge will be of similar composition to a pargasitic amphibole and hence will largely dehydrate at around the same conditions. From Sudo and Tatsumi [1990] we see that potassium-rich amphiboles are very stable, so stable that they would survive the conditions in the wedge and if prevalent in the wedge could take a lot of water deep into the mantle. If potassium-rich pargasitic amphiboles also show greater thermal stability, then this could be the explanation for the increase in the $K$ content of lavas as we increase in distance from the trench [Hatherton and Dickinson, 1969]. Equally, the increased stability of phlogopite could be a partial explanation, but it might also be too stable, as was dis- cussed previously, and take water away from the postulated source region. The width and height dimensions are poorly predicted and to some extent arbitrary, but the equivalent radius cannot be wrong by more than a factor of 2 . This is in contrast to the uncertainty in predicting the appropriate viscosity, which will be discussed next.

The efficiency of the buoyancy force depends critically upon the wedge viscosity. It is the viscosity around the source of buoyancy which is relevant, not the viscosity of the source itself. Since there are clearly large gradations in viscosity, evaluating the viscosity of the appropriate zone is obviously nontrivial. There is a suggestion that peridotite has a viscosity of $\mathrm{O}\left(10^{18}\right) \mathrm{Pa} \mathrm{s}$ at its solidus [ $C \mathrm{raig}$ and McKenzie, 1986]. Hence, given that the viscosity of a partially melted region is at least a factor of 5 less, [Cooper and Kohlstedt, 1984] and possibly as much as 4 orders of magnitude [Borch and Green, 1990] less than the subsolidus mantle, we can expect that peridotite away from the source region has a viscosity greater than $10^{19} \mathrm{~Pa}$. Wdowinski et al. [1989] suggest viscosity of $<10^{20} \mathrm{~Pa} s$ from deformation of Andes and Aegean, while Cathles [1975] estimates $4 \times 10^{19} \mathrm{~Pa}$ s from postglacial rebound for the uppermost asthenosphere. Thatcher et al. [1980] estimate the wedge viscosity to be $10^{19} \mathrm{~Pa}$ s from the relaxation of the deformation following the Sanriku earthquake of 1896. Since we require the relevant viscosity to be $\leq 6 \times 10^{18} \mathrm{~Pa} s$ for appreciable flow reversal, we see that the viscosity is probably too large for appreciable flow reversal. We are possibly close to the critical viscosity, and hence there is probably modulation of the flow field, even if there is not an appreciable flow reversal.

\subsection{Decoupling of Wedge}

From the estimates presented above it is probable that the viscosity of the wedge will be too large to allow flow reversal given the magnitude of buoyancy forces available. Flow reversal could be achieved, however, if the mantle wedge flow is locally decoupled from the slab. This can be achieved by the presence of a weak layer near or at the surface of the slab. In Figure 13 we show the results of buoyancy-induced reversal with a thin layer in the wedge on top of the slab with a viscosity one tenth and one hundreth the viscosity of the rest of the wedge, extending to a depth of $200 \mathrm{~km}$. The lower diagrams with the more decoupled wedge show substantially higher reversal velocities. Possible mechanisms for generating a weak zone include phase changes (dehydration, hydration, basalt-eclogite), presence of water and sediments, and the generation of shear zones. The results of Borch and Green [1990] suggest that the viscosity of twophase media could be appreciably lower than for solid media. Even though friction along a megashear might not produce melting, it can potentially produce low viscosities because a rock's strength drops dramatically before it reaches its melting temperature.

A slab decoupled from the wedge by a layer of viscosity $10^{20} \mathrm{~Pa} \mathrm{~s}$ will be important for modeling the migration of seismicity along the slab [Dmwoska et al., 1988] and from the slab to the continental overriding lithosphere and vice versa [Rydelek and Sacks, 1988]. Unfortunately, the wedge viscosity is but one component in the migration of stresses and cannot be easily disentangled from other components. Moreover, the observations of correlations between the slab 
and overriding lithosphere seismicity are preliminary. As these studies progress they will help constrain the coupling of the slab and wedge.

Evidence for potential decoupling and weakness can be found in the work of Raleigh and Paterson [1965] on the deformation of serpentine and in the work of Heard and Rubey [1966] on the tectonic implications of the dehydration of gypsum. Also the work of Yuen et al. [1978] and Yuen and Schubert [1979] suggests that there could be a shear zone, since even though the increase in temperature is unlikely to be dramatic, there would be a substantial reduction in viscosity. This would be more than sufficient for the wedge to become decoupled.

\subsection{Dimensionality of Problem}

Two comments need to be made regarding the above discussion. First, the dimensionality of the problem needs consideration, and second, other sources of buoyancy may be present. Even though the problem seems two-dimensional with plates extending into a homogeneous mantle, we observe localized volcanic edifices at the surface, while there are also along arc variations in both geophysical and geochemical data.

Hence it is conceivable that the partial melting process has a large degree of along arc variation. If so, and if they are well separated, then it becomes more difficult for individual diapirs to reverse the flow. This can be seen by calculating the radius required for a diapir to move at $5 \mathrm{~cm} / \mathrm{yr}$ through a matrix of viscosity $10^{19} \mathrm{~Pa}$ s. It is $\approx 40 \mathrm{~km}$, that is, a factor of 16 more buoyancy. Hence if the sources of buoyancy are localized along arc, then they will lead to weaker wedge flow reversal and less melting by adiabatic decompression. The variation in degree of melting along arc need not be large or localized to produce the localized edifices. This localization could be more a reflection of the segregation process than the distribution of melting [Stevenson, 1988]. If the variation in the amount of melt present is small and smooth, then the process can be conceived of as being twodimensional rather than three-dimensional, since the diapirs would interact (possibly approaching a cylinder) and add to each others' flow and reduce the drag. The model presented here differs from that of Plank and Langmuir [1988] and Tatsumi et al. [1983] in that it does not allow appreciable diapiric movement. Note also that we distinguish between rigid lithosphere and crust rather than equating them as did Plank and Langmuir [1988].

\subsection{Other Sources of Buoyancy}

Other sources of buoyancy that have not been explicitly addressed here include the intrinsic buoyancy of residue in the solid wedge (which is a function of the degree of melting) and the thermal buoyancy due to the thermal gradients. An indication of the potential contribution of these and other effects to the buoyancy balance is presented in Table 2 .

One can see that there are many potentially significant components contributing to the buoyancy of the subduction zone wedge. The figures in Table 2 suggest that if the hydration of the mantle wedge is as extensive as suggested in our previous discussion, it might be as significant as the combined buoyancy of melt and residue. One needs to consider the rheology of the surrounding matrix in deciding the efficiency of the various sources of buoyancy in generating flow reversal. In the case of hydration the viscosity of the surrounding matrix is expected to be generally much higher than near the partially molten regions and hence will be much less effective in reversing the slab-induced flow.

The residue is less dense than the fertile source rock and hence is a source of buoyancy. Given that it is lighter, it tends to stay near the surface and the source region. Therefore the lateral density gradients that it develops locally cannot be sharp, though the total buoyancy could be large due to its extent. Thermal buoyancy is difficult to incorporate in this kinematic model since the major temperature contrast (slab to wedge) drives the subduction to some unknown extent [Carlson, 1983; Davies, 1984; Richter, 1977; and Spence, 1987]. Therefore the kinematic boundary conditions include the thermal buoyancy to an equally unknown extent. Since there are very large viscosity contrasts, the effects of the unaccounted temperature contrasts would be difficult to model numerically. The buoyancy of the residue will tend to reverse the flow, while the effect of the unaccounted thermal buoyancy is unknown.

\subsection{Need for Time Dependence}

If flow reversal is allowed to develop to a steady state temperature field, then it is actually colder than a model without flow reversal since there will be closed streamlines in the model with flow reversal. This is because the closed streamlines in the wedge corner are continually cooled by the downgoing slab. If on the other hand the mechanism is allowed to be time dependent, hotter temperatures can be periodically produced. To demonstrate the initial increase in temperature followed by the long term decrease due to a permanent constant buoyancy force, we ran the following model. We took the result of a steady state calculation of a model without any sources of buoyancy and used it as the initial conditions for a time dependent calculation using an explicit version of the implicit code. In the model there was no decoupling, and there was a buoyancy number of $10^{8}$ extending over an area of approximately $100 \mathrm{~km}^{2}$. From Figure 14 we see that after $0.5 \mathrm{~m} . \mathrm{y}$. the temperatures are hotter than those due solely to corner flow but by 1.0 m.y.

TABLE 2. Sources of Buoyancy

\begin{tabular}{|c|c|c|}
\hline Source of Buoyancy & $\begin{array}{c}\text { Buoyancy per Meter } \\
\text { Along Slab } \\
\Delta \rho / \rho \%\end{array}$ & Comments \\
\hline Melt & 0.4 & $f=2 \%, \Delta \rho=7 \times 10^{2} \mathrm{~kg} \mathrm{~m}^{-3}$ \\
\hline Water & 0.07 & $w=0.1 \%, \Delta \rho=2.3 \times 10^{3} \mathrm{~kg} \mathrm{~m}^{-3}$ \\
\hline Hydrated mantle & 0.4 & $h=10 \%, \Delta \rho=1.4 \times 10^{2} \mathrm{~kg} \mathrm{~m}^{-3}$ \\
\hline Temperature & 1.0 & $\Delta T=400^{\circ} \mathrm{C}, \alpha=2.5 \times 10^{-5}$ \\
\hline Mantle residue & 0.1 & $F=10 \%, \Delta \rho=4 \times 10^{1} \mathrm{~kg} \mathrm{~m}^{-3}$ \\
\hline
\end{tabular}



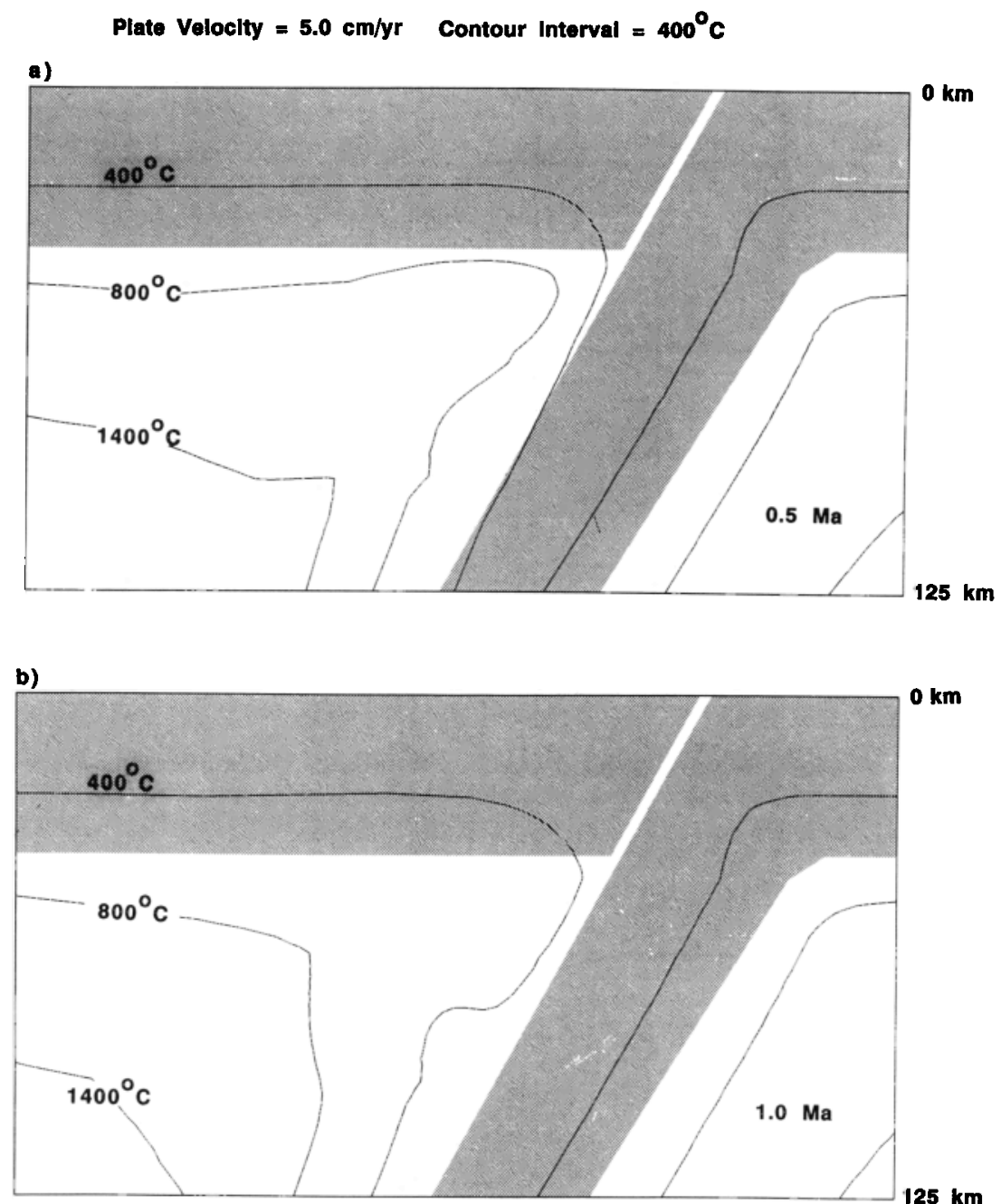

Fig. 14. Temperature contours of models with localized source of buoyancy near to site of the postulated source region. They are at around (a) $0.5 \mathrm{~m} . \mathrm{y}$. and (b) $1.0 \mathrm{~m}$.y. after the introduction of a localized source of buoyancy. The thermal field at 0 m.y. was a steady-state temperature field with no buoyancy force. Notice the temperature increases until 0.5 m.y. but by $1.0 \mathrm{~m} . y$. the mantle wedge is cooler.

the temperatures are colder. Hence this flow would oscillate with a half period of $\approx 0.75 \mathrm{~m}$.y. Since the exact magnitude of the decoupling (even its existence is unproven) and the buoyancy force are uncertain, the period could be shorter or longer. This mechanism will develop a time dependence: since as material goes along a closed streamline in the wedge corner it will cool down each time it comes past newly subducted cold slab and produce less melt, driving force for the reversal is reduced. Equally, the fertility of the matrix decreases in periods of flow reversal since the same material continues to melt by adiabatic decompression during each loop. This also makes it harder for the reversal to persist, but as the reversal dies the infertile matrix is carried away from the source region by the induced flow and replaced with more fertile, hotter material. It is significant that the residue of the melting is lighter than fertile mantle and tends to remain behind in the wedge. As the process continues, one can imagine the wedge becoming more refractory until it produces insufficient melt to give the system the necessary buoyancy to generate flow reversal. This process is illustrated in Figure 15. Therefore we expect that over time, the source region of subduction zone magmas (before meta- somatism by the mobile slab phase) is infertile, depleted, and refractory compared to the MORB source region.

The lifetimes of individual volcanos are very short, up to $10 \mathrm{~m} . y$. , but most are probably much shorter, around $100 \mathrm{kyr}$ to $1 \mathrm{~m} . y$. Ida [1983a] discusses a study in which Tsunakawa [1982] claims to have evidence for alternation in the stress field in the Japan arc at a time scale of a few million years. There is also some estimate on the time scale for variations from the volumes of lavas erupted as a function of time; for example, Kennet et al [1977] estimates a few million years, as do McBirney et al. [1974], from studies of the Cascades in Oregon. Hence there is tentative support for a periodicity in volcanicity of order a few million years.

\section{Petrological and Geochemical IMPLICATIONS OF MODEL.}

The transport of a hydrous phase into the mantle wedge can potentially explain many of the distinctive features of subduction zone volcanism. To assess this explanation completely, we would need to know the composition of the mobile phase from the slab and its partition coefficients with 


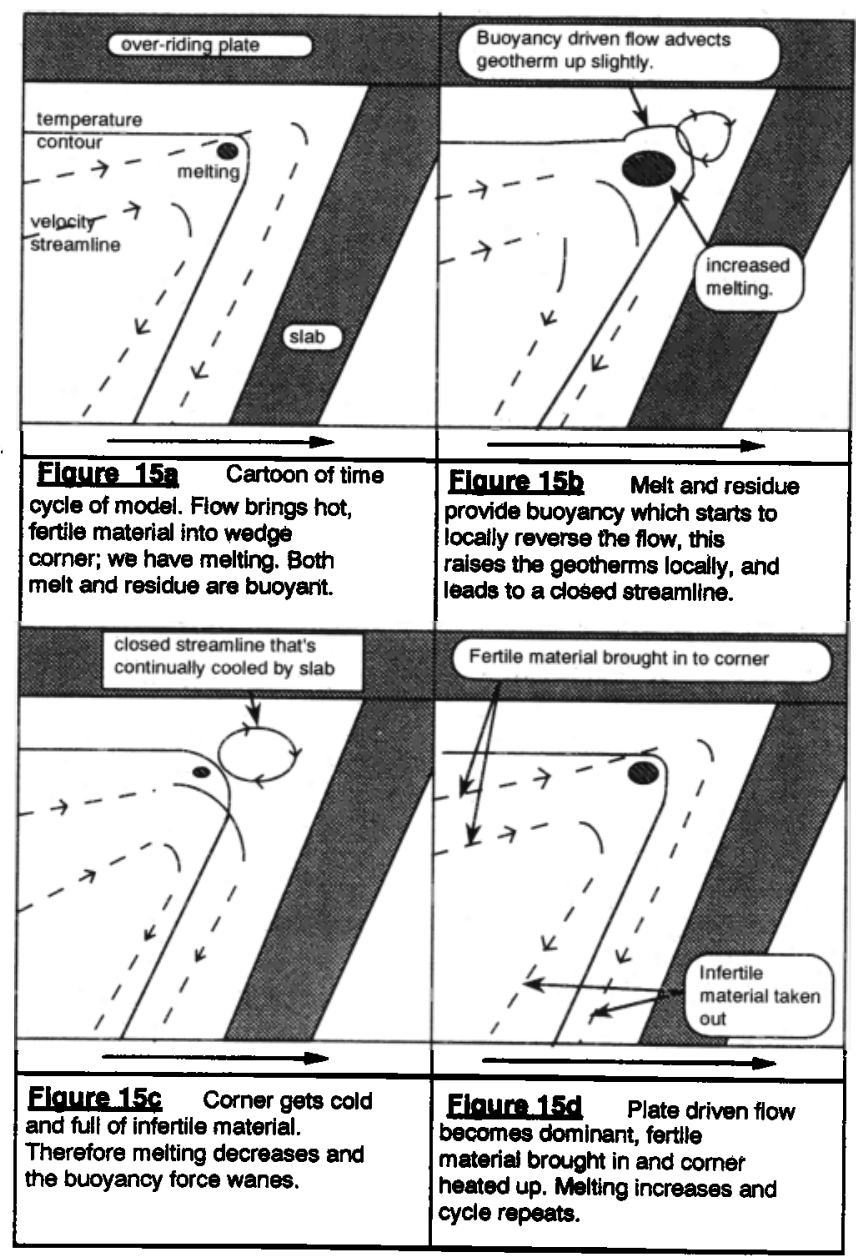

Fig. 15. Process of flow reversal.

amphibole minerals, amongst other things! Very little is known about these, but amphiboles are quite open structures and could accommodate a wide range of trace elements.

The subduction zone magmas have high water contents (2-5 wt \%), hydrous phenocrysts including amphiboles, and high chlorine contents. Isotopically, subduction zone magmas have higher ${ }^{87} \mathrm{Sr} /{ }^{86} \mathrm{Sr}$ than do MORB, while the ${ }^{143} \mathrm{Nd} /{ }^{144} \mathrm{Nd}$ are lower or similar (i.e., subduction zone volcanics are on or above the "mantle array"). Seawater has a high concentration of radiogenic $\mathrm{Sr}$ but negligible Nd. Hence it is probable that the oceanic crust is enriched in radiogenic Sr. The hydrous phase will pass through any sediment subducted and will leach any component with a high solubility out from the sediment. ${ }^{207} \mathrm{~Pb} /{ }^{204} \mathrm{~Pb}$ versus ${ }^{206} \mathrm{~Pb} /{ }^{204} \mathrm{~Pb}$ is high compared to other oceanic basalts. Sediments have large $\mathrm{Pb}$ concentrations and high ${ }^{207} \mathrm{~Pb} /{ }^{204} \mathrm{~Pb}$ compared to ${ }^{200} \mathrm{~Pb} /{ }^{204} \mathrm{~Pb}$. In volcanic rocks, ${ }^{10} \mathrm{Be}$ has been found only in those from subduction zones but it is not ubiquitous. ${ }^{10} \mathrm{Be}$ has a short half-life and is generated solely on the surface of the Earth. Hence its presence has been interpreted as a reflection of the recent input of sediment into the source. Tatsumi and Isoyama [1988] have demonstrated that ${ }^{10} \mathrm{Be}$ is highly soluble in water and could be leached from the sediment by a hydrous fluid dehydrating from the underlying basalt and migrating through the sediment and onto the source region. The ${ }^{3} \mathrm{He} /{ }^{4} \mathrm{He}$ is $\approx 6.5-7.0$, which is slightly lower than MORB $(\approx 8)$. This has generally been interpreted as due to addition of crustal "He from downgoing sediment or from assimilation in passage through crust. Extensive melting of subducted oceanic crust would lead to values closer to 1 , since the crust and sediments are contaminated by atmospheric helium [Staudacher and Allegre, 1988].

Large ion lithophile elements (LILE) are enriched relative to rare earth elements (REE), while high field strength elements (HFSE) are depleted relative to REE. Hence the most diagnostic geochemical characteristic of arc magmas is $\mathrm{Ba} / \mathrm{Th}>450$. The high LILE content can be attributed to fluids/melts from the slab carrying these elements in solution. It has been determined that LILE are much more soluble in water at high pressure than are HFSE [Tatsumi et al., 1986]. Island arc tholeiites are depleted in light (L) REE, while calcalkaline subduction zone volcanics are relatively enriched in LREE and P. Hence the REE pattern of subduction zone volcanics is not unique, but Davidson [1987] pointed out the interesting observation that the REE as a whole are depleted in subduction zone volcanics relative to MORB. This suggests either that the wedge is highly depleted or that subduction zone volcanics reflect a higher degree of melting. Kelemen et al. [1990] suggests that the HFSE depletion and calcalkaline trend can be explained by the interaction of a basaltic melt with harzburgite. In the model that we present there is very little opportunity for basalt to interact with harzburgite other than in the source region. We would expect this mechanism to apply more in MOR than in subduction zone magmas since the source region extends all the way to the surface in MOR. Rather than requiring a mechanism to decrease the HFSE, we instead propose that the mantle is originally depleted and is enriched with elements with high mobilities in the hydrous phase. The generally hydrous nature of the subduction zone volcanics and the high chlorine contents can also be explained by the incorporation of seawater.

The oxygen isotopes are generally $\delta^{18} \mathrm{O} \approx 5.5-9.0 \%$, with the higher values signifying interaction with material that has been recently in the near-surface environment (sediments, continental crust, or oceanic crust). The majority of the values are 5.5-7.0 \% , that is, similar to MORB. Gregory and Taylor [1981] discovered that the upper levels (pillow lavas and diabase dike complex) of the Oman Ophiolite had very high values of $\delta^{18} \mathrm{O}(>5.7 \%$ and up to $12.0 \%$ ) while the lower gabbroic levels had low $\delta^{18} \mathrm{O}$ (< $5.7 \%$ down to $4.0 \%$ \%). Hence, if it is argued that the oceanic crust is extensively melted to provide the subduction zone volcanics source, one would expect the upper layers to be preferentially melted and for the $\delta^{18} \mathrm{O}$ to be $>$ 5.5 \%. Since most values are similar to MORB, this is an argument against the slab being the sole source of the volcanics. For the hydrogen isotopes the $\delta \mathrm{D}$ values are generally between -40 and $-80 \%$, spanning a similar range as OIB and MORB.

Other features of the data have been explained as resulting from the slower ascent to the surface compared to MORB. These include assimilation in passage through crust and increased fractionation. A distinctive feature of subduction zone volcanics is the high normative silica of some of the volcanics with a tendency for volcanics above thicker crust to have higher normative silica, for example, the andesitic volcanism of the Andes. Various suggestions have been ad- 
vanced, including more silicic parent magmas due to unique conditions at the source (possibly hydrous, high $\mathrm{fO}_{2}$, high alkalies), or increased fractional crystallization as a result of slower ascent. Slower ascent could be a result of (1) higher viscosity (due to high normative silica (chicken and egg argument) and/or lower temperature), (2) more compressive stress regime, or (3) a density barrier, for example, a thick crust. Geochemically, calcalkaline subduction zone magmas are characterized by suppression of Fe-enriching processes [Grove and Kinzler, 1986]. The suppression of iron enrichment has been ascribed to be due to the fractionation of magnetite [Gill, 1981] and/or hornblende [Grove and Baker, 1984]. Our model does not address these upper level processes, but the above suggestions are reasonable explanations for the above features. Davies and Bickle [1991] have shown that major element compositions of basalts due to hydrous fluxing of a mantle wedge are consistent with estimates of primary magmas.

In evaluating the water budget, we mentioned the probability that very water-rich lavas do not reach the rigid lithosphere but are swept back into the source region. This might explain the decoupling of incompatible elements from major elements required by the high concentration of incompatible elements in the crust relative to its total volume. The very hydrous melts will be the result of small degrees of melting, allowing fractionation of the more incompatible elements. This effect, however, is magnified since these melts can undergo multiple freezing-melting episodes before they enter melts that exit the convecting wedge to the mechanical lithosphere. O'Nions and McKenzie [1988] suggested that the decoupling could be achieved by extracting very small degrees of melting $(<1 \%)$ at the periphery of the melting zone, that is, extracting the more incompatible elements from a proportionally larger volume of the mantle compared to the major elements. It has been argued that such small degrees of melt can be extracted since the dihedral angle of basalt with olivine is $\left\langle 60^{\circ}\right.$; but the work of Toramaru and $F u j i i[1986]$ and the electrical conductivity observation of Sato et al. [1988a] mentioned above suggests that there could be a threshold and it might be $2 \%$. If it is true, then repeated small degrees of melting $(\approx 2 \%)$ in subduction zones could still accomplish the decoupling, whereas the $<1 \%$ amounts of melt required to produce the same decoupling in one-pass melting could not be extracted from the source region. This might contribute to the fact that subduction zone volcanics have higher levels of incompatible elements relative to MORB. The flow geometry in a subduction zone is conducive to repeat melting of the same material, while the diverging flow at ridges favors single-pass melting.

The flow reversal mechanism can allow for higher temperatures but not as high as required by petrology from analyses of "primitive" lavas (e.g., $1400^{\circ} \mathrm{C}$ Tatsumi et al. [1983] and $\left(1600^{\circ} \mathrm{C}\right.$ Nye and Reid [1986]). These experiments are meaningful only if they have correctly identified the primary magma, and then only if the melting process can be thought of as batch equilibrium melting at a single temperature and pressure. Since the erupted lavas are most probably a reflection of an integration of melts generated at very different temperatures and depths, one suspects that it is probably too simplistic to ascribe the source location to a single pressure and depth. Since we argue that the most hydrous melts from the source region do not reach the surface and are not integrated into the "primitive" lavas of Tatsumi et al. [1983] and Nye and Reid [1986], we suspect the values quoted and would argue for lower values.

A lower bound on the temperature of magmas in the source region can be estimated from the eruption temperatures. The eruption temperatures for andesites range from $1050^{\circ}$ to $1100^{\circ} \mathrm{C}$ [ Gill, 1981]; since the water-saturated solidus of peridotite is $900^{\circ}-1000^{\circ} \mathrm{C}$ from 1 to $3 \mathrm{GPa}$, this is a strong argument for the bulk of the melting to occur at a higher temperature, for example, the amphibole-buffered solidus. Eruption temperatures from MOR seem less variable and are $\approx 1200^{\circ} \mathrm{C}$. Assuming a source depth of $\approx 80$ km for subduction zone magmas and adiabatic temperature gradient for the magmas of $1^{\circ} \mathrm{C} / \mathrm{km}$, we estimate a minimum temperature at the source of $1130^{\circ}-1180^{\circ} \mathrm{C}$. Given the prediction of McKenzie and Bickle [1988] that the MORB source region is at $\approx 1320^{\circ} \mathrm{C}$, they lose $80^{\circ} \mathrm{C}$ in addition to that due to adiabatic decompression (assumed source depth $\approx \mathbf{4 0} \mathrm{km}$ ). Subduction zone magmas have a much harder path to the surface, hence subduction zone magmas might be expected to lose at least this much to their surroundings, that is, a minimum of $1210^{\circ}-1270^{\circ} \mathrm{C}$ for subduction zone magmas at their source. Temperatures predicted for our model are up to $1200^{\circ} \mathrm{C}$ and because of the model's cyclical behavior will show higher temperatures during the later stages and in general should show a wide range of temperatures. Hence there is a suggestion that our model temperatures are too low. One explanation is that our dimensionalization of temperature using the data McKenzie and Bickle [1988] is inappropriate; possibly subduction zones are hotter than MOR. These eruption temperature arguments are only suggestive since we do not know the path history of magmas from their source region to the surface, including how long they reside in magma chambers. The temperatures are buffered by crystallization; subduction zone magmas contain more crystals than MORB, and therefore the eruption temperatures of the lavas might be closer to the source temperature given this buffering effect. The eruption temperature might be related to the magma chamber dynamics and the density of the magma compared to its surroundings [Huppert and Sparks, 1980] and hence might not be related to time of ascent but rather bulk composition and density evolution of magma. In this case, the eruption temperatures give us a lower bound of only $1130^{\circ}-1180^{\circ} \mathrm{C}$ at the source. Our model temperatures satisfy this bound.

There is further evidence for a depleted source from the observation of Davidson [1987] that subduction zone volcanics are depleted in REE relative to normal MORB and the observation of Bonatti and Michael [1989] that the most depleted peridotites come from the subduction zone environments. Also, Falloon and Green [1986] state that their experimental study suggests that the source of island arcs basalts is more refractory.

This mechanism suggests that the first melts produced in a young subduction zone (before there has been sufficient subduction to cool down the wedge) will have very high water contents since the hotter wedge will allow larger volumes of water saturated melts to be generated, increasing their probability of reaching the surface. They would be expected to appear closer to the trench. These might be equated with boninites [Dobson and O'Neil, 1987]. Boninites are very depleted, and the boninite explanation would fit only if the initial wedge was very depleted and got less depleted with time as the slab increasingly metasomatized the wedge and 
material was recycled by the melting-arrested propagating crack-induced flow cycle.

During the reversal stage of the periodic cycle the water will still leave the slab and will be transported laterally by the mechanism described earlier, since it takes up only a small proportion of the wedge, that is, is localized to $\approx 1$ $\mathrm{km}$ width perpendicular to the slab, near the slab, from a depth of around $75-100 \mathrm{~km}$, and $\approx 5-10 \mathrm{~km}$ in depth across the wedge at a depth of $\approx 100 \mathrm{~km}$ (Appendix B). Hence it would not be much affected by a possible decoupling, which extends more than a few kilometers into the wedge. Equally, it would not be greatly affected by a flow reversal, since a flow reversal does not develop much of an "updraft".

\section{Conclusions}

1. Induced corner flow cannot generally generate extensive partial melting of the subducted slab to produce high-Al basalts from an eclogitic source. The exception would be the subduction of very hot oceanic crust, for example, near a ridge.

2. Induced corner flow can laterally transport water large distances by a combination of transport fixed in amphibole carried by the induced flow in the mantle and vertical transport as a free phase.

3. This water will produce melting only if the local relative velocity of wedge and plate is $\approx>6 \pm 2 \mathrm{~cm} / \mathrm{yr}$. If this model is the explanation for the source of subduction zone magmas, then we suggest that the relative normal subduction velocity is relatively high and uniform worldwide, as claimed by Otsuki [1989].

4. Balancing water input into the subduction zone with volume and water content of subduction zone magma entering the crust leads us to suggest the possibility that more magma is generated in the subduction zone but that it is very hydrous and is arrested in the lithospheric mantle. Some of these water-rich frozen melts (amphibolites and serpentinites) might become diapirically unstable and produce tonalitic plutons and, possibly, the granites seen in continental convergent margins. Also, the hydrous melts will exsolve free water towards the end of their crystallization and might be the source of the water suggested in electrical conductivity and seismic reflection work. The most hydrous magmas are the result of small degrees of melting. These will not reach the mechanical lithosphere but will be swept back into the molten zone and undergo further melting. This leads to a process where the same material can be melted repeatedly, allowing large fractionations and a decoupling of incompatible elements from the major elements.

5. If the magmas are transported to the base of the lithosphere by cracks whose direction of propagation is controlled by the least compressive stress, then this leads to a mechanism that helps in focusing the melts at the volcanic front and in explaining its nearly constant height of $120 \mathrm{~km}$ above the Wadati-Benioft zone for most dips and its increase at very high dips.

6. The width of the source region will be partly controlled by the stability range of the dominant amphiboles. The increasing $K$ content of lavas as we go further away from the trench could be explained by the possible higher thermal stability of amphiboles richer in potassium. The concentration of potassium is low in oceanic mantle, and what is present is probably incorporated in various amounts in pargasitic amphiboles as a minor component. K-amphiboles studied by Sudo and Tatsumi [1990] were very stable and would be stable throughout our source region; as a consequence we speculate that pargasitic amphiboles richer in potassium have higher thermal stability. Since the limited potassium is probably accommodated in pargasitic amphiboles, we do not expect $\mathrm{K}$-amphiboles or phlogopite to be common hydrous minerals in the subduction zone environment. Phlogopite could also explain the K-h correlation, in that it is a potassium-rich hydrous phase with greater thermal stability than pargasite; current work, however, suggests that it is also too stable.

7. Due to the buoyancy of the depleted residue it is suggested that the fertility of the subduction zone volcanics source is variable and that the time-averaged source is more depleted and refractory than the source of MORB since the residue is not cleared out of the source region as efficiently as in the MOR environment. Hence for the major elements we prefer a depleted source. The metasomatism due to the mobile phase from the slab will complicate the issue for minor incompatible elements. If boninites are very waterrich melts from a hot, initiating subduction zone, then their very depleted nature suggests that the pre-subduction zone wedge is very depleted.

8. Modulation in subduction zone volcanics could be explained by a weak time dependent flow reversal due to intrinsic buoyancy generated by the melting process. Local decoupling of the wedge from the slab induced flow would increase the efficiency of the flow reversal. This mechanism suggests periods of the order of a few million years.

\section{APPENDIX A: ANalytic APPRoximations}

\section{A.1. Interface Temperature, at the "Magic Corner"}

Marsh [1979] speculates that the slab will melt in the "magic corner" where the slab-induced flow impinges nearly perpendicularly on the slab. This idea was expanded upon by Brophy and Marsh [1986] to explain the lack of a garnet signature in the REE. Here we shall look at a simple model which illustrates a point also made in the numerical models: the impinging induced flow cannot increase the interface temperature dramatically since it cannot advect heat right to the slab surface. The flow turns the corner and in so doing reduces its normal velocity to the slab to zero at the slab surface. Hence it must conduct heat across this nearly stagnant layer. This is very inefficient, and therefore the interface stays cool.

Specifically, we can solve the problem of a flow perpendicular to a slab decreasing from a velocity of $v_{0}$ a distance $l_{2}$ away from the slab, linearly to zero at the slab surface. If the temperature is $T_{1}$ at a distance $l_{2}$ away from the slab, and it is $T_{0}$ a distance $l_{1}$ into the slab, which is assumed to be stationary, then one finds that the interface temperature $T_{1 / 2}$ is

$$
\frac{T_{1}-T_{1 / 2}}{T_{1 / 2}-T_{0}}=\frac{\beta}{l_{1}} \sqrt{\frac{\pi}{4}} \Phi(\beta)
$$

which is nearly constant, being largely insensitive to the details within reasonable bounds, given the behavior of $\Phi(x)$, the probability integral; that is, erf $(x)$; where $\beta=$ $\sqrt{v_{o} l_{2} / 2 \kappa}$. For instance, if $\kappa=10^{-6} \mathrm{~m}^{-2} \mathrm{~s}^{-1}, v_{0}=7 \mathrm{~cm} / \mathrm{yr}$, and $l_{2}=l_{1}=5 \mathrm{~km}$, then $T_{1 / 2}=0.333$ if $T_{1}=1.0$ and $T_{0}$ $=0.0$. In fact, only a slab which is already very hot (in the 
sense that the cold from the face of the slab has migrated very deeply (relative to the distance that the flow reduces its velocity over) into the slab) will have an appreciably high interface temperature. This has been found to be the case in our numerical investigations, not all of which are presented. The slab wedge interface can attain high temperatures only if the slab is very young, for example $<10 \mathrm{~m}$.y., that is, very close to the ridge. If for instance we increased the temperature of the flow before it impinges on the slab for example, from of the order of $800^{\circ}$ to $1200^{\circ} \mathrm{C}$, (for instance because the return flow is forced to come from deeper because of a neighboring deep continental root, or that the rigid lithosphere is very thick (up to $100 \mathrm{~km}$ )) the interface temperature increases by only around $200^{\circ} \mathrm{C}$; this is insufficient to generate $20 \mathrm{wt} \%$ melting as required by Brophy and Marsh [1986] to generate a density reversal to allow an instability.

\section{A.2. Analytic Model}

The second aspect concerns the temperature of the wedge and slab once the flow has turned parallel to the slab. Here we present a simplified analytic model which retains the primary behavior. It shows the interface being sheltered by a thermal boundary layer in the wedge. As a result, the slab remains cold while the wedge away from the slab remains hot. This model was suggested to us by A. Howard and B. Hager (personal communication, 1987).

The model considers a slab descending at a constant velocity into a wedge at an angle $\theta$. The $x$ axis is perpendicular to the slab (positive out into the wedge), and the $y$ axis is parallel and down the slab, with the origin at the point that the slab enters the asthenosphere. The flow is assumed to be parallel to the slab and equal to the velocity of the slab everywhere. We solve for the steady state thermal regime. The temperature gradient is assumed to be much stronger perpendicular to the slab than parallel to it. Hence we are left to solve

$$
v_{y} \partial T / \partial y=\kappa \partial^{2} T / \partial x^{2}
$$

We solve the above equation for the following initial condition at $y=0$, where the temperature in the mantle away from the slab is constant at $T_{1}$, while there is a linear gradient across the slab from $T=T_{o}$ for the slab upper surface to $T=T_{1}$ at its lower surface. We find that the solution is

$$
\begin{aligned}
T= & T_{1}+\left(T_{1}-T_{0}\right) \times \\
& \left(\frac{(x-h)}{2 h}[\operatorname{erf}(b)-\operatorname{erf}(a)]-\alpha \frac{\left[e^{-b^{2}}-e^{-a^{2}}\right]}{h \sqrt{\pi}}\right)
\end{aligned}
$$

where $\mathbf{a}=-x / \alpha ; \mathbf{b}=-(x-h) / \alpha ; \alpha=\sqrt{(4 \kappa y) / v} ; T_{1}$, is the mantle temperature, $T_{o}$ is the temperature of the upper surface of the plate as it enters the asthenosphere, and $h$ is the width of the slab. This model also illustrates the low interface temperature at $x=0$.

\section{Appendix B: Transport of Water}

Assume that water leaves the slab between the depths of 50 and $80 \mathrm{~km}$ and enters the mantle, where it immediately reacts with the peridotite to form amphibole. This amphibole remains stable until it reaches a depth of $\approx 100$ $\mathbf{k m}$, where it breaks down and releases its water. It is argued that before the water can be incorporated into high- pressure phases, the water forms an interconnected network with the hydrated peridotite [Watson et al., 1990]. Therefore it rises vertically by porous flow through the mantle. When it first enters the region of amphibole stability, it will traverse through mantle that is already saturated with amphibole (which has been formed higher up and has been carried down by the induced flow). After rising sufficiently, it will reach mantle that is free of amphibole; here it reacts rapidly to form amphibole which is carried back down by the slab-induced mantle flow, further away from the slab. The net result of the two processes is a horizontal flux of water away from the slab.

We can evaluate the extent of the region that is hydrated and also the volume of free water by equating fluxes. The extent of the hydrated region and the volume of free water will vary as we move further away from the slab. We are interested in these values as the water reaches the potential source region, so we shall use the values applicable to this region. The variables with the largest uncertainty are the horizontal component of the mantle wedge velocity and the viscosity of the water.

The horizontal flux carried by the mantle wedge in the amphibole and the free water must equal the flux out of the plate that enters the mantle wedge. Hence

$$
\rho_{m} V_{x}\left(w+\left(f \rho_{w} / \rho_{m}\right)\right) h=F
$$

where $V_{x}$ is the horizontal component of the mantle wedge flow, $w$ is the weight fraction of $\mathrm{H}_{2} \mathrm{O}$ in the hydrated peridotite, $f$ is the volume fraction of $\mathrm{H}_{2} \mathrm{O}$ as a free supercritical vapor, $\rho_{w}$ is the density of the free supercritical vapor, $\rho_{m}$ is the density of the mantle wedge, $h$ is the depth over which the mantle is hydrated and free water is present, and $F$ is the mass flux of water per unit length along arc through the system. Also the vertical flux in the mantle wedge of water is zero; that is, the amount of water carried down in the fixed amphibole must equal the volume of water carried up by the free mobile phase. Using the expression for the relationship between porosity and permeability, from McKenzie [1984], $k \propto f^{3}$, we get

$$
\rho_{m} V_{z}\left(w+\left(f \rho_{w} / \rho_{m}\right)\right)=\rho_{w} a^{2} f^{3} \Delta \rho g / b \eta
$$

where $V_{z}$ is the vertical component of the mantle wedge flow, $a$ is the grain size of the mantle wedge, $b$ is a constant in the permeability law $k=a^{2} f^{3} / b, \approx 10^{3}, \Delta \rho$ is $\rho_{m}-\rho_{w}, g$ is the acceleration due to gravity, and $\eta$ is the viscosity of the supercritical fluid. If we know the composition of the mantle, then we can predict the value of $w$. Green [1972] and $B V T P$ [1981] estimated that $w$ might be $0.4 \mathrm{wt} \%$. Assuming that the metasomatising fluid has 20 wt $\% \mathrm{Na}$, and that $\mathrm{Na}$ is the limiting component for the formation of amphibole, then we can expect at most a $20 \mathrm{wt} \%$ increase in the amount of amphibole formed. Hence $0.5 \mathrm{wt} \%$ seems a reasonable upper bound for the amount of bound water in a wedge peridotite saturated with amphibole. Estimates of the viscosity of water at these temperatures and pressures [e.g., Spera, 1987; Ahrens and Schubert, 1975] range from $7 \times 10^{-3}$ to $2 \times 10^{-4} \mathrm{~Pa}$ s. If the typical grain size is $10^{-3} \mathrm{~m}$, then we can solve for $f$ given that $\Delta \rho \approx 2.5 \times 10^{3} \mathrm{~kg} \mathrm{~m}^{-3}$, and $V_{z} \approx 10^{-9} \mathrm{~m} \mathrm{~s}^{-1}(3 \mathrm{~cm} / \mathrm{yr})$. We can ignore the free water component being carried down by the solid matrix to first order.

$$
f=\left(V_{z} b \eta w \rho_{m} / \rho_{w} a^{2} \Delta \rho g\right)^{1 / 3} \approx 2 \times 10^{-3}
$$


If we had used the permeability/porosity relationship of von Bargen and $W a f f[1986], k=a^{2} f^{2} / 10^{4}$, then we would find $f \approx 2 \times 10^{-4}$. Cheadle [1989], using a sophisticated technique, suggests that the permeability becomes proportional to the second power of porosity at low porosity and suggests even higher permeability at lower porosity; hence our preferred water porosity is $<2 \times 10^{4}$.

Since we now have an estimate of $w, f$, and $V_{x}$, given an estimate of $F$ we can estimate the extent of this mantle hydration, $h$, from equation (1). Various people have estimated the water content of the slab to be up to $3 \mathrm{wt} \%$; many workers consider 2 wt \% a generous maximum [Peacock, 1987; Ito et al., 1983], while others estimate $\approx 3 \mathrm{wt} \%$ [Anderson et al., 1976; Fyfe et al., 1978]. If $10 \%$ of this water is released between 50 and $80 \mathrm{~km}$ and enters the wedge, then $0.2 \%$ is a reasonable estimate of the water content of the slab which enters the wedge, that is, most water is released at shallower depths returning to the surface. In considering that only $10 \%$ of the water escapes into the mantle we are assuming that most of the volatiles can escape during the metamorphism from greenschist to amphibolite facies and that the thrust zone is not a "tight" fault in the oil industry parlance; both are unlikely, and hence this is potentially a large underestimate. Then the flux $F$ is

$$
F=w_{s} V_{z} h_{c} \rho_{p}
$$

where $w_{s}$ is the weight fraction $\mathrm{H}_{2} \mathrm{O}$ in the slab that enters the wedge $\left(2 \times 10^{-3}\right) ; V_{z}$ is the vertical velocity of the slab, $2 \times 10^{-9} \mathrm{~m} \mathrm{~s}^{-1}(6 \mathrm{~cm} / \mathrm{yr}) \times \sin (\mathrm{dip}) ; h_{c}$ is the width of dehydrating oceanic crust, $6 \mathrm{~km} / \mathrm{sin}(\mathrm{dip})$; and $\rho_{p}$ is the density of the subducting plate, $3.5 \times 10^{3} \mathrm{~kg} \mathrm{~m}^{-3}$. We have assumed that most of the dehydration is caused by the amphibole going beyond its high-pressure stability limit, so as the slab descends $6 \mathrm{~km}$ in $0.1 \mathrm{~m} . \mathrm{y}$, $6 \mathrm{~km}$ of slab is dehydrated in this time. Therefore we estimate $F \approx 8 \times 10^{-5} \mathrm{~kg} \mathrm{~s}^{-1}$ per meter along arc.

If we believe that most of the water subducted returns to the surface in subduction zone volcanics (SZV), then we can also estimate $F$. An estimate of lava production is found in the corner flow section, $2.5 \times 10^{4}$ to $5 \times 10^{4} \mathrm{~kg} \mathrm{yr}^{-1}$ per meter along the arc. It is estimated that SZV close to the surface have $0.5-4 \mathrm{wt} \% \mathrm{H}_{2} \mathrm{O}$; this leads to an estimate of $F \approx 0.8 \times 10^{-5}$ to $5 \times 10^{-5} \mathrm{~kg} \mathrm{~s}^{-1}$ per meter along arc. If these melts were the result of $10 \%$ degree of melting and $50 \%$ crystallization, then we evaluate that the initial melts at the source had $0.025-0.2 \mathrm{wt} \% \mathrm{H}_{2} \mathrm{O}$ in their source. Note that more water is estimated to enter the wedge than to leave by melts. This could be due to the fact that part of the water is returned to the deep mantle to be sampled at MOR and in OIB after a long residence time. It could also reflect the uncertainty in estimating the amount of melt produced and also the amount of water that the slab injects into the mantle wedge. Becker et al. [1989] report on the drilling of hole $504 \mathrm{~B}$, the deepest penetration into oceanic crust by an ODP hole. The initial results from the neutron activation tool indicates that alteration products are concentrated along contacts between relatively unaltered units of fairly homogeneous geochemistry. The deepest $200 \mathrm{~m}$ of sheeted dikes (1.5 km below the surface) were only slightly altered, while the alteration increased as one approached the surface; this has been suggested to be controlled by permeability. These results seem to suggest that the alteration is nowhere pervasive and that it is largely restricted to the upper $1.2 \mathrm{~km}$. This suggests the presence of possibly less $\mathrm{H}_{2} \mathrm{O}$ than has been previously estimated; the hole did not reach the gabbros, but if the permeability argument is correct, then they should be altered even less than the sheeted dikes. Most probably excess water is released by the slab relative to the water returned by the lavas to the crust but it might not be as large as previously estimated [Ito et al., 1983]. As discussed in the text, a probable resolution of the discrepancy involves the incorporation of water in melts that do not make it to the crust but are ponded at the Moho; they enter the crust later as tonalites and release some water as a free phase. From the two estimates of water flux we suggest that the thickness of the hydrated mantle $(h)$ will be 0.25 to $5 \mathrm{~km}$, if the horizontal component of the velocity is $1 \mathrm{~cm} / \mathrm{yr}$. Hence, given either estimate, we get reasonable degrees of hydration.

Equally, this flux needs to be carried down from the slab to the $100 \mathrm{~km}$ dehydration depth of mantle in the wedge. If we assume that the water is produced uniformly throughout the depth from 50 to $80 \mathrm{~km}$, then we estimate the thickness of hydrated layer parallel to the slab to be $0.05-1 \mathrm{~km}$ at a depth of $80 \mathrm{~km}$, where the amphibole dehydration is complete.

\section{Appendix C: Water-INduced Melting}

We shall briefly comment on constraints arising from water-induced melting. First, we shall assume that water is completely incompatible and that all of it enters the melt. It is widely believed to have a distribution coefficient similar to potassium, that is, $\approx 0.01$. Hence the only way water can go through the supersolidus region is in the melt phase. If the system is in steady state, then this requires that the water flux $(F)$ is constant through the system. Hence the product of the solubility of water in the melt and the melt flux has to equal the water flux.

$$
F=s a^{2} f^{3} \Delta \rho g / b \eta
$$

where $s$ is the solubility of water in the melt, $a$ is the mean grain size, $f$ is the melt porosity, $\Delta \rho$ is the density difference between the melt and the matrix, $b$ is a parameter in the permeability expression (see Appendix B), and $\eta$ is the melt's viscosity. We can solve for the melt porosity cubed times the solubility. Equally, we can limit the melt porosity since we need a certain amount of melt to generate the arc. Hence

$$
F_{m}=a^{2} f^{3} \Delta \rho g / b \eta
$$

where $F_{m}$ is the melt flux.

Using the estimates of $1 \mathrm{~km}^{3} \mathrm{yr}^{-1}$ for the whole island arc system $(40,000 \mathrm{~km}$ long), we get an estimate of $f \approx$ 0.08 if $\eta \approx 10 \mathrm{~Pa}$ s. The final melt that leaves the system most probably can have no more than 2 wt $\% \mathrm{H}_{2} \mathrm{O}$, but of course lower down in the melting column the amount of melt might be lower and the amount of water higher. The very first melts will be saturated because we have an infinitesimal $\left(<2 \times 10^{-2} \%\right)$ amount of free water. At this depth the solubility of water in melt is $\approx 25 \mathrm{wt} \%$. Hence we will produce $<8 \times 10^{-4}$ melt! The next change in melting will occur on the breakdown of a pargasitic amphibole. This will be at $\approx 1150^{\circ} \mathrm{C}$, where we will get appreciable melting, and the melts will be undersaturated in water. 


\section{Appendix D: Direction of Propagation of Fractures}

The direction of propagation of small fractures is controlled by the least compressive stress. The direction of opening of the crack will be in this direction, while the direction of propagation will always maintain this relationship. Conditions where this might not be true are mentioned in the text, and we caution that a full solution to the problem of a finite crack propagating in a nonuniformly stressed medium has not been solved. Corner flow can be solved exactly [see Batchelor, 1967]. The following derivation of the corner flow equations follows closely the derivation due to McKenzie [1969]. If $\Psi$ is the stream function and hence the velocity is given by

$$
\left(v_{r}, v_{\theta}\right)=\left(\frac{1}{r} \frac{\partial \Psi}{\partial \theta},-\frac{\partial \Psi}{\partial r}\right)
$$

then for the corner flow problem illustrated in Figure D1 with an acute angle $\theta_{d}$ we find that

$$
\Psi=\frac{r v\left[\left(\theta_{d}-\theta\right) \sin \left(\theta_{d}\right) \sin (\theta)-\theta_{d} \theta \sin \left(\theta_{d}-\theta\right)\right]}{\theta_{d}^{2}-\sin ^{2} \theta_{d}}
$$

Similarly, given the velocity field and a constant viscosity rheology, one can solve for the stress regime. The deviatoric stresses in general are as follows

$$
\begin{gathered}
\sigma_{r r}=2 \eta \frac{\partial v_{r}}{\partial r} \\
\sigma_{\theta \theta}=2 \eta\left(\frac{1}{r} \frac{\partial v_{\theta}}{\partial \theta}+\frac{v_{r}}{r}\right) \\
\sigma_{r \theta}=\eta\left(\frac{1}{r} \frac{\partial v_{r}}{\partial \theta}+\frac{\partial v_{\theta}}{\partial r}-\frac{v_{\theta}}{r}\right)
\end{gathered}
$$

For this specific case we find

$$
\sigma_{r r}=\sigma_{\theta \theta}=0
$$

and

$$
\sigma_{\theta r}=\frac{2 v \eta\left[\theta_{d} \cos \left(\theta_{d}-\theta\right)-\sin \theta_{d} \cos \theta\right]}{r\left(\theta_{d}^{2}-\sin ^{2} \theta_{d}\right)}
$$

Hence we can see that the greatest shear stresses are parallel to $r=$ const. and the $\theta=$ const. directions. In general, the axes which maximize the shear stress lie at $45^{\circ}$ to the

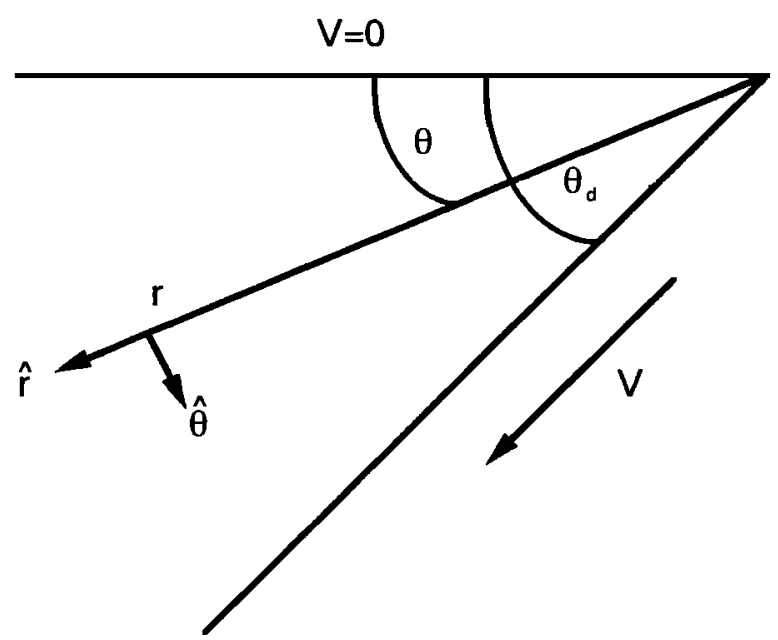

Fig. D1. Coordinate system of Appendix D.

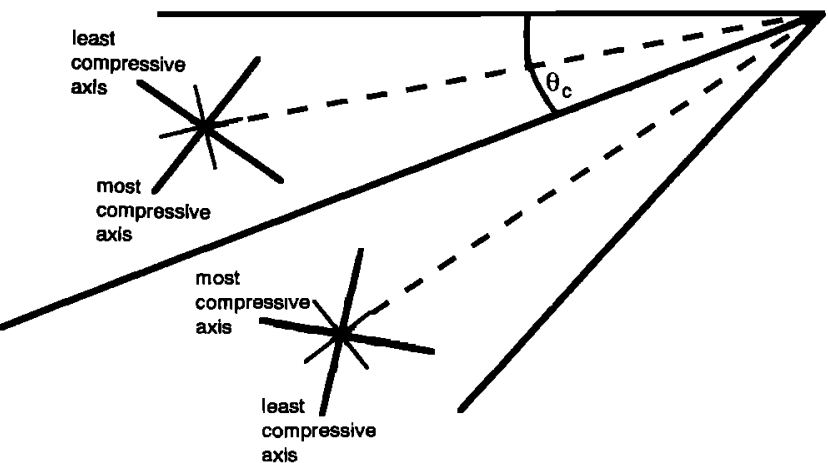

Fig. D2. Relationship of principal axes in corner flow regime.

principal axes. In the coordinates of the principal axes the shear stress is zero. We are using the fluid mechanics sign convention that compression is positive while dilatation is negative. Hence the axis of maximum and minimum compression are at $45^{\circ}$ to the radial direction, with the direction of least compressive stress oriented as shown in Figure D2. When the shear stress is negative, then the minimum compressive axis is between the two coordinate axes, while when the shear stress is positive, the maximum compressive axis is between the $\theta$ and radial axes. The line bounding the two regimes lies at an angle $\theta_{c}$ given by

$$
\theta_{c}=\tan ^{-1}\left(\frac{\sin \theta_{d}-\theta_{d} \cos \theta_{d}}{\theta_{d} \sin \theta_{d}}\right)
$$

What is the direction of propagation of the fracture? We know the instantaneous direction of the dike at each position, and hence we can define the equation of the path. From Figure D3 we find that

$$
d r / d \theta=r
$$

hence

$$
r=r_{o} \exp [\theta]
$$

in the region above the bounding curve and

$$
-d r / d \theta=r
$$

hence

$$
r=r^{\prime} \exp \left[\theta_{d}-\theta\right]
$$

below the bounding angle. The integration constants $r_{0}$ and $r^{\prime}$ are the point of intersection of the curve with the

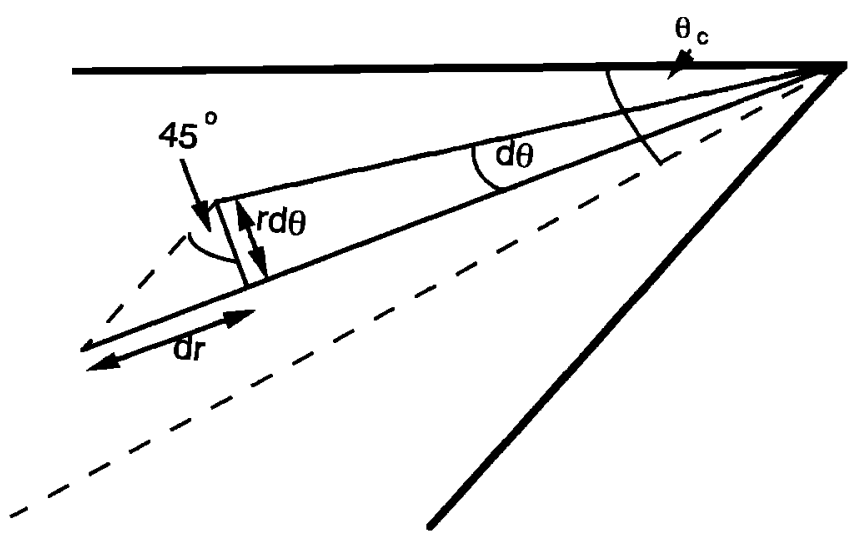

Fig. D3. Derivation of equation (D5). 
upper stationary plate and the point of intersection with the subducting slab, respectively. In either regime the curves are parts of a logarithmic spiral. The cracks near the subducting plate would be directed away from the wedge corner, but once $\theta<\theta_{c}$, the cracks would be focussed towards the wedge corner.

Notice that the magnitude of the deviatoric stress is proportional to the viscosity. The viscosity is low in the region from the source to the point at which there is a transition in the direction of propagation, due to the high temperatures. Hence we suggest that in this region the deviatoric stress will be unlikely to control the direction of propagation but will be dominated by the buoyancy force and hence that the cracks will propagate vertically. The choice of the upper limit of the buoyancy dominated regime as the point at which there is a transition in the stress orientation is slightly arbitrary but is motivated by the fact that the stress decreases to zero at this point even though temperature is decreasing.

Acknowledgments. This work was supported by grant EAR8618511 and EAR8816268 from the National Science Foundation. We would like to thank $P$. Wyllie for his detailed discussion of this paper. Also, D. Bell and T. Duffy provided valuable comments and advice that have improved this paper. H.D. would like to thank Don Anderson, Brad Hager, and Bruce Marsh for encouraging him to investigate this problem, and John Holloway and Don Turcotte for introducing him to interesting twists. We should also like to thank M. Baker, M. Fahnestock, O. Gudmundsson, P. Ihinger, S. King, M. Rutter, J. Saleeby, D. Scott, and R. Stead for their help and stimulating discussions. We would also like to thank R. O'Connell, J. Saleeby, H. Sato, Y. Tatsumi, B. Watson, and S. Wdowinski for providing preprints of their papers, and J. Davidson, P. Wyllie, G. Miller, J. Lister, and A. Nur for reprints of their papers. The most important issues in the paper were brought more clearly to the fore as the result of the comments of two anonymous reviewers and the associate editor B. Marsh. H.D. would also like to acknowledge the support of an NERC postdoctoral fellowship and the use of the facilities of ITG and DES at the University of Cambridge during the final stages of writing up. Sam Lal and Hilary Alberti helped with completing the figures. Contribution 5061, Division of Geological and Planetary Sciences, California Institute of Technology, Pasadena.

\section{REFERENCES}

Abbott, D. H., and M. Lyle, Age of oceanic plates and volatile recycling, Geophys. Res. Lett., 11, 951-954, 1984.

Ahrens, T. J., and G. Schubert, Gabbro-eclogite reaction rate and its geophysical significance, Rev. Geophys. Space Phys., $13,1975$.

Ahrens, T. J., Water storage in the mantle, Nature, 342, 122-123, 1989.

Aines, R. D., and G. R. Rossman, The water content of mantle garnets, Geology, 12, 720-723, 1984.

Andrews, D. J., and N. H. Sleep, Numerical modelling of tectonic flow behind island arcs, Geophys. J. R. Astron. Soc., 38, 237$251,1974$.

Anderson, D. L., Temperature and pressure derivatives of elastic constants with application to the mantle, J. Geophys. Res., 99, 4688-4700, 1988.

Anderson, D. L., and J. Bass, Transition region of the Earth's upper mantle, Nature, $320,321-328,1986$.

Anderson, O. L., E. Schreiber, R. C. Liebermann, and N. Soga, Some elastic constant data on minerals relevant to geophysics, Rev. Geophys., 6, 491-498, 1968.

Anderson, R. N., S. Uyeda, and A. Miyashiro, Geophysical and geochemical constraints at converging plate boundaries - Part 1. Dehydration in the downgoing slab, Geophys. J. R. Astron. Soc., 44, 333-357, 1976.

Anderson, R. N., S. E. Delong, and W. M. Schwarz, Thermal model for subduction with dehydration in the downgoing slab, J. Geol, , 86, 731-739, 1978.
Anderson, R. N., S. E. Delong, and W. M. Schwarz, Dehydration, asthenospheric convection and seismicity in subduction zones, J. Geol., 88, 445-451, 1980.

Arculus, R. J., and R. Powell, Source component mixing in the regions of arc magma generation, J. Geophys. Res., 91, 5913$5926,1986$.

Astiz, L., T. Lay, and H. Kanamori, Large intermediate-depth earthquakes and the subduction process, Phys. Earth Planet. Inter., 53, 80-166, 1988.

Ballhaus, C., R. F. Berry, and D. H. Green, Oxygen fugacity controls in the Earth's upper mantle, Nature, 948, 437-440, 1990.

Barnes, I., W. C. Evans, and C. D. White, The role of $\mathrm{CO}_{2}$ in volcanism, App. Geoch em., 3, 281-285, 1988.

Basaltic Volcanism Study Project (BVTP), Basaltic Volcanism on the Terrestrial Planets, 1286 pp., Pergamon, New York, 1981.

Batchelor, G. K., An Introduction to Fluid Dynamics, 615 pp., Cambridge University Press, New York, 1967.

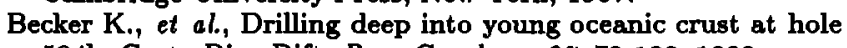
504b, Costa Rica Rift, Rev. Geophys., 27, 79-102, 1989.

Bercovici, D., G. Schubert, and G. A. Glatzmaier, Threedimensional spherical models of convection in the Earth's mantle, Scien ce, 244, 950-955, 1989.

Bergman, E. A., and S. C. Solomon, Source mechanisms of earthquakes near mid-ocean ridges from body waveform inversion: Implications for the early evolution of oceanic lithosphere, $J$. Geophys. Res., 89, 11415-11441, 1984.

Beukel, J. van den, and R. Wortel, Temperatures and shear stresses in the upper part of a subduction zone, Geophys. Res. Lett., 14, 1057-1060, 1987.

Blundy, J. D., J. P. Brodholt, and B. J. Wood, Carbon-fluid equilibria and the oxidation state of the upper mantle, Nature, $349,321-324,1991$.

Bodine, J. H., M. S. Steckler, and A. B. Watts, Observation of flexure and the rheology of the oceanic lithosphere, J. Geophys. Res., 86, 3695-3707, 1981 .

Bodri, L., and B. Bodri, Numerical investigation of tectonic flow in island-arc areas, Tectonophysics, $50,163-175,1978$.

Bohlen, S. R., and K. Mezger, Origin of granulite terranes and the formation of the lowermost continental crust, Science, 244 , 326-329, 1989.

Bonatti, E., and P. J. Michael, Mantle peridotites from continental rifts to ocean basins to subduction zones, Earth Planet. Sci. Lett., 91, 297-311, 1989.

Borch, R. S., and H. W. Green II, Experimental investigation of the rheology and structure of partially molten lherzolite deformed under upper mantle pressures and temperatures, Eos Trans. $A G U, 71,629,1990$.

Brophy, J. G., Basalt convection and plagioclase retention: A model for the generation of high-alumina arc basalt, J. Geol., 97, 319-329, 1989.

Brophy, J. G., and B. D. Marsh, On the origin of high-alumina arc basalts and the mechanics of melt extraction, J. Petrol., 27, 763-789, 1986.

Brown, G. C., and A. E., Mussett, The In accessible Earth, Allen and Unwin, Wincester, Mass., 1981.

Byrne, D. E., D. M. Davis, and L. R. Sykes, Mechanics of the shallow region of subduction zones and the loci and maximum size of thrust earthquakes, Tectonics, 7, 833-857, 1987.

Carlson, R. L., Plate motions, boundary forces, and horizontal temperature gradients: implications for the driving mechanism, Tecton ophysics, 99, 149-164, 1983.

Carslaw, H. S., and J. C. Jaeger, Conduction of Heat in Solids, 2nd ed., 510 pp., Oxford University Press, New York, 1959.

Cathles, L. M., The Viscosity of the Earth's Mantle, 386 pp., Princeton University Press, Princeton, N. J., 1975.

Cheadle, M. J., Properties of texturally equilibrated two-phase aggregates, Ph.D. thesis, Univ. of Cambridge, Cambridge, United Kingdom, 1989.

Cooper, R. F., and D. L. Kohlstedt, Solution-precipitation enhanced diffusional creep of partially molten olivine-basalt aggregates during hot-pressing, Tectonophysics, 107, 207-233, 1984.

Cooper, R. F., and D. L. Kohlstedt, Interfacial energies in the olivine-basalt system, in, High Pressure Research in Geo- 
physics, edited by S. Akimoto and M. H. Manghnani, $A d v$. Earth Planet. Sci., 12, 217-228, 1982.

Cooper, R. F., and D. L. Kohlstedt, Rheology and structure of olivine-basalt partial melts, J. Geophys. Res., 91, 9315-9323, 1986.

Craig, C. H., and D. P., McKenzie The existence of a thin low-viscosity layer beneath the lithosphere, Earth Plan et. Sci. Lett., 78, 420-426, 1986.

Crawford, A. J., T. J. Falloon, and S. Eggins, The origin of highalumina basalts, Contrib. Min eral. Petrol., 97, 417-430, 1987.

Crough, S. T., Thermal origin of mid-plate hot-spot swells, Geophys. J. R. Astron. Soc., 55, 451-469, 1978.

Crough, S. T., and G. A. Thompson, Numerical and approximate solutions for lithospheric thickening and thinning, Earth Planet. Sci. Lett., 91, 397-402, 1976.

Dahlen, F. A., and J. Suppe, Mechanics, growth, and erosion of mountain belts, Spec. Pap. Geol. Soc. Am., 218, 1987.

Davidson, J. P., Crustal contamination versus subduction zone enrichment: Examples from the Lesser Antilles and implications for mantle source compositions of island arc volcanic rocks, Geochim. Cosmochim. Acta, 51, 2185-2198, 1987.

Davies, G. F., Geophysical and isotopic constraints on mantle convection: An interim synthesis, J. Geophys. Res., 89, 6017$6040,1984$.

Davies, J. H., and D. J. Stevenson, Flow direction of mantle in subduction zone wedge, Eos Trans. $A G U, 69,1439,1988$.

Davies, J. H., and M. J. Bickle, A physical model for the volume and composition of melt produced by hydrous fluxing above subduction zones, Philos. Trans. R. Soc. London, Ser. A, 355, 355-364, 1991.

DeBari, S. M., and R. G. Coleman, Examination of the deep levels of an island arc: Evidence from the Tonsina ultramafic-mafic assemblage, Tonsina, Alaska, J. Geophys. Res., 94, 4373-4391, 1989.

DeBari, S. M., S. M. Kay, and R. W. Kay, Temperatures from tectonized ultramafic xenoliths, J. Geol, 95, 329-341, 1987.

Delany, J. M., and H. C. Helgeson, Calculation of the thermodynamic consequences of dehydration in subducting oceanic crust to $100 \mathrm{~kb}$ and $780^{\circ} \mathrm{C}, A m$. J. Sci. $278,638-686,1978$.

Detrick, R. S., and S. T. Crough, Island subsidence, hot spots and lithospheric thinning, J. Geophys. Res., 83, 1236-1244, 1978.

Dmwoska R., J. R. Rice, L. C. Lovison, and D. Josell, Stress transfer and seismic phenomena in coupled subduction zones during the earthquake cycle, $J$. Geophys. Res., 93, 7869-7884, 1988.

Dobson, P. F., and J. R. O'Neil, Stable isotope compositions and water contents of boninite series volcanic rocks from Chichijima, Bonin Islands, Japan, Earth Planet. Sci. Lett., 82, 75-86, 1987.

Eggler, D. H., Solubility of major and trace elements in mantle metasomatic fluids: experimental constraints, in Mantle Metasomatism, edited by M. A. Menzies and C. J. Hawkesworth, pp. 21-41, Academic, San Diego, Calif., 1987.

Emerman, S. H., and R. Marrett, Why dikes?, Geology 18, 231$233,1990$.

Falloon, T. J., and D. H. Green, Glass inclusions in magnesian olivine phenocrysts from Tonga: evidence for highly refractory parental magmas in the Tongan Arc, Earth Planet. Sci. Lett., 81, 95-103, 1986.

Falloon, T. J., D. H. Green, C. J. Hatton, and K. L. Harris, Anhydrous partial melting of a fertile and depleted peridotite from 2 to $30 \mathrm{kbar}$ and application to basalt peterogenesis, $J$. Petrol., 29, 1257-1282, 1988.

Falloon, T. J., and D. H. Green, Solidus of carbonated, fertile peridotite under fluid-saturated conditions, Geology, 18, 195$199,1990$.

Fujisawa, H., N. Fujii, H. Mizutami, H. Kanamori, and S. Akimoto, Thermal diffugivity of $\mathrm{Mg}_{2} \mathrm{SiO}_{4}, \mathrm{Fe}_{2} \mathrm{SiO}_{4}$, and $\mathrm{NaCl}$ at high pressure and temperature, J. Geophys. Res., 79, 4727$4733,1968$.

Furlong, K. P., D. S. Chapman, and P. W. Alfeld, Thermal modeling of the geometry of subduction with implications for the tectonics of the overriding plate, J. Geophys. Res., 87, 1786$1802,1982$.

Furukana, Y., and S. Uyeda, Thermal state under the Tohoko arc with consideration of crustal heat generation, Tecton ophysics, 164, 175-187, 1989.
Fyfe, W. S., N. J. Price, and A. B. Thompson, Fluids in the Earth's crust, Elsevier, Amsterdam, 1978.

Gill, J., Orogenic andesites and plate tectonics, Springer-Verlag, New York, 1981.

Green, D. H., Magmatic activity as the major process in the chemical evolution of the Earth's crust and mantle, Tecton ophysics, 19, 47-71, 1972.

Green, D. H., Contrasted melting relations in a pyrolite upper mantle under mid-oceanic ridge, stable crust and island arc environments, Tecton ophysics, 17, 285-297, 1973.

Green, D. H., Experimental testing of "equilibrium" partial melting of peridotite under water-saturated, high pressure conditions, Can. Mineral., 14, 255-268, 1976.

Gregory, R. T., and H. Taylor, An oxygen isotope profile in a section of cretaceous oceanic crust, Samail ophiolite, Oman: Evidence for $\delta^{18} \mathrm{O}$ buffering of the oceans by deep ( $>5 \mathrm{~km}$ ) seawater-hydrothermal circulation at mid-ocean ridges, $J$. Geophys. Res., 86, 2737-2755, 1981.

Griggs, D. T., The sinking lithosphere and the focal mechanism of deep earthquakes. The Nature of the Solid Earth, edited by E. C. Robertson, J. F. Hays, and L. Knopoff, pp. 361-384, McGraw-Hill, New York, 1972.

Grove, T. L., and M. B. Baker, Phase equilibrium controls on the tholeiitic versus calc-alkaline differentiation trends, $J$. Geophys. Res., 89, 3253-3274, 1984.

Grove, T. L., and R. J. Kinzler, Petrogenesis of andesites, Annu. Rev. Earth Planet. Sci., 14, 417-454, 1986.

Gurnis, M., A reassessment of the heat transport by variable viscosity convection with plates and lids, Geophys. Res. Lett., $16,179-182,1989$.

Haggerty, S. E., and L. A. Tompkins, Redox state of Earth's upper mantle from kimberlitic ilmenites, Nature, 303, 295-300, 1983.

Hasebe, K., N. Fujii, and S. Uyeda, Thermal processes under Island Arcs, Tectonophysics, 10, 335-355, 1970.

Hatherton, T., and W. R. Dickinson, The relationship between andesitic volcanism and seismicity in Indonesia, the Lesser Antilles, and other island arcs, J. Geophys. Res., 74, 5301-5310, 1969.

Heard, H., and W. Rubey, Tectonic implications of gypsum dehydration, Geol. Soc. Am. Bull., 77, 741-760, 1966.

Hildreth, W., and S. Moorbath, Crustal contribution to arc magmatism in the Andes of central Chile, Contrib. Mineral. Petrol., 98, 455-489, 1988.

Holloway, J. R., B. J. Wood, and S. Esperanca, Amphibole breakdown in peridotite at high pressure, Terra Abstr., s, 420, 1991.

Honda, S., Thermal structure beneath Tohoku, Northeast Japan A case study for understanding the detailed thermal structure of the subduction zone, Tect on ophysics, 112, 69-102, 1985.

Houseman, G., The dependence of convection planform on mode of heating, Nature, 392, 346-349, 1988.

Hsui, A. T., B. D. Marsh, and M. N. Toksöz, On the melting of the subducted oceanic crust: Effects of subduction induced mantle flow, Tect on ophysics, 99, 207-220, 1983.

Huang, W.-L., P. J. Wyllie, and C. E. Nehru, Subsolidus and liquidus phase relationships in the system $\mathrm{CaO}-\mathrm{SiO}_{2}-\mathrm{CO}_{2}$ to 30 kbar with geological applications, $A m$. Min eral., 65, 285$301,1980$.

Hughes, T. J. R., W. K. Liu, and A. Brooks, Finite element analysis of incompressible viscous flows by the penalty function formulation, J. Comput. Phys., 30, 1-60, 1979.

Huppert, H. E., and R. S. J. Sparks, Restrictions on the compositions of mid-ocean ridge basalts : a fluid dynamical investigation, Nature, 286, 46-48, 1980.

Hyndman, R. D., and P. M. Shearer, Water in the lower continental crust : modelling magnetotelluric and seismic reflection results, Geophys. J. Int., 98, 343-366, 1989.

Ida, Y., Thermal and mechanical processes producing arc volcanism and back-arc spreading, in Arc Volcanism : Physics and Tectonics, edited by D. Shimozuru and I. Yokoyama, pp. 165-175, Terra Scientific, Tokyo, $1983 a$.

Ida, Y., Convection in the mantle wedge above the slab and tectonic processes in subduction zones, J. Geophys. Res., 88, 7449-7456, $1983 b$.

Ida, Y., Structure of the mantle wedge and volcanic activities in the island arcs, in High Pressure Research in Mineral Physics, edited by Manghnani M. H. and Y. Syono., pp. 473-480, Terra Scientific, Tokyo, 1987. 
Isacks, B.L., and M. Barazangi, Geometry of Benioff zones, lateral segmentation and downwards bending of the subducted lithosphere, in Island Arcs, Deep Sea Trenches and Back-Arc Basins, Maurice Ewing Ser., vol. 1, edited by M. Talwani and W.C. Pitman III, pp. 99-114, AGU, Washington, D. C., 1977.

Ito, E. I., D. M. Harris, and A. T. Anderson, Jr., Alteration of oceanic crust and geologic cycling of chlorine and water, Geochim. Cosmochim. Acta, 47, 1613-1624, 1983.

James, D. E., Andean crustal and upper mantle structure, $J$. Geophys. Res., 76, 3246-3271, 1971.

Jeanloz, R., and A. B. Thompson, Phase transitions and mantle discontinuities, Rev. Geophys. Space Phys., 21, 51-74, 1983.

Johnston, A. D., Anhydrous P-T phase relations of near-primary high alumina basalt from the South Sandwich Islands, Contrib. Mineral Petrol., 92, 368-382, 1986.

Kay, R. W., Volcanic arc magmas : Implications of a meltingmixing model for element recycling in the crust-upper mantle system, J. Geol, 88, 497-522, 1980.

Kelemen, P. B., D. B. Joyce, J. D. Webster, and J. R. Holloway, Reaction between ultramafic rock and fractionating basaltic magma : II Experimental investigation of reaction between olivine tholeiite and harzburgite at $1150^{\circ} \mathrm{C}-1050^{\circ} \mathrm{C}$ and $5 \mathrm{~kb}$, J. Petrol., 31, 99-134, 1990.

Kennett, J. P., A. R. McBirney, and R. C. Thunnell, Episodes of cenozoic volcanism in the circum-Pacific region, $J$. Volcanol. Geotherm. Res., 2, 145-163, 1977.

Klein, E. M., and C. H. Langmuir, Global correlations of ocean ridge basalt chemistry with axial depth and crustal thickness, J. Geophys. Res., 92, 8089-8115, 1987.

Landau, L. D., and E. M. Lifshitz, Fluid Mechanics. Course of Theoretical Physics, vol. 6, 536 pp., Pergamon Press, New York, 1959.

Lister, J. R., Buoyancy-driven fluid fracture: The effects of material toughness and of low-viscosity precursors, J. Fluid Mech., 210, 263-280, 1990.

Liu, L., Water, low-velocity zone and the descending lithosphere, Tecton ophysics, 164, 41-48, 1989.

Maaløe, S., and T. S. Petersen, Petrogenesis of oceanic andesite, J. Geophys. Res., 86, 10273-10286, 1981.

Marsh, B. D., Island-arc volcanism, Am. Sci., 67, 161-172, 1979.

Marsh, B. D., The Aleutians, Andesites, edited by R. S. Thorpe, John Wiley, New York, 1982.

Mattioli, G. S., M. B. Baker, M. J. Rutter, and E. M. Stolper, Upper mantle oxygen fugacity and its relationship to metasomatism, J. Geol., 97, 521-536, 1989.

Mavko, G. M., Velocity and attenuation in partially molten rocks, J. Geophys. Res., 85, 5173-5189, 1980.

McBirney, A. R., J. F. Sutter, H. R. Naslund, K. G. Sutton, and $C$. M. White, Episodic volcanism in the central Oregon Cascade range, Geology, 2, 585-589, 1974.

McKenzie, D. P., Speculations on the consequences and causes of plate motions, Geophys. J. R. Astron. Soc., 18, 1-32, 1969.

McKenzie, D. P., The generation and compaction of partially molten rock, J. Petrol., 25, 713-765, 1984.

McKenzie, D. P., and M. J. Bickle, The volume and composition of melt generated by extension of the lithosphere, J. Petrol., 29, 625-680, 1988.

Miller, G. H., G. R. Rossman, and G. E. Harlow, The natural occurrence of hydroxide in olivine, Phys. Chem. Miner., 14, 461-472, 1987.

Minear, J. W., and M. N. Toksöz, Thermal regime of a downgoing slab and new global tectonics, J. Geophys. Res., 75, 1397-1419, 1970.

Morris, J. D., and S. R. Hart, Isotopic and incompatible element constraints on the genesis of island arc volcanics, Geochim. Cosmochim. Acta., 47, 2015-2030, 1983.

Mutter, J. C., W. R. Buck, and C. M. Zehnder, Convective partial melting, 1, A model for the formation of thick basaltic sequences during the initiation of spreading, J. Geophys. Res., 93, 1031-1048, 1988.

Myers, J. D., B. D. Marsh, and A. K. Sinha, Primitive high-Al basalts in Aleutians, Contrib. Mineral. Petrol., 91, 221-234, 1985.

Mysen, B. O., and A. L. Boettcher, Melting of a hydrous mantle: I. Phase relations of natural peridotite at high pressures and temperatures with controlled activities of water, carbon dioxide and hydrogen, J. Petrol., 16, 520-548, 1975.
Nagao, T., and S. Uyeda, Heat flow measurements in the northern part of Honshu, Northeast Japan, using shallow holes, Tecton ophysics, 164, 301-314, 1989.

Nicholls, I. A., and A. E. Ringwood, Effect of water on olivine stability in tholeiites and the production of $\mathrm{SiO}_{2}$-saturated magmas in the island arc environment, J. Geol., 81, 285-300, 1973.

Nicolas, A., A melt extraction model based on structural studies in mantle peridotites, J. Petrol., 27, 999-1022, 1986.

Nur, A., and Z. Ben-Avraham, Volcanic gaps due to oblique subduction of aseismic ridges, Tectonophysics, 99, 355-362, 1983.

Nye, C. J., and M. R. Reid, Geochemistry of primary and least fractionated lavas from Okmok volcano, central Aleutians: Implications for arc magmagenesis, J. Geophys. Res., 91, 10271$10287,1986$.

Olafsson, M., and D. H. Eggler, Phase relations of amphibole, amphibole-carbonate, and phlogopite-carbonate peridotite: petrologic constraints on the asthenosphere, Earth Planet. Sci. Lett., 64, 305-315, 1983.

O'Nions, R. K., and D. P. McKenzie, Melting and continent generation, Earth Planet. Sci. Lett., 90, 449-456, 1988.

Otsuki, K., Empirical relationships among the convergence rate of plates, rollback rate of trench axis and island-arc tectonics: "laws of convergence rate of plates.", Tectonphysics, 159, 7394, 1989.

Oxburgh, E. R., and D. L. Turcotte, Problems of high heat flow and volcanism associated with zones of descending mantle convective flow, Nature, $216,1041-1043,1968$.

Oxburgh, E. R., and D. L. Turcotte, Thermal structure of island arcs, Geol. Soc. Am. Bull., 81, 1665-1688, 1970.

Peacock, S. M., Thermal effects of metamorphic fluids in subduction zones, Geology, 15, 1057-1060, 1987.

Perfit, M. R., D. A. Gust, A. E. Bence, R. J. Arculus, and S. R. Taylor, Chemical characteristics of island-arc basalts : implications for mantle sources, Chem. Geol., 30, 227-256, 1980.

Plank, T., and C. H. Langmuir, An evaluation of the global variations in the major element chemistry of arc basalts, Earth Planet. Sci. Lett., 90, 349-370, 1988.

Presnall, D. C., and P. C. Baternan, Fusion relations in the system $\mathrm{NaAlSi}_{3} \mathrm{O}_{8}-\mathrm{CaAl}_{2} \mathrm{O}_{8}-\mathrm{KAISi}_{3} \mathrm{O}_{8}-\mathrm{SiO}_{2}-\mathrm{H}_{2} \mathrm{O}$ and the generation of granitic magma in the Sierra Nevada batholith, Geol. Soc. Am. Bull., 84, 3181-3202, 1973.

Raleigh, C. B., and M. S. Paterson, Experimental deformation of Serpentinite and its tectonic implications, J. Geophys. Res., $70,3965-3985,1965$.

Reymer, A., and G. Schubert, Phanerozoic addition rates to the continental crust and crustal growth, Tectonics, 3, 63-77, 1984.

Richter, F. M., On the driving mechanism of plate tectonics, Tecton ophysics, 38, 61-88, 1977.

Rigden, S. M., T. J. Ahrens, and E. M. Stolper, Densities of liquid silicates at high pressures, Science, 226, 1071-1074, 1984.

Ruff, L., and H. Kanamori, Seismic coupling and uncoupling at subduction zones, Tecton ophysics, 99, 99-118, 1987.

Rydelek, P. A., and I. S. Sacks, Asthenospheric viscosity inferred from correlated land-sea earthquakes in noth-east Japan, $\mathrm{Na}$ ture, 936, 234-237, 1988.

Saleeby, J. B., Progress in tectonic and petrogenetic studies in an exposed cross-section of young $(\approx 100 \mathrm{Ma})$ continental crust, southern Sierra Nevada, California, in Exposed Cross Sections of the Continental Crust, NATO ASI Ser., edited by M. H. Salisbury, D. Reidel, Norwell, Mass., in press, 1989.

Sato, H., I. S. Sacks, T. Murase, G. Muncill, and H. Fukuyama, Attenuation of compressional waves in peridotite measured as a function of temperature at $200 \mathrm{MPa}$, Pure Appl. Geophys., $128,433-447,1988$ a.

Sato, H., I. S. Sacks, T. Murase, and C. M. Scarfe, Thermal structure of the low velocity zone derived from laboratory and seismic investigations, Geophys. Res. Lett., 15, 1227-1230, 1988 b.

Sato, H., I. S. Sacks, E. Takahashi, and C. M. Scarfe, Geotherms in the Pacific Ocean from laboratory and seismic attenuation studies, Nature, 336, 154-156, $1988 \mathrm{c}$.

Sato, H., I. S. Sacks, and T. Murase, The use of laboratory velocity data for estimating temperature and partial melt fraction in the low-velocity zone: Comparison with heat low and electrical conductivity studies, J. Geophys. Res., 94, 5689-5704, 1989.

Sato, H., and I. S. Sacks, Anelasticity and thermal structure of 
the oceanic upper mantle: Temperature calibration with heat How data, J. Geophys. Res., 94, 5705-5715, 1989.

Scott, D. R., and D. J. Stevenson, A self-consistent model of melting, magma migration and buoyancy-driven circulation beneath mid-ocean ridges, J. Geophys. Res., 94, 2973-2988, 1989.

Sleep, N. H., Tapping of melt by veins and dikes, J. Geophys. Res., 93, 10255-10272, 1988.

Spence, D. A., and D. L. Turcotte, Magma-driven propagation of cracks, J. Geophys. Res., 90, 575-580, 1985.

Spence, W., Slab pull and the seismotectonics of subducting lithosphere, Rev. Geophys., 25, 55-69, 1987.

Spence, W., Stress origins and earthquake potential in Cascadia, J. Geophys. Res., 94, 3076-3088, 1989.

Spera, F. J., Dynamics of translithospheric migration of metasomatic fluid and alkaline magma, Mantle Metas omatism, edited by M. A. Menzies and C. J. Hawkesworth, pp. 1-20, Academic, San Diego, Calif., 1987.

Spiegelman, M., and D. McKenzie, Simple 2-D models for melt extraction at mid-ocean ridges and island arcs, Earth Planet. Sci. Lett., 83, 137-152, 1987.

Staudacher, T., and C. J. Allegre, Recycling of oceanic crust and sediments : the noble gas subduction barrier, Earth Planet. Sci. Lett., 89, 173-183, 1988.

Stevenson, D. J., Rayleigh-Taylor instabilities in partially molten rock, Eos, Trans. AGU, 69, 1404, 1988.

Stolper, E., A phase diagram for mid-ocean ridge basalts: Preliminary results and implications for peterogenesis, Contrib. Mineral. Petrol., 74, 13-27, 1980.

Sudo, A., and Y. Tatsumi, Phlogopite and K-amphibole in the upper mantle: Implication for magma genesis in subduction zones, Geophys. Res. Lett., 17, 29-32, 1990.

Suyehiro, K., and I. S. Sacks, P- and S-wave velocity anomalies associated with subducting lithosphere determined from traveltime residuals in the Japan region, Bull. Seismol. Soc. Am., 69, 97-114, 1979.

Sydora, L. J., F. W. Jones, and R. St. J. Lambert, The thermal regime of the descending lithosphere: The effect of varying angle and rate of subduction, $C a n$. J. Earth Sci., 15, 626-641, 1978.

Sykes, M. L., and J. R. Holloway, Evolution of granitic magmas during ascent: A phase equilibrium model, in Magamtic Processes: Physiochemical Principles, Spec. Publ. 1, edited by B. O. Mysen, pp. 447-461, The Geochemical Society, Penn State Univ., Pa., 1987.

Tatsumi, Y., and H. Isoyama, Transportation of Beryllium with $\mathrm{H}_{2} \mathrm{O}$ at high pressures: Implications for magma genesis in subduction zones, Geophys. Res. Lett., 15, 180-183, 1988.

Tatsumi, Y., Migration of fluid phases and genesis of basalt magmas in subduction zones, J. Geophys. Res., 94, 4697-4707, 1989.

Tatsumi, Y., Formation of the volcanic front in subduction zones, Geophys. Res. Lett., 13, 717-720, 1986.

Tatsumi, Y., M. Sakuyama, H. Fukuyama, and I. Kushiro, Generation of arc basalt magmas and thermal structure of the mantle wedge in subduction zones, $J$. Geophys. Res., 88, 5815-5825, 1983.

Tatsumi, Y., D. L. Hamilton, and R. W. Nesbitt, Chemical characteristics of fluid phase released from subducted lithosphere and origin of arc magmas: Evidence from high-pressure experiments and natural rocks, J. Volcan ol. Geotherm. Res., 29, 293-309, 1986.

Tera, F., L. Brown, J. Morris, I. S. Sacks, J. Klein, and R. Middleton, Sediment incorporation in island-arc magmas: inferences from ${ }^{10} \mathrm{Be}$, Geochim. Cosmochim. Acta, 50, 535-550, 1986.

Thatcher, W., T. Matsuda, T. Kato, and J. B. Rundle, Lithospheric loading by the 1896 Riku-u Earthquake, Northern Japan: Implications for plate flexure and asthenospheric rheology, J. Geophys. Res., 85, 6429-6435, 1980.

Tichelaar, B. W., and L. Ruff, Variability in depth of seismic coupling along the Chilean subduction zone, Eos, Trans. $A G U$, $70,398,1989$.

Toksöz, M. N., and A. T. Hsui, A review of the thermo-mechanical structures at convergent plate boundaries and their implications for crust/mantle recycling, in Crust/Mantle Recycling at Convergence Zones, NATO ASI Ser., edited by S. R. Hart and L. Gulen, pp. 75-80, Kluwer Academic, Boston, Mass., 1987.
Toksöz, N., J. W. Minear, and B. R. Julian, Temperature field and geophysical effects of a down-going slab, $J$. Geophys. Res., $76,1113-1138,1971$.

Toramaru, A., and N. Fujii, Connectivity of melt phase in a partially molten peridotite, J. Geophys. Res., 91, 9239-9252, 1986.

Tovish, A., G. Schubert, and B. P. Luyendyk, Mantle flow presBure and the angle of subduction: Non-Newtonian corner flows, J. Geophys. Res., 83, 5892-5898, 1978.

Tritton, D. J., Physical Fluid Dynamics, Van Nostrand Reinhold, New York, 1977.

Tsunakawa, H., Ancient stress field in Japan based on K-Ar ages of neogene dikes and boninite, Ph.D. thesis, Univ. of Tokyo, 1982.

Tsunakawa, H., Simple two-dimensional model of propagation of magma-filled cracks, J. Volcanol. Geoth erm. Res., 16, 335-343, 1983.

Turcotte, D. L., A heat pipe mechanism for volcanism and tectonics on Venus, J. Geophys. Res., 94, 2779-2785, 1989.

Turcotte, D., Physics of magma segregation processes, in Magmatic Processes: Physiochemical Principles, Spec. Publ. 1, edited by B. O. Mysen, pp. 69-74, The Geochemical Society, Penn State Univ., Pa., 1987.

Turcotte, D., and G. Schubert, A fluid theory for the deep structure of dip-slip fault zones, Phys. Earth Planet. Inter., 1, 381$386,1968$.

Turcotte, D., and G. Schubert, Frictional heating of the descending lithosphere, J. Geophys. Res., 78, 5876-5886, 1973.

Uyeda, S., Subduction zones : An introduction to comparative subductology, Tecton ophysics., 81, 133-159, 1982.

von Bargen, N., and H. S. Waff, Permeabilities, interfacial areas, and curvatures of partially molten systems: Results of numerical computations of equilibrium microstructures, Geophys. J. R. Astron. Soc., 91, 9261-9276, 1986.

Vrolijk, P., G. Myers, and J.C. Moore, Warm fluid migration along tectonic melanges in the Kodiak accretionary complex, Alaska, J. Geophys. Res., 93, 10313-10324, 1988.

Waff, H. S., and J. R. Bulau, Equilibrium fluid distribution in an ultramafic partial melt under hydrostatic stress conditions, $J$. Geophys. Res., 84, 6109-6114, 1979.

Waff, H. S., and J. R. Bulau, Experimental determination of nearequilibrium textures in partially molten silicates at high pressures, in High Pressure Research in Geophysics, edited by S. Akimoto and M. H. Manghnani, Adv. Earth Planet. Sci., 12, pp. 229-236, 1982.

Wallace, M. E., and Green, D. H., An experimental determination of primary carbonatite composition, Nature, $335,343-345$, 1988.

Watson, B. E., J. M. Brenan, and D. R. Baker, Distribution of fluids in the continental mantle, in Contin ental Mantle, edited by M. Menzies, pp. 111-125, Clarendon Press, Oxford, 1990.

Watson, B. E., and J. M. Brenan, Fluids in the lithosphere, Part 1 : Experimentally-determined wetting characteristics of $\mathrm{CO}_{2}$ $-\mathrm{H}_{2} \mathrm{O}$ fluids and their implications for fluid transport, hostrock physical properties and fluid inclusion formation, Earth Plan et. Sci. Lett., 85, 497-515, 1987.

Wdowinski, S., R. J. O'Connell, and P. England, Continuum models of continental deformation above subduction zones: Application to the Andes and the Aegean, J. Geophys. Res., 94, 10331-10346, 1989.

Weidner, D. J., and E. Ito, Mineral physics constraints on a uniform mantle composition, in High Pressure Research in Mineral Physics, edited by M. H. Manghnani and Y. Syono, pp. 439-446, Terra Scientific, Tokyo, 1987.

Wiens, D. A., and S. Stein, Age dependence of oceanic intraplate seismicity and implications for lithospheric evolution, $J$. Geophys. Res., 88, 6455-6468, 1983.

Wyllie, P. J., Magmas and volatile components, Am. Mineral., $64,469-500,1979$.

Wyllie, P. J., M. R. Carroll, A. D. Johnston, M. J. Rutter, T. Sekine, and S. R. Van Der Laan, Interactions among magmas and rocks in subduction zone regions: experimental studies from slab to mantle to crust, Eur. J. Mineral., 1, 165-179, 1989.

Yuen, D. A., L. Fleitout, G. Schubert, and C. Froidevaux, Shear deformation zones along major transform faults and subducting slabs, Geophys. J. R. Astron. Soc., 54, 93-119, 1978.

Yuen, D. A., and G. Schubert, On the stability field of friction- 
ally heated shear flows in the asthenosphere, Geophys. J. $R$. Astron. Soc., 57, 189-207, 1979.

J. Huw Davies, Department of Earth Sciences, University of Cambridge, Downing Street, Cambridge, CB2 3EQ, United Kingdom.
D. J. Stevenson, Division of Geological and Planetary Sciences, California Institute of Technology, Pasadena, CA 91125.

(Received August 7, 1990; revised May 15, 1991; accepted August 30, 1991.) 